\title{
Análise cladística da tribo Rhopalophorini Blanchard, 1845 (Coleoptera, Cerambycidae) $^{1}$
}

\author{
Marinêz Isaac Marques ${ }^{2}$ \\ Dilma Solange Napp ${ }^{3}$
}

\begin{abstract}
Cladistic analysis of the tribe Rhopalophorini Blanchard, 1845 (Coleoptera, Cerambycidae). Rhopalophorini is primarily a New World group. Of the 23 known genera, 19 were described from the Neotropical region. A cladistic analysis of the American genera was carried out with 91 morphological characters. The genera Ozodes Audinet-Serville and Lissozodes Bates, recently transferred to Necydalopsini, were included in the analysis in order to investigate their relationships with the Rhopalophorini. The results suggested that their shared similarities with the Rhopalophorini are symplesiomorphies at the level considered in the analysis, so they are maintained in Necydalopsini, and Neozodes Zajciw, indicated as the sister group of Ozodes, is herein transferred to this tribe. In the same way, Elaphopsis Audinet-Serville is transferred to Ibidionini. Rhopalophorini, as defined in the present work, is a monophyletic group and includes 17 American genera. Within Rhopalophorini, Argyrodines + Parozodes constitute the basalmost group, and Cycnoderus is the sister group of the two major clades formed, one by Ischionodonta, Disaulax, Cosmisoma, Closteropus and Gurubira, and the other, by Rhopalophora, Coremia, Merocoremia, Dirocoremia, Thalusia and Lathusia; the relationships of Rhopalophorella, Rhopalina and Muxbalia remain inconclusive. A phylogenetic classification of Rhopalophorini at the genus level is proposed.
\end{abstract}

KeYwords. Cerambycinae; cladistics; New World; Rhopalophorini; taxonomy.

\section{INTRODUÇÃO}

A tribo Rhopalophorini Blanchard,1845 está representada, atualmente, por 23 gêneros, 2 subgêneros e cerca de 140 espécies (AuRIVILLIUs 1912; Gressit 1951; GrESSIT \& RoNDON 1970; Giesbert \& CheMsaK 1993; Monné 1994; MonNÉ \& GiesberT 1994; Marques \& NAPP 1996; NAPP \& MARQues 1999a).

Sua distribuição é quase exclusivamente neotropical. Dos 23 gêneros, 19 são americanos e apenas um, Rhopalophorella Linsley, 1942, restringe-se à Baixa Califórnia, USA. Dentre os gêneros neotropicais, somente Rhopalophora AudinetServille, 1834, ocorre nos Estados Unidos da América, onde está representado por seis espécies. Gêneros exóticos ao continente americano, são Amphirhoe Newman,1840, da Austrália, Pelossus Thomson, 1864, da África, Dymorphocosmisoma Pic, 1918 e Camelocerambyx Pic, 1918, da China.

Pouco se conhece sobre a fase imatura dos Rhopalophorini. MonNÉ (2001) reúne as informações disponíveis sobre plantas hospedeiras de espécies dos gêneros Argyrodines Bates, 1867,
Coremia Audinet-Serville, 1834, Cosmisoma Audinet-Serville, 1834, Cycnoderus Audinet-Serville, 1834, Dirocoremia Marques, 1994, Disaulax, Audinet-Serville, 1833, Ischionodonata Chevrolat, 1859, Rhopalophora AudinetServille, 1834 e Thalusia Thomson, 1864. Di IoRIo (2001) fornece dados sobre a biologia de adultos e imaturos de espécies de Ischionodonta, incluindo descrição de galerias e câmaras pupais.

O conceito de Rhopalophorini, assim como o da grande maioria das tribos de Cerambycinae, ainda é o estabelecido por LACORDAIRE (1869). Nesse sistema, os Cerambycinae com olhos finamente granulados foram divididos em dois grupos, com base, principalmente, nas cavidades coxais anteriores e médias, sendo Rhopalophorini incluída no grupo caracterizado pelas cavidades coxais anteriores e médias fechadas, próxima às tribos Cleomenini Lacordaire, 1869, Heteropsini Lacordaire, 1869, Glaucytini Lacordaire, 1869 e Smodicini Lacordaire, 1869.

Após Lacordaire (l.c.), nenhum outro sistema de classificação para os Cerambycinae foi proposto e o que se observa atualmente é a formação de agrupamentos

\footnotetext{
1. Contribuição no 1396 do Departamento de Zoologia, Universidade Federal do Paraná.

2. Departamento de Biologia e Zoologia, Universidade Federal de Mato Grosso. Av. Fernando Correa da Costa s/n, 78060-900 Cuiabá-MT, Brasil. Endereço eletrônico: m.marque@zaz.com.br

3. Departamento de Zoologia, Universidade Federal do Paraná. Caixa Postal 19020, 81531-980 Curitiba-PR, Brasil.
} 
heterogêneos, o que dificulta, em muito, a tentativa de se encontrar caracteres definidores dos grupos em qualquer que seja o nível, ou até de se estabelecer as relações existentes entre os mesmos.

Da mesma forma, a escassez de revisões taxonômicas das tribos de Cerambycinae e de trabalhos referentes à morfologia comparada, bem como de estudos com utilização da metodologia cladística, dificulta a definição de grupos em Cerambycinae.

Entre as subfamílias, apenas Anoplodermatinae (DIAS 1981) e Lamiinae (MARINONI 1979) foram estudadas com esse enfoque e, entre as tribos de Cerambycinae, somente Elaphidionini (Lingafelter 1998) e Heteropsini (Santos 1999). Além destes pesquisadores, NAPP (1994) tratou do relacionamento entre as subfamílias de Cerambycidae.

Esses fatores foram relevantes na delimitação deste estudo que teve como objetivo principal testar a monofilia da tribo Rhopalophorini e o inter-relacionamento dos grupos subordinados, fornecendo subsídios para um melhor conhecimento de sua morfologia.

Como resultado da análise, propõe-se a transferência do gênero Neozodes Zajciw, 1958 para a tribo Necydalopsini Lacordaire, 1869 e do gênero Elaphopsis Audinet-Serville, 1834 para Ibidionini Thomson, 1860.

\section{REVISÃODA LITERATURA}

Os primeiros gêneros a comporem a tribo Rhopalophorini Rhopalophora, Ozodes, Cosmisoma, Cycnoderus, Coremia e Disaulax - foram descritos por Audinet-Serville $(1833,1834)$ que os distribuiu em diferentes grupos do seu sistema de classificação. Disaulax foi inserido no primeiro grande grupo, próximo de Callichroma Latreille, 1816, Aromia Audinet-Serville, 1833 e Rosalia Audinet-Serville, 1833, além de outros gêneros, e caracterizado por palpos maxilares mais curtos que os labiais, os artículos apicais de ambos diferentes, e gálea alongada. Os demais gêneros, posicionados em diferentes grupos na Segunda Divisão, apresentam palpos maxilares tão a mais longos que os labiais, os artículos apicais de ambos semelhantes e fêmures bruscamente clavados. Coremia e Cosmisoma foram situados relativamente próximos em um agrupamento, assim como Rhopalophora, Ozodes e Cycnoderus, com base, principalmente, na conformação do protórax e das antenas. Elaphopsis, proposto por Audinet-Serville (1834) para uma das espécies incluídas em Rhopalophora - Elaphopsis rubida -, não constou do sistema de classificação mas, implicitamente, estaria no mesmo grupo de Rhopalophora.

LAPORTE (1840), referindo-se aos caracteres dos palpos labiais, considerou Cosmisoma semelhante a Disaulax, seguindo Audinet-SERviLle (1833), e situou estes dois gêneros após Coremia. Cycnoderus foi inserido depois de Ancylocera Audinet-Serville, 1834 e próximo a este, diferenciando-se por caracteres das antenas, protórax e pernas. Rhopalophora, Ozodes e também Listroptera Audinet-Serville, 1834 foram relacionados após Cycnoderus, sem maiores comentários.

Guérin-Méneville (1844) descreveu Closteropus, relacionando-o a Callichroma e Aromia, dos quais se distinguia pelos fêmures abruptamente clavados, e situou Rhopalophora próximo a Obrium Curtis, 1825 e Leptocera (= Glaucytes Thomson, 1858).

BLANCHARD (1845) estabeleceu "Rhopalophorites", caracterizada por: antenas simples, maxila com lobos curtos, artículo apical dos palpos ovóide e fêmures clavados. Além de Rhopalophora, incluiu os gêneros Cosmisoma, Cycnoderus, Ozodes e também Ancylocera. Listroptera foi considerado sinônimo de Rhopalophora, e Disaulax de Cosmisoma, enquanto Coremia foi inserido no grupo dos Callichromatini.

LeConte (1850) utilizou, além das peças bucais, a conformação das cavidades cotilóides anteriores para propor agrupamentos em Cerambycinae. Dois grandes grupos foram estabelecidos de acordo com o comprimento dos palpos maxilares. No grupo com palpos maxilares curtos, Disaulax foi posicionado junto a Callichroma, Rosalia, Aromia, entre outros. Os demais gêneros foram agrupados com base nos palpos maxilares mais longos que a gálea e fêmures clavados. Cosmisoma, Rhopalophora, Cycnoderus e Listroptera, o último com dúvidas, foram incluídos no grupo com artículos apicais dos palpos não dilatados e cavidades coxais anteriores arredondadas ou angulosas. Coremia e Ozodes, este com dúvidas, foram alocados no grupo com artículos apicais dos palpos dilatados e cavidades coxais anteriores arredondadas aos lados e abertas atrás. Ozodes, não examinado, foi colocado junto a Distenia Audinet-Serville, 1825.

White (1855) listou os atuais gêneros da tribo com Listroptera, Ancylocera e Chariergus, citando entre eles, Amphirhoë [sic] Newman, 1840, descrito da Tasmânia.

Chevrolat (1859) considerou duas Seções em Rhopalophora. Na Seção B, denominada, informalmente, Ischionodonta, agrupou as espécies que apresentavam asperosidades nos fêmures, protórax alargado aos lados e processo mesosternal moderadamente largo. Além disso, descreveu 14 espécies para Rhopalophora, nas Seções A e B.

ThOMson (1860) também utilizou caracteres das peças bucais no seu sistema de classificação e relacionou os Rhopalophorini aos Callichromatini e aos Rhinotragini por apresentarem palpos maxilares curtos e gálea alongada, além de cavidades cotilóides anteriores arredondadas a angulosas aos lados. No grupo Rhopalophoritae, considerou duas divisões: Rhinotragitae e Rhopalophoritae verae, incluindo, nesta, gêneros atuais de Rhinotragini (Acyphoderes Audinet-Serville, 1833), Cleomenini (Dihammaphora Chevrolat, 1859 e Listroptera) e de Rhopalophorini (Rhopalophora, Cosmisoma, Disaulax, Coremia e Amphirhö̈ [sic]). Closteropus foi mantido em Callichromatini, enquanto Cycnoderus, Elaphopsis e Ozodes foram incluídos em Ibidionini por apresentarem palpos maxilares mais longos que a gálea. Em proposta posterior, THOMSON (1864) incluiu gêneros atuais de Cleomenini, Rhinotragini e Rhopalophorini no grupo Callichromitae verae, Primeira Divisão, Pseudolepturitae, com base em caracteres do escapo antenal e dos palpos maxilares e labiais. Nesta divisão, relacionou os gêneros americanos com fêmures clavados, entre os quais posicionou Coremia, Disaulax, Cosmisoma, Rhopalophora, Listroptera e Dihammaphora, além de 
Closteropus e Thalusia Thomson, 1864. Elaphopsis, Ozodes e Cycnoderus foram incluídos na divisão Ancyloceritae, caracterizada por escapo antenal curto, fêmures clavados e processos intercoxais lameliformes, entre outros.

Bates (1867) descreveu Argyrodines em Rhopalophorini e o considerou muito próximo de Cosmisoma.

LACORDAIRE (1869) reformulou as classificações de AuDINETServille (1833) e de Thomson $(1860,1864)$ e situou Rhopalophorini no grupo de tribos com olhos finamente granulados e cavidades coxais médias fechadas, junto a Cleomenini, Glaucytini, Heteropsini, Smodicini e Tillomorphini. Callichromatini e Rhinotragini foram incluídas entre as tribos com cavidades coxais médias abertas. Em Rhopalophorini, manteve, além de Rhopalophora, os gêneros Cosmisoma e Amphirhoë [sic] e acrescentou Cycnoderus, Ozodes, Elaphopsis, Ornithia Thomson, 1864 e Pelossus Thomson,1864, este descrito do Gabão. Disaulax foi considerado sinônimo de Cosmisoma, e Argyrodines incluído com dúvidas. Com relação a Elaphopsis, ressaltou os olhos com granulação grossa. Coremia e Thalusia foram transferidos para Compsocerini e Closteropus mantido em Callichromatini. Rhopalophorini foi definida, basicamente, pelos seguintes caracteres: palpos curtos; genas pouco alongadas; antenas filiformes, bem mais longas que o corpo nos machos; protórax cilíndrico, raramente tuberculado aos lados; cavidades coxais anteriores abertas ou fechadas atrás, não angulosas aos lados e as médias fechadas; pernas longas, fêmures clavados ou subclavados, os posteriores quase sempre mais longos que os élitros. Ao propor Cleomenini, LACORDAIRE (l.c.) ressaltou a semelhança desta tribo com Rhopalophorini, diferenciando-as apenas pelo comprimento das antenas e forma dos antenômeros. Listroptera e Dihammaphora foram os únicos gêneros americanos inseridos em Cleomenini por LACORDAIRE (1869) que destacou a diferença desses gêneros com relação aos demais.

Chenu (1861) manteve Listroptera e Ancylocera na tribo e considerou Disaulax como gênero distinto de Cosmisoma.

BATES (1870) descreveu Lissozodes para Rhopalophorini e confirmou Argyrodines nesta tribo por apresentar cavidades coxais médias fechadas. Lissozodes foi relacionado a Ozodes, diferindo pelo protórax cilíndrico, sem tubérculos, fronte muito curta e vertical e pela conformação dos artículos apicais dos palpos. BATES (1879), ao descrever Closteropus argentatus, considerou que Closteropus não se enquadrava perfeitamente em Callichromatini e constituiria uma conexão entre esta tribo e os Rhopalophorini, via Cosmisoma.

LEConTE (1873) redescreveu Rhopalophora, único gênero da tribo com representantes nos Estados Unidos, destacando os palpos maxilares e labiais curtos, subiguais e as cavidades coxais anteriores abertas atrás. Ao contrário de autores anteriores, na sua opinião, Rhopalophora estaria mais relacionado a Stenopterus Illiger, 1804 do que a Callichroma. Foi o primeiro autor a observar a placa estridulatória e o mesoscuto não dividido. LeCONTE \& Horn (1883), basicamente, repetiram LeCONTE (1873) no tocante a Rhopalophorini.

LENG (1884) seguiu a classificação proposta por LACORDAIRE
(1869), incluindo Rhopalophora entre as tribos com olhos finamente granulados, pernas alongadas com fêmures abruptamente clavados e cavidades coxais anteriores abertas atrás.

Aurivillius (1897) descreveu Parozodes, relacionando-o a Ozodes por apresentar artículos apicais dos palpos alargados, antenas sem sulcos ou carenas e processo mesosternal largo.

Blatchey (1910), ao tratar dos Cerambycidae de Indiana (USA), apresentou uma breve caracterização da tribo com base apenas em Rhopalophora.

GouneLLe (1911) formalizou Ischionodonta Chevrolat, 1859 como subgênero de Rhopalophora e arrolou vários caracteres que distinguiam este gênero de Cycnoderus, considerados, por autores anteriores, como muito semelhantes. Em Cycnoderus, propôs o subgênero Ulododerus para Cycnoderus barbatus Gounelle, 1911 e C. dispar Gounelle, 1911. Em Cycnoderus (sensu stricto) incluiu, além de C. tenuatus AudinetServille, 1834, C. chlorizans Chevrolat, 1859 e C. rufithorax Gounelle, 1911.

AurIVILLIUS (1912) atribuiu a autoria da tribo a LACORDAIRE (1869) e manteve os mesmos gêneros relacionados por este autor, acrescentando Lissozodes Bates, 1870 e Parozodes Aurivillus, 1897 e restabelecendo Disaulax. À época deste catálogo, doze gêneros integravam a tribo, sendo apenas dois, Amphirhoë [sic] e Pelossus, estranhos ao continente americano. Rhopalophorini foi posicionada entre Cleomenini e Glaucytini.

BRADLEY (1930), na chave para tribos de Cerambycinae, situou Rhopalophorini próxima a Ancylocerini. Cleomenini foi omitida por ser representada por apenas uma espécie de Dihammaphora.

SAALAS (1936), no estudo sobre a venação alar dos Cerambycidae, considerou que Rhopalophorini e Cleomenini, além de Callichromatini, Rhinotragini, Molorchini, Clytini e Tillomorphini, teriam uma venação derivada em relação aos Callidiini por apresentarem a veia $\mathrm{Cu} 1$ (=Plical, sensu HAMILTON 1972) com apenas um ramo. Rhopalophorini, representada por Rhopalophora axillaris (atualmemente no gênero Gurubira Napp \& Marques, 1999) e Ornithia mexicana Sturm, 1843 (atualmente na tribo Dryobiini), foi posicionada em uma linhagem distinta e basal à de Cleomenini, representada por Apiogaster Perroud, 1859 e Listroptera.

LinsLey (1942), ao propor Rhopalophorella para Rhopalophora bicincta Horn, 1895 (= Gracilia fasciata LeConte, 1873), ressaltou que o gênero poderia ser incluído em Cleomenini, como definida por LACORDAIRE (1869), próximo a Dihammaphora, mas que igualmente relacionava-se a Rhopalophora. Do primeiro, diferia pelas antenas longas e filiformes e élitros sem carenas laterais e de Rhopalophora, pelas antenas não setáceas, olhos pouco desenvolvidos, fêmures posteriores curtos e metepisterno carenado.

GRESSIT (1951), na chave para tribos de Cerambycinae, inseriu Rhopalophorini entre as tribos com cavidades coxais médias abertas e as anteriores arredondadas aos lados. Cleomenini, junto com Tillomorphini, foi caracterizada por cavidades coxais médias fechadas. Em Rhopalophorini, tratou unicamente de Dymorphocosmisoma Pic, 1918. 
Zajciw (1958) estabeleceu Neozodes para $N$. signata e sugeriu que o gênero deveria situar-se entre Ozodes e Ornithia.

Tippmann (1960) também considerou que Closteropus estaria mal posicionado em Challichromatini, como indicado por BATES (1879), e o transferiu para Rhopalophorini, próximo a Rhopalophora (Ischionodonta). De acordo com esse autor, Ischionodonta distinguia-se de Closteropus apenas pela presença de asperosidades nos fêmures.

LinsLey $(1962,1964)$, na revisão dos Cerambycidae NorteAmericanos, considerou Rhopalophorini e Cleomenini intimamente relacionadas, diferenciando-as, assim como LACORDAIRE (1869), apenas pelas antenas filiformes e longas na primeira, e curtas e serreadas na última. Tratando apenas de Dihammaphora (Cleomenini) e Rhopalophora, apresentou uma redescrição sucinta das duas tribos.

GRESSIT \& RoNDON (1970) incluíram Camelocerambyx Pic,1918 na chave para gêneros de Cleomenini. Entretanto, no texto, trataram deste gênero e de Dymorphocosmisoma Pic, 1918, em Rhopalophorini.

Martins (1975) sugeriu o relacionamento de Ozodes, Neozodes, Argyrodines e Parozodes (Rhopalophorini) com Epropetes Bates, 1870 (Tillomorphini) e Aphysotes Bates, 1885 (Anaglyptini). Os gêneros de Rhopalophorini, juntamente com Aphysotes, foram reunidos em um grupo por apresentarem pronoto com tubérculos ou acentuadamente aplanado e alargado ao nível do meio.

Fragoso (1978), em estudo sobre a terminália masculina e feminina de representantes de diversas tribos de Cerambycinae, ressaltou que Cleomenini poderia ser considerada como subtribo de Rhopalophorini se, em estudos futuros, fosse registrada a presença de estruturas esclerotinizadas na terminália do macho de Rhopalophorini.

Monné \& MAGno (1988) trataram do gênero Cosmisoma, para o qual descreveram sete espécies novas, considerando-o muito próximo de Rhopalophora, do qual se distinguiria pela presença de tufo de pêlos no antenômero V.

MonNé (1989) descreveu Rhopalina para Rhopalophora discicollis Chevrolat, 1859, diferenciando-o de Rhopalophora por caracteres das antenas e do protórax, e de Ischionodonta, pela ausência de espículos no meso- e metafêmures.

GIESBERT \& CHEMSAK (1993), na revisão dos Rhopalophorini das Américas do Norte e Central, elevaram Ischionodonta à categoria de gênero e descreveram Muxbalia, gênero monotípico, da Guatemala. Ozodes e Lissozodes foram transferidos para Necydalopsini devido à sua semelhança com Eucharassus Bates, 1885 (único representante de Necydalopsini na América Central) por diferirem dos demais Rhopalophorini pela conformação do protórax, pro- e mesocoxas e fêmures. Sobre Muxbalia consideraram que, apesar dos fêmures gradualmente clavados, o gênero reunia todas as demais características típicas de Rhopalophorini, sendo, provisoriamente, incluído na tribo. Na chave para os gêneros, Rhopalophorella foi inserido junto a Rhopalophora por serem os únicos com o quarto artículo antenal muito mais curto que o terceiro e Rhopalophorella foi diferenciado pela pilosidade elitral, metepisternos carenados e antenas curtas e subserreadas.

MonNÉ (1994), no catálogo dos Cerambycinae Americanos, listou 13 gêneros, três subgêneros e 118 espécies para a tribo, enquanto MonNé \& GIESBERT (1994) relacionaram 13 gêneros, dois subgêneros e 114 espécies.

Marques (1994 a, b, c), na revisão do gênero Coremia, propôs o subgênero Dirocoremia e descreveu Merocoremia. A revisão de MARQues (1994a) evidenciou que Coremia englobava grupos de espécies (subgêneros) bastante heterogêneos e o estudo morfológico comparado com espécies de Compsocerus Lepeletier \& Audinet-Serville, 1830, Rhopalophora e Cosmisoma, revelou maiores afinidades de Coremia e Merocoremia com Rhopalophora e Cosmisoma (Rhopalophorini) do que com outros gêneros de Compsocerini. A constatação dessas diferenças e afinidades embasou o trabalho de MARQUES \& NAPP (1996) que deram status de gênero aos subgêneros de Coremia e transferiram os mesmos para Rhopalophorini. Assim, foram adicionados mais cinco gêneros a esta tribo.

NAPP \& MARQUES (1999a, b) propuseram o gênero Gurubira para algumas espécies de Rhopalopha e revisaram Ischionodonta, ressaltando as diferenças entre estes gêneros e sugerindo o relacionamento de Ischionodonta com Gurubira e Closteropus.

Desde a descrição de Gurubira, a tribo Rhopalophorini inclui 19 gêneros americanos:Disaulax Audinet-Serville, 1833, Rhopalophora Audinet-Serville, 1834, Elaphopsis AudinetServille, 1834, Cosmisoma Audinet-Serville, 1834, Coremia Audinet-Serville, 1834, Cycnoderus Audinet-Serville, 1834 [com os subgêneros $C$. (Cycnoderus) Audinet-Serville, 1834 e $C$. (Ulododerus) Gounelle,1911], Closteropus GuérinMéneville,1844, Ischionodonta Chevrolat,1859, Thalusia Thomson,1864, Argyrodines Bates, 1867, Parozodes Aurivillius,1897, Rhopalophorella Linsley,1942, Neozodes Zajciw,1958, Lathusia Zajciw,1959, Rhopalina Monné,1989, Muxbalia Giesbert \& Chemsak, 1993, Dirocoremia Marques,1994, Merocoremia Marques, 1994 e Gurubira Napp \& Marques, 1999.

\section{MATERIALEMÉTODOS}

\section{Material}

O material estudado pertence às seguintes instituições e coleções particulares: Departamento de Zoologia, Universidade Federal do Paraná, Curitiba (DZUP); Museu Nacional, Universidade Federal do Rio de Janeiro, Rio de Janeiro (MNRJ); Muséum National d'Histoire Naturelle, Paris (MNHN); Museu de Zoologia, Universidade de São Paulo, São Paulo (MZSP); E. F. Giesbert, Beverly Hills, Califórnia, Estados Unidos da América.

Para a realização deste trabalho foram utilizados, aproximadamente, 250 exemplares representantes dos 19 gêneros americanos da tribo Rhopalophorini e de Ozodes e Lissozodes. Diante da impossibilidade de se obterem representantes de todas as espécies de cada um destes gêneros, optou-se pelo estudo da espécie-tipo que, segundo NAPP 
(1994), "estará sempre associada ao nome genérico, o qual serve de base para formação do nome das categorias superiores". Quando não se pôde contar com exemplares da espécie-tipo, foram analisadas aquelas com o maior número de espécimens disponíveis.

Em relação a Rhopalophora e Cosmisoma, gêneros com um número mais expressivo de espécies, 30 e 41, respectivamente (MonNÉ 1994), decidiu-se pela dissecação de um maior número de espécies para se avaliar a constância dos caracteres que melhor definissem a monofilia dos referidos gêneros. De Rhopalophora, estudou-se R. collaris, espécietipo e $R$. neivai, selecionada pela disponibilidade de material.

Dois fatores foram decisivos na escolha das espécies de Cosmisoma: a disponibilidade de material e o estudo de ZAJCIW (1962). Este autor ressaltou a homogeneidade do gênero e dividiu as espécies brasileiras em três grupos, sem observância a um critério filogenético, mas sim a um critério prático para sua identificação. Apesar disso, além da espécie-tipo, foram selecionadas três espécies com base em Zajciw (l. c.): $C$. aeneicolle ( $1^{\circ}$ grupo), C. scopulicorne, espécie-tipo, e C. batesi ( $2^{\circ}$ grupo) e $C$. ammirallis ( $3^{\circ}$ grupo).

Os gêneros Coremia, Thalusia, Lathusia, Merocoremia e Dirocoremia, tratados por MARQUES (1994a), tiveram todas as suas espécies representadas. Devido à falta de material disponível, apenas a fêmea de Lathusia ferruginea foi dissecada e o estudo de Lathusia parvipilipes limitou-se aos caracteres da morfologia externa do alótipo fêmea, acrescido de dados de literatura.

Com base em NAPP \& MARQUES (1999b), que ressaltaram a uniformidade anatômica de Ischionodonta e na disponibilidade de material, esse gênero foi representado por apenas duas espécies: I. platensis e I. rufomarginata. O estudo do holótipo de I. brasiliensis (espécie-tipo) (NAPP \& MARQUES 1998), único exemplar conhecido, permitiu confirmar caracteres da morfologia externa.

O estudo de Neozodes, Rhopalophorella e Muxbalia, gêneros monotípicos, restringiu-se aos caracteres de morfologia externa, pela falta de material disponível para dissecção. De Neozodes, um único exemplar de N. signatus foi estudado; de Rhopalophorella fasciata, obteve-se apenas um exemplar fêmea e de Muxbalia monzoni, um casal de parátipos.

Lissozodes e Ozodes - transferidos para Necydalopsini por GIESBERT \& CHEMSAK (1993) - foram incluídos na análise com o objetivo de testar o seu relacionamento com os demais Rhopalophorini. De Lissozodes, monotípico, pode-se realizar o estudo completo do macho e da terminália da fêmea e Ozodes foi representado pela espécie-tipo, $O$. nodicollis.

Como grupos-externos utilizaram-se, inicialmente, representantes das tribos Cleomenini e Glaucytini, grupos considerados mais relacionados a Rhopalophorini (LACORDAIRE 1869; Fragoso 1985). Cleomenini foi representada por Cleomenes auricollis (oriental), Haenkea atra e Listroptera tenebricosa (neotropicais) e Glaucytini, pela espécie-tipo do gênero-tipo, Glaucytes scripta.

A relação das espécies examinadas encontra-se na Tabela I.

\section{Métodos}

\section{Dissecação, ilustrações e terminologia}

Os procedimentos empregados na dissecação dos exemplares seguiram, basicamente, MARques (1994a). Na confecção das ilustrações, utilizou-se um estereomicroscópio Wild-M5, com câmara-clara acoplada e, para estruturas muito pequenas, uma duplicadora Wild. Todas as estruturas do macho foram desenhadas e das fêmeas, somente as mandíbulas, antenas, asa e terminália.

A terminologia empregada na identificação das estruturas em Cerambycidae e/ou Coleoptera foi a usualmente citada na literatura. Na análise da venação alar, seguiu-se HAMILTON 1972 (apud Marinoni \& Almeida1983); no metendosternito, Crowson $(1938,1944)$; para a terminália masculina, LiNDROTH \& Palmén (1970), complementada por Iuga \& Rosca (1962) e EhARA (1954) e para a terminália feminina, LindROTH \& PALMÉN (l.c.).

Como a maioria das espécies estudadas pertencem a gêneros diferentes, utilizou-se, para simplificar a apresentação, apenas o nome do gênero e/ou subgênero. Subentende-se que toda citação do nome do gênero e/ou subgênero é indicativo apenas das espécies examinadas. Quando mais de uma espécie do mesmo gênero foi estudada, o nome específico é fornecido. Para designar grupos monofiléticos não nominados formalmente, utilizou-se o sistema proposto por AMORIM (1982).

\section{Análise cladística}

A análise dos caracteres e interpretação dos resultados seguiu a metodologia proposta por HenNig (1966), posteriormente detalhada por ELDREDGE \& CRACRAFT (1980), Wiley (1981), Nelson \& Platnick (1981), Wiley et al. (1991) e AMORIM (1997).

Para a confecção da matriz de dados foi utilizado o programa NEXUS, versão 0.5.0 (PAGE 2001). As análises foram processadas pelos programas PAUP, versão 4.0 beta 10 (Swofford 2000) e NONA (Goloboff 1993). Em ambos, realizaram-se procuras heurísticas com permuta de ramos por corte, seqüência de adição de táxons ao acaso (random), 1000 réplicas, otimização Deltran e/ou Acctran, com os caracteres multiestado tratados, alternativamente, como ordenados, nãoordenados e em parte ordenados. Os caracteres receberam pesos iguais e os cladogramas mais parcimoniosos gerados pelos dois programas foram em tudo semelhantes (vide Resultados: Análises). O estudo da distribuição dos estados dos caracteres foi feito por meio do WINCLADA (NIXON 1999). As autapomorfias foram mantidas por justificarem a monofilia dos gêneros. Inicialmente, a matriz constava de 140 caracteres para 32 táxons terminais. Ao final, consolidou-se com 91 caracteres, sendo 12 multiestado, para 30 táxons terminais, representando 17 gêneros de Rhopalophorini e dois de Necydalopsini (Tabela II).

A diferença no número de táxons terminais deve-se à exclusão de Muxbalia e Rhopalophorella nas análises finais. Significativa parte dos caracteres analisados refere-se à morfologia interna e a impossibilidade de dissecção de 
exemplares de Rhopalophorella fasciata e de Muxbalia monzoni resultou em um grande número de caracteres codificados como não comparáveis o que ocasionou a indefinição do seu relacionamento. Sua exclusão nas análises finais pode ser justificada: 1) pelas controvérsias sobre a manutenção de táxons com grande número de caracteres não comparáveis nas análises com métodos numéricos (PlatNick et al.1991); 2) por não ter sido possível definir, com os dados disponíveis e um mínimo de confiabilidade, o nível de parentesco de Rhopalophorella e Muxbalia. Além disso, a manutenção desses táxons nas análises resultou tão somente em alterações no relacionamento de outros táxons, em um maior número de reversões e homoplasias e em diferenças significativas na distribuição dos caracteres ou estados de caracteres. Situação contrária foi observada com relação a
Neozodes, cuja manutenção nas análises foi possível já que este táxon teve seu parentesco definido desde as primeiras análises, por inúmeros caracteres morfológicos externos compartilhados com Ozodes.

A polaridade dos caracteres foi estimada pelo método de comparação com o grupo externo (WATHROUS \& WHEELER 1981; WiLEY 1981; BROOKS 1989; Maddison et al. 1984; WiLEy et al. 1991; NIXON \& CARPENTER 1993).

Devido à falta de outras informações, os grupos externos foram selecionados com base na literatura e representados por Cleomenini e Glaucytini, indicados como os mais relacionados aos Rhopalophorini (Lacordaire 1869; Fragoso 1985). Glaucytini é de origem Oriental e não tem representantes nas Américas. Cleomenini é predominantemente Oriental e Afrotropical e, nas Américas, está representada por sete

Tabela I. Espécies estudadas para a análise cladística dos Rhopalophorini americanos. ( ) número de espécies atuais dos gêneros de Rhopalophorini; (*) espécie-tipo.

\begin{tabular}{|c|c|}
\hline Rhopalophorini & Muxbalia Giesbert \& Chemsak,1993 (1) \\
\hline Argyrodines Bates, 1867 (2) & M. monzoni Giesbert \& Chemsak,1993 (*) \\
\hline A. pulchella Bates, $1867(*)$ & Neozodes Zajciw, 1958 (1) \\
\hline Closteropus Guérin-Méneville, 1844 (4) & N. signatus Zajciw, $1958(*)$ \\
\hline C. blandus Guérin-Méneville, 1844 (*) & Parozodes Aurivilius, 1897 (2) \\
\hline Coremia Audinet-Serville, 1834 (2) & P. erythrocephalus Aurivillius, 1897 (*) \\
\hline C.plumipes (Pallas, 1772) $(*)$ & Rhopalina Monné, 1989 (2) \\
\hline C. signaticollis Buquet, 1844 & R. discicollis (Chevrolat, 1859) (*) \\
\hline Cosmisoma Audinet-Serville, 1834 (41) & Rhopalophora Audinet-Serville, 1834 (27) \\
\hline C. scopulicorne (Kirby, 1818) (*) & R. collaris $($ Germar, 1824$)(*)$ \\
\hline C. ammirallis (Linnaeus, 1767) & R. neivai Mendes, 1940 \\
\hline C. batesi Erichson, 1848 & Rhopalophorella Linsley, 1942 (1) \\
\hline C. aeneicolle Zajciw, 1962 & R. fasciata (LeConte, 1873) (*) \\
\hline Cycnoderus Audinet-Serville, 1834 (7) & Thalusia Thomson, 1864 (2) \\
\hline C.(C.) tenuatus Audinet-Serville, $1834(*)$ & T. erythromera (Audinet-Serville, 1834$)(*)$ \\
\hline C. (Ulododerus) barbatus Gounelle, 1911 & T. atrata (Melzer, 1918) \\
\hline \multicolumn{2}{|l|}{ Dirocoremia Marques, 1994 (3) } \\
\hline D. ingae (Marques, 1994) (*) & Cleomenini \\
\hline D. bruchi (Gounelle, 1905) & Cleomenes Thomson, 1864 \\
\hline D. simplicipes (Gounelle, 1911) & C. auricollis Kano, 1933 \\
\hline Disaulax Audinet-Serville, 1833 (1) & Haenkea Tippmann, 1953 \\
\hline D. hirsuticornis (Kirby, 1818) (*) & H. atra (Chevrolat, 1855) \\
\hline Elaphopsis Audinet-Serville, 1834 (2) & Listroptera Audinet-Serville, 1834 \\
\hline E. rubida Audinet-Serville, $1834(*)$ & L. tenebricosa (Olivier, 1790) \\
\hline \multicolumn{2}{|l|}{ Gurubira Napp \& Marques, 1999 (6) } \\
\hline G. axillaris (klug, 1825) $(*)$ & Glaucytini \\
\hline Ischionodonta Chevrolat, 1859 (19) & Glaucytes Thomson, 1858 \\
\hline I. platensis (Chevrolat, 1859) & G. scripta (Fabricius, 1798) \\
\hline \multicolumn{2}{|l|}{ I. rufomarginata (Fischer, 1937) } \\
\hline I. brasiliensis (Chevrolat, 1859) (*) & Necydalopsini \\
\hline Lathusia Zajciw, 1959 (2) & Lissozodes Bates, 1870 \\
\hline L. parvipilipes (Zajciw, 1959) $(*)$ & L. basalis (White, 1855) \\
\hline L. ferruginea (Bruch, 1908) & Ozodes Audinet-Serville, 1834 \\
\hline Merocoremia Marques, 1994 (1) & O. nodicollis Audinet-Serville, 1834 \\
\hline M. monnei Marques, 1994 (*) & \\
\hline
\end{tabular}




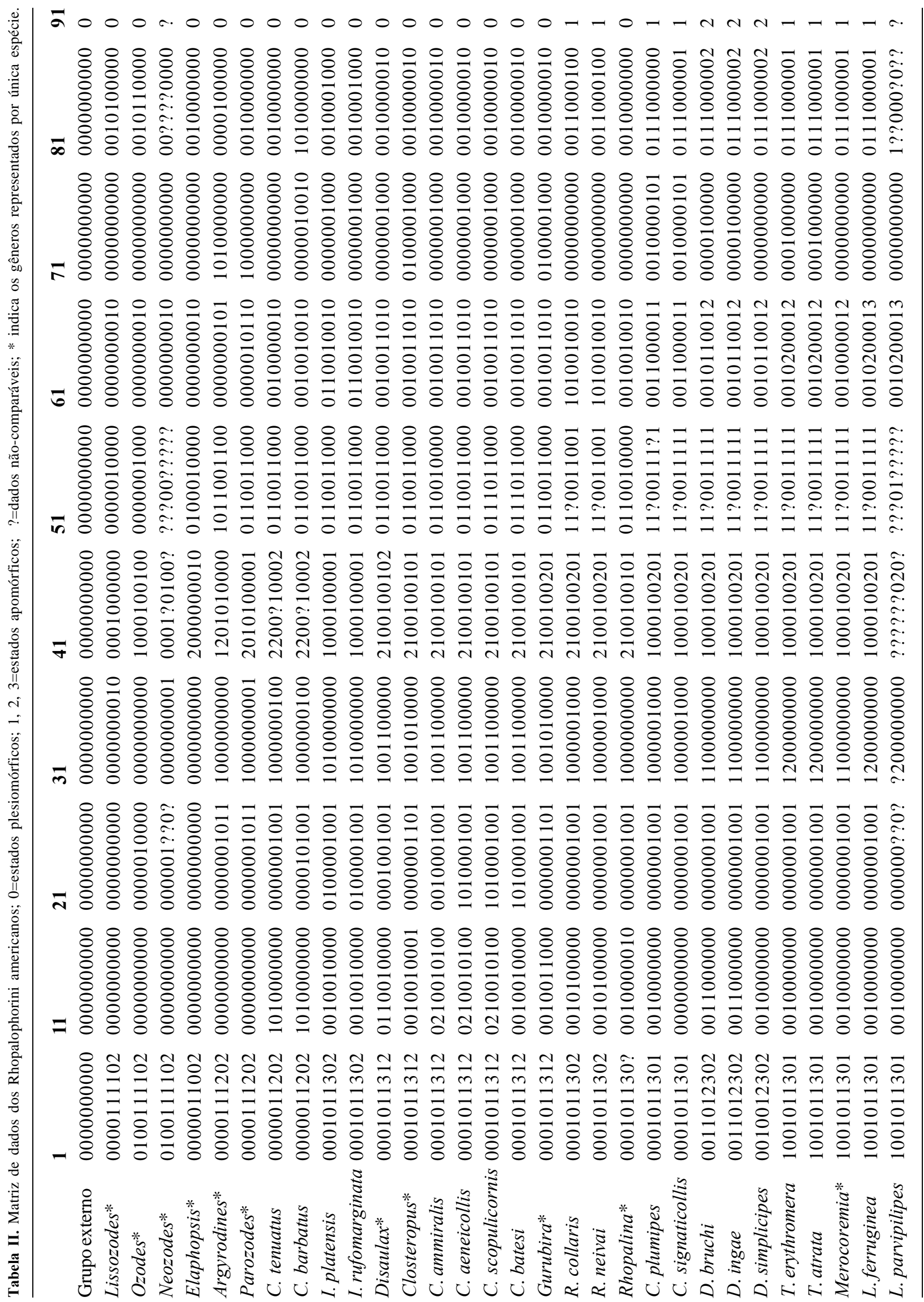


gêneros descritos da América do Sul. Devido à sua ampla distribuição inclui formas bastante diversificadas (GRESSIT \& RONDON 1970; MERMUdes 1999) e inexistem trabalhos de revisão. O estudo de Fragoso (1985) com espécies americanas de Cleomenini levou, inclusive, ao questionamento da manutenção desta como tribo distinta de Rhopalophorini e estudos recentes têm evidenciado que os gêneros neotropicais de Cleomenini não têm afinidades com Cleomenes ou com outros representantes não neotropicais de Cleomenini (Mermudes 1999; Mermudes \& NAPP 2001, 2002). O estudo preliminar de espécies dos gêneros neotropicais Listroptera e Haenkea, quando da seleção de representantes de Cleomenini como grupos externos, corroborou MERMUdes (1999)

Dessa forma, considerando a escassez de estudos cladísticos em Cerambycidae e em Cerambycinae, a extrema plasticidade dos caracteres dos Cerambycinae como apontado desde LACORDAIRE (1869) e evidenciado por NAPP (1994) e LiNGAFELTER (1998) e o questionamento sobre as afinidades dos Cleomenini americanos, optou-se, para efeitos de análise, pela alternativa de estimar os estados ancestrais dos caracteres (NIXON \& CARPENTER 1993) utilizando-se todas as informações disponíveis na literatura sobre Cerambycinae, além dos dados levantados sobre Cleomenes e Glaucytes.

\section{RESULTADOS}

\section{Análises}

As análises realizadas com o programa PAUP, caracteres multiestado não-ordenados e otimização Acctran resultaram em 36 cladogramas, com 124 passos, índice de consistência de 0,85 e de retenção de 0,94 . Com os caracteres multiestado ordenados, obtiveram-se 10 cladogramas com 129 passos, índice de consistência de 0,81 e o de retenção, 0,93 . Mantendose alguns dos caracteres multiestado ordenados e otimização Acctran e/ou Deltran, 12 cladogramas foram gerados, com 126 passos, IC=0,84 e IR=0,94. Em todas as análises, o número de cladogramas gerados foi conseqüência de alterações no interrelacionamento das espécies de Cosmisoma e do parentesco indefinido de Rhopalina. O maior número de cladogramas gerados, quando todos os caracteres multiestado foram tratados como não-ordenados, deveu-se também à indefinicação do parentesco de Merocoremia com os gêneros do grupo Coremia+. Com o programa NONA, as análises com parte dos caracteres multiestado ordenados geraram apenas dois cladograms com topologia e índices iguais aos obtidos com o PAUP: comprimento de 126 passos, $\mathrm{IC}=0,84 \mathrm{e} \mathrm{IR}=0,93$.

A opção pelos cladogramas com parte dos caracteres multiestado não-ordenados e otimização Deltran justifica-se, principalmente, pela distribuição dos caracteres e/ou estados dos caracteres 32, 37 e 65 . Estes caracteres, quando tratados como não-ordenados, resultam em reversões não aceitáveis. Por exemplo, o padrão de protórax (37.1) é indicado como sinapomórfico para o grupo Rhopalophora+, embora apenas Coremia e Rhopalophora apresentem este padrão, revertendo para o estado plesiomórfico no grupo Merocoremia+. Neste grupo, ocorrem, ainda, reversões nos caracteres 32 e 65 (padrão de protórax e de clavas). Mantendo-se estes caracteres como ordenados, as séries de transformações hipotetizadas são mantidas, o caráter 37 é indicado como homoplásico para Coremia e Rhopalophora e o inter-relacionamento dos gêneros do grupo Coremia+ fica melhor sustentado. A distribuição dos estados dos demais caracteres multiestado permaneceu inalterada independente das opções utilizadas. Assim, apenas os caracteres $8,10,12,41,42$, 48 e 50 foram mantidos como nãoordenados considerando não haver certeza quanto à polaridade das séries de transformação hipotetizadas.

Em todas as análises, as árvores geradas apresentaram a mesma topologia e distribuição dos caracteres e/ou estados dos caracteres (exceto no grupo Coremia + nas análises com todos os caracteres multiestado não-ordenados; vide Discussão e Conclusões). O relacionamento entre os gêneros permaneceu inalterado, mantendo-se a formação dos mesmos grupos monofiléticos, assim como o inter-relacionamento entre os seus integrantes. Esta situação permanece inalterada incluindo ou excluindo-se os gêneros Lissozodes, Ozodes, Neozodes e Elaphopsis (Figs. 300, 301).

\section{Caracteres}

A seqüência adotada para a análise dos caracteres segue a mesma ordem da matriz de dados. A condição plesiomórfica é indicada por $0 ; 1,2 \ldots$, indicam os estados apomórficos.

\section{Cabeça. Caracteres 1 -9}

Caráter 1. Cabeça, na região posterior, com constrição: pouco acentuada - 0 ; acentuada -1

Autapomorfia de Thalusia (Figs. 5, 6). Em Cleomenes (Fig. 1), Glaucytes e na maioria das espécies estudadas de Rhopalophorini (Figs. 2-4) a cabeça tem constrição pouco acentuada.

Caráter 2. Fronte: não-deprimida - 0; evidentemente deprimida, com rebordos laterais elevados - 1

LinSLEY (1961) considerou fronte horizontal a inclinada como o mais usual em Cerambycinae, sendo fronte vertical o estado apomórfico. A fronte em Ozodes e Neozodes (Fig. 278), embora curta, é subvertical, evidentemente deprimida, com os bordos laterais elevados, formando um rebordo nítido entre a fronte e a área malar, condição sinapomórfica. Dirocoremia (Fig. 279) também apresenta fronte deprimida mas difere em outros aspectos, sendo considerado como um evento independente (caráter 3).

Caráter 3. Fronte: não-deprimida - 0; deprimida, com rebordos laterais arredondados - 1

A fronte em Dirocoremia (Fig. 279) difere das de Ozodes e Neozodes (Fig. 278) por ser mais alongada e pouco deprimida com bordos laterais não nitidamente elevados, condição autapomórfica, independente da que ocorre naqueles táxons.

Caráter 4. Cabeça: não-rostrada - 0; rostrada -1

Cabeça projetada à frente dos olhos, com as genas e fronte 
alongadas, aspecto rostrado, é condição sinapomórfica para Rhopalina +, com reversão em Dirocoremia simplicipes (Fig. 16). Em Cleomenes (Fig. 7), Ozodes + (Fig. 280) e nos grupos mais basais de Rhopalophorini (Elaphopsis, Fig. 281, Cycnoderus, Fig. 282, Argyrodines, Fig. 12, Parozodes, Fig. 13), a cabeça é pouco projetada à frente dos lobos oculares inferiores e a fronte é curta, condição plesiomórfica.

Caráter 5. Genas: não-volumosas - 0; volumosas, intumescidas $-1$

Genas intumescidas, embora curtas, é uma sinapomorfia do grupo Lissozodes+ (Fig. 280). Essa mesma condição embasa o parentesco de Argyrodines e Parozodes.

\section{Caracteres 6- 9. Olhos.}

Os olhos apresentam uma grande diversidade quanto à forma e tamanho dos lobos superiores e inferiores e quanto à largura da ligação entre os lobos, até mesmo entre espécies de um mesmo gênero. Essa constatação corrobora a verificada por NAPP (1994) para os Cerambycidae e também para os Cerambycinae.

Inicialmente, um grande número de caracteres foi formulado e avaliado. Entretanto, devido à plasticidade da estrutura, o desdobramento em vários caracteres somente resultou em homoplasias e/ou reversões não sendo útil para o entendimento, seja da evolução do caráter, seja do interrelacionamento dos táxons do grupo em estudo. Por isso, apenas as condições explicitadas a seguir e indicadas como apomórficas em todas as análises, foram mantidas.

Caráter 6. Ligação entre os lobos oculares afastada do tubérculo antenífero

Faixa de ligação afastada do tubérculo antenífero é condição sinapomórfica para os Rhopalophorini (Figs. 8, 10-17), incluindo Ozodes e Lissozodes. Em Cleomenes e Glaucytes (Figs. 7, 9) a faixa de ligação entre os lobos oculares é bem próxima do tubérculo antenífero.

Caráter 7. Margem superior do lobo ocular inferior, em relação ao tubérculo antenífero: afastada - 1; muito afastada - 2

Nos Rhopalophorini (Figs. 8, 10-14) e em Ozodes e Lissozodes, a margem ocular superior pode ser desde pouco a bem afastada do tubérculo antenífero, condição sinapomórfica intermediária. A condição apomórfica extrema é uma autapomorfia de Dirocoremia (Figs. 15-17).

Caráter 8. Granulação ocular: média - 1; fina - 2; muito fina -3 Em Cerambycinae, olhos grosseiramente facetados são considerados plesiomórficos. No grupo em estudo, foi possível estabelecer uma série de transformação linear quanto à granulação ocular. Olhos com granulação grossa, os omatídeos bem destacados, condição plesiomórfica, ocorre apenas em Elaphopsis (Fig. 281). No grupo Lissozodes+ (Fig. 280), os omatídeos ainda são bem salientes, mas menos proeminentes, condição sinapomórfica inicial (8.1). Olhos com granulação fina (8.2) como ocorre em Argyrodines, Parozodes e Cycnoderus
(Fig. 282), é uma sinapomorfia para os demais Rhopalophorini e a condição sinapomórfica extrema (8.3) embasa a monofilia do grupo Rhopalina+ (Fig. 283). Cleomenini e Glaucytini também apresentam granulação ocular fina. Entretanto, pelas diferentes condições de granulação verificadas nos Rhopalophorini, é possível que o mesmo gradiente seja encontrado naquelas tribos e a granulação muito fina, em Rhopalophorini, seja um evento independente.

Caráter 9. Lobo ocular inferior desenvolvido, a margem superior retilínea: 1

Disaulax, Cosmisoma (Fig. 283), Closteropus (Fig. 10) e Gurubira (Fig. 11) apresentam o mesmo padrão de lobo ocular inferior: muito desenvolvido, contíguo à linha da fronte, com a margem superior retilínea ou pouco sinuosa, condição considerada sinapomórfica. Nos demais Rhopalophorini (Figs. 8, 12-17), os lobos inferiores são muito variáveis, mas nenhum apresenta este padrão. Em Cleomenes (Fig. 7), o lobo ocular inferior ocupa quase toda a região lateral da cabeça e em Glaucytes (Fig. 9) os olhos são totalmente distintos de todos os Rhopalophorini.

\section{Antenas. Caracteres 10 - 26}

Assim como em outras estruturas estudadas, as antenas apresentam uma grande variabilidade quanto a: 1) pilosidade; 2) escapo, com relação ao comprimento, forma e presença/ ausência de diferentes tipos de sulcos na base; 3 ) forma e comprimento dos antenômeros; 4) presença/ausência de carenas, pouco ou bem acentuadas e 5) presença/ausência de asperosidades e espinhos. Inicialmente, um grande número de caracteres foi avaliado, mas a variabilidade inter- e intragenérica limitou sua utilização. Dessa forma, as seguintes condições indicadas como apomórficas foram consideradas nas análises finais:

Caráter 10. Comprimento: moderadamente longas -1 ; bastante alongadas - 2

Segundo Crowson (1981), o mais comum em Coleoptera são antenas curtas, com a metade do comprimento do corpo. NAPP (1994) considerou antenas que alcançam o meio ou o terço apical dos élitros, como a condição plesiomórfica em Cerambycidae, com dois estados apomórficos: antenas curtas, atingindo apenas a base dos élitros e mais longas do que o corpo.

Na maioria dos gêneros de Cleomenini, as antenas são curtas, atingindo o meio dos élitros, condição plesiomórfica. Nos Rhopalophorini (Figs. 20, 21, 288), exceto Rhopalina, os artículos antenais são moderadamente alongados e as antenas ultrapassam o ápice elitral em um a dois artículos (estado 1), ou em cinco ou seis artículos (Figs. 22-25, 38-41, 284, 286-287) (estado 2). Rhopalina (Fig. 285) foi codificado como não comparável para este caráter, tendo em vista que suas antenas diferem das observadas tanto em Cleomenini (Fig. 18) quanto em Rhopalophorini (Vide caráter 19).

Considerando que o comprimento das antenas é variável em Cleomenini e que antenas longas ou curtas podem ocorrer 
em diferentes tribos de Cerambycinae, o alongamento das antenas em Rhopalophorini foi assumido como evento independente do verificado em Cleomenini e Glaucytes.

\section{Caráter 11. Doze artículos antenais}

Antenas com doze artículos é uma sinapomorfia de Cycnoderus (Figs. 23, 24). Essa condição pode ocorrer em Ischionodonta, mas com grande variabilidae intra- e interespecífica, pois em algumas espécies os dois sexos têm 11 ou 12 antenômeros, ou os machos têm 12 e as fêmeas, 11 antenômeros. Dessa forma, a condição sinapomórfica foi considerada apenas para Cycnoderus.

\section{Caracteres 12-14. Escapo.}

Em Cleomenes (Fig. 29) e Glaucytes, o escapo é curto, sem sulcos ou depressões na base. Nos Rhopalophorini (Figs. 26, $27,30-37)$ o escapo é extremamente variável em todos os aspectos, e apenas as seguintes condições apomórficas foram mantidas nas análises finais:

Caráter 12. Escapo: alongado, cilíndrico - 1; alongado, alargado para o ápice - 2

Em Cosmisoma, exceto C. batesi (Fig. 33), e em Disaulax o escapo é bastante alongado. Em Disaulax (Fig. 37), é robusto, tão largo na base quanto no ápice, condição autapomórfica. Escapo longo e subpiriforme é uma sinapomorfia de Cosmisoma (Figs. 35, 36).

Caráter 13. Escapo com sulco ou depressões na base

Escapo sulcado ou com depressões na base (Figs. 26, 27, 30-37) é sinapomórfico para o grupo Cycnoderus+, com reversões em Coremia signaticollis (Fig. 28) e em Merocoremia.

Caráter 14. Escapo robusto com duas depressões separadas por carena

Escapo robusto, engrossado e largo para o ápice, com duas depressões longitudinais na base separadas por carena obtusa, é condição exclusiva de Dirocoremia (Figs. 26, 27), exceto $D$. simplicipes (Fig. 30).

Caráter 15. Artículo antenal IV encurtado

Em Rhopalophora (Fig. 286) os artículos antenais são alongados, com nítido encurtamento apenas do artículo IV, condição autapomórfica. Artículo IV encurtado também ocorre em Rhopalina (Fig.285), contudo os demais artículos também são curtos, além de carenados e deprimidos e, portanto, não comparável à condição observada em Rhopalophora (Vide caráter 19).

Caráter 16. Artículos antenais III e V ou III a V alongados

Os artículos antenais em Cleomenes (Fig. 18), Dihammaphora e Listroptera são, de um modo geral, curtos e subiguais em comprimento. Artículos antenais III e V ou III a V muito alongados quando comparados aos demais, sendo o $\mathrm{V} o$ mais longo com seu ápice quase atingindo o ápice elitral, é uma sinapomorfia do grupo Ischionodonta+ (Figs. 22, 25, 38-41, 284, 287). Em Cosmisoma, C. ammirallis (Fig. 41) tem o artículo $\mathrm{V}$ bem mais longo que nas demais espécies, enquanto o IV é curto, com metade do comprimento do III. Parozodes e Dirocoremia simplicipes (Fig. 289) também apresentam os artículos III a V muito alongados, o V atingindo o ápice elitral. $\mathrm{O}$ alongamento destes artículos, nestes táxons, foi considerado como eventos independentes, pelo conjunto das demais características das antenas. Nos demais gêneros de Rhopalophorini, o ápice do artículo V, no máximo, alcança ou ultrapassa um pouco o meio do élitro.

Caráter 17. Artículos antenais III a VI com comprimentos crescentes

Autapomorfia de Gurubira (Fig. 22). Nos demais gêneros de Rhopalophorini (Figs. 23-25, 38-41), ocorre grande variabilidade no comprimento e proporção destes artículos e nos Cleomenini (Fig.18), com poucas exceções, são curtos e subiguais em comprimento.

Caráter 18. Artículos antenais VI a XI sensivelmente encurtados Artículos antenais VI-XI nitidamente mais curtos que os III-V é condição exclusiva de Cosmisoma (Figs. 40, 41), exceto C. batesi (Fig. 284).

Caráter 19. Artículos antenais carenados e deprimidos

Em Rhopalina (Fig. 285), os artículos antenais III-XI são curtos, carenados e deprimidos, sendo o IV o mais curto, condição autapomórfica. Conforme discutido no caráter 15, a condição curta do artículo IV não é homóloga à que ocorre em Rhopalophora (Fig. 286).

Caráter 20. Artículos antenais com espinho

Presença de espinho curto, robusto e acuminado no ápice interno dos artículos III a VI, mais evidente no V, é condição autapomórfica de Closteropus (Fig. 43). Em Cleomenes e Glaucytes (Figs. 18, 19), as antenas são inermes e, entre os Rhopalophorini, Cosmisoma (Fig. 42) apresenta espinho apenas no artículo $\mathrm{V}$ (Vide caráter 21) e Ischionodonta spinicornis, nos artículos IV a VII.

Caráter 21. Artículo antenal V com espinho

As espécies estudadas de Cosmisoma (Fig. 42), exceto $C$. ammirallis (Fig. 41), têm um espinho curto, mas bem aparente no ápice interno do artículo $\mathrm{V}$, condição sinapomórfica. ZAJcIW (1962) ressaltou que 11 espécies deste gênero possuem este espinho. Citou, ainda, que “...tais espinhos estão escondidos por tufos de pêlos longos, razão pela qual talvez nunca tenham sido observados pelos autores mencionados nas descrições anteriores."

Caráter 22. Escapo e artículos III a V com pontos ásperos

Dentre os gêneros estudados de Rhopalophorini, apenas Ischionodonta (Figs. 44, 45) apresenta o escapo e os artículos III a V com pontos ásperos, condição autapomórfica. 
Caráter 23. Artículos antenais V aVI com tufos de pêlos

Cleomenes e Glaucytes (Figs. 18, 19) não possuem pilosidade diferenciada nas antenas. Em Rhopalophorini, os gêneros Cosmisoma (Figs. 40, 41, 302), Disaulax (Fig. 287), e também Cycnoderus barbatus (Fig. 24), apresentam pilosidade diferenciada em forma de franja, tufos ou escovas de pêlos em diferentes artículos antenais. Em Cosmisoma, nota-se a presença de tufos de pêlos com aspecto condensado e uniforme, circundando todo o artículo, nos artículos V e/ou V-VI, condição sinapomórfica. ZAJCIW (1962) salientou que “... apesar do gênero ser caracterizado pela presença de tufos de pêlos no V ou V-VI artículos antenais, aliás caráter muito importante, ele conta também com uma espécie $C$. nudicorne Bates (Panamá) e uma variedade cyaneum Gounelle sem esse caráter." Sendo Cosmisoma o maior gênero de Rhopalophorini, com 41 espécies, e estando este caráter ausente apenas em uma, aceita-se a afirmativa de ZAJcIw (l.c.) e considera-se a presença de tufos de pêlos nas antenas como sinapomórfica para o gênero. A pilosidade compacta, diferenciada, presente nas antenas de Disaulax e de Cycnoderus barbatus foi interpretada como eventos independentes (Caracteres 24 e 25).

Caráter 24. Artículos antenais III a V com escova de pêlos

Em Disaulax (Fig. 287) a pilosidade, em forma de escova adensada, reveste apenas as faces laterais e inferior dos artículos III a V, condição autapomórfica. Segundo ZaJciw (1962), este é um dos caracteres que diferencia Disaulax de Cosmisoma.

Caráter 25. Artículo antenal VI com franja de longos pêlos

Presença de franja de pêlos alongados no artículo antenal VI é condição autapomórfica de Cycnoderus barbatus (Fig. 24). Este tipo de franja é distinta da apresentada por Disaulax. Em C. barbatus, a franja está restrita à face inferior do artículo VI e os pêlos são bem mais alongados.

Caráter 26. Artículos antenais com pêlos alongados

Ozodes e Neozodes (Fig. 46) apresentam numerosos pêlos longos, eretos, distribuídos em todos os artículos antenais, inclusive no escapo, condição sinapomórfica. Em Cleomenini e na maioria dos Rhopalophorini, as antenas são revestidas por pêlos decumbentes, curtos, distribuídos uniformemente.

\section{Peças bucais. Caracteres 27-31}

Caráter 27. Maxila: gálea reduzida ou pouco desenvolvida - 0; gálea desenvolvida - 1

Algumas variações foram observadas nas maxilas dos Rhopalophorini, levando ao estabelecimento de padrões quanto à estrutura da maxila, aspecto geral da gálea e dos palpos maxilares.

Ainda considerando as observações de NAPP (1994), a maxila em Cerambycinae tem as seguintes características: “....a gálea é freqüentemente alongada e capitada, mais alargada em direção ao palpo; a pilosidade pode se estender de forma característica no terço apical, usualmente com um adensamento na região interna em direção à lacínia; a base da gálea retrai-se entre o palpífero e a lacínia, formando uma espécie de dobra, o que confere à gálea a possibilidade de distender-se."

Ozodes e Lissozodes (Figs. 58, 59) apresentam um padrão de maxila bastante distinto dos demais Rhopalophorini, e também de Cleomenes e de Glaucytes (Figs. 56, 57), constatando-se: fusão do basistipe e dististipe; gálea cilíndrica, pouco desenvolvida, não capitada e não alargada em direção aos palpos; pilosidade curta, pouco adensada, principalmente em Lissozodes; lacínia reduzida, notavelmente em Ozodes, com pilosidade curta e escassa. Este padrão de maxila é observado, também, no plano básico dos Cerambycinae. Em Elaphopsis (Fig. 60), o basistipe e dististipe não são fusionados, mas a lacínia e a gálea são menos desenvolvidas se comparadas ao padrão de Cerambycinae descrito acima; a gálea é levemente constrita no meio, dilatada e arredondada, com pilosidade mais adensada no ápice. Essas condições foram interpretadas como plesiomórficas.

No grupo Argyrodines+, a gálea é cilíndrico-alongada, até mais longa que o palpo maxilar, dilatada e obliquamente truncada no ápice, condição sinapomórfica que corrobora a monofilia desse grupo.

Caráter 28. Maxila: gálea fortemente expandida no ápice

Gálea fortemente expandida no ápice é sinapomórfica para Gurubira+Closteropus (Figs. 62, 63). Parozodes e Argyrodines também apresentam este padrão de gálea, aqui interpretada como como evento independente, como indicado em todas as análises realizadas (Vide caráter 29).

Caráter 29. Maxila: gálea fortemente expandida no ápice

Como descrito no caráter 28, a gálea cilíndrico-alongada, fortemente expandida no ápice, presente em Argyrodines e Parozodes (Figs. 65, 66), foi considerada uma evolução independente e sinapomórfica para estes dois gêneros.

Caráter 30. Palpo maxilar: artículos $2^{\circ} \mathrm{e} 4^{\circ}$ longos - 0 ; artículos $2^{\circ}$

- $3^{\circ}$ cônicos, subiguais, $\mathrm{o} 4^{\circ}$ tão longo quanto o $1^{\circ}$, atenuado no ápice - 1

De acordo com NAPP (1994), os palpos maxilares apresentam grande variabilidade, mas na maioria dos Cerambycinae o $2^{\circ}$ artículo é mais longo que o $3^{\circ}$, o apical mais longo que o basal e usualmente cilíndrico, não atenuado no ápice. Esta condição é verificada em Cleomenes e Glaucytes.

Em Ozodes, Lissozodes e Elaphopsis, o palpo maxilar apresenta características particulares, podendo, eventualmente, representar autapomorfias. Em todos, o palpo é bem desenvolvido e o artículo apical é o que mais se diferencia pelo comprimento e/ou pela forma. Em Elaphopsis (Fig. 60), o artículo apical é o mais alongado, fortemente dilatado no ápice; os $2^{\circ} \mathrm{e}$ $3^{\circ}$ são cilíndrico-alongados, pouco mais curtos que o apical, e o $1^{\circ}$ é curto, com cerca da metade do comprimento do $2^{\circ}$. Em Ozodes (Fig. 58), o artículo apical é robusto, truncado no ápice, os $2^{\circ}$ e $3^{\circ}$ são alongados e o basal tem cerca da metade do comprimento do apical. EmLissozodes (Fig. 59), o artículo apical é alongado, os $2^{\circ}$ e $3^{\circ}$ são curtos e o basal é cerca de um terço mais curto que o apical. 
Nos demais Rhopalophorini (Figs. 61-66), os $2^{\circ}$ e $3^{\circ}$ artículos são cônicos e subiguais e o apical é encurtado, tão longo quanto o basal e atenuado no ápice, condição sinapomórfica. No aspecto geral, o palpo maxilar em Rhopalophorini é pouco alongado.

Caráter 31. Mento: transverso - 0; quadrangular - 1

Mento fortemente transverso com a região membranosa anterior reduzida é a condição presente no plano básico de Cerambycinae (NAPP 1994) e também em Lissozodes, Ozodes (Fig. 67) e Elaphopsis (Fig. 68). Em Cleomenes (Fig. 69) e nos demais Rhopalophorini (Figs. 70-74), a região membranosa anterior é desenvolvida, sendo o mento em Cleomenes, transverso e, no grupo Argyrodines-Parozodes+, quadrangular, condição sinapomórfica.

\section{Protórax. Caracteres 32 - 46}

O protórax em Rhopalophorini apresenta uma grande variabilidade, o que inviabilizou o estabelecimento de séries de transformação ou mesmo de sinapomorfias para grupos, tendo sido mais útil na definição de diferentes gêneros.

No plano básico dos Cerambycinae, protórax mais largo que longo e destituído de tubérculos e/ou constrições é condição plesiomórfica. A partir deste padrão, diferentes formas de protórax, bem como presença de tubérculos seriam apomórficos. Nos grupos externos sua conformação é variável: em Cleomenes é mais longo que largo, subtuberculado aos lados e com tubérculos pronotais, enquanto em Glaucytes é quadrangular e destituído de tubérculos.

Em Rhopalophorini, o protórax pode ser transverso ou alongado, ambas as formas podendo apresentar tubérculos e/ ou constrições. A formulação de caracteres, levando-se em conta apenas a presença de tubérculos e/ou constrições, independente do tipo de protórax, induziu a inúmeras homoplasias, uma vez que não foi possível estabelecer séries de transformação. Por esta razão, a presença de tubérculos e/ ou constrições nas formas alongadas foi considerada não homóloga à observada nas formas transversas, e as seguintes condições considerados apomórficas:

Caráter 32. Protórax transverso: subtuberculado aos lados - 1; com tubérculo mediano - 2

Protórax dilatado ao nível do meio, com aspecto hexagonal e pronoto aplanado, é sinapomórfico para o grupo Merocoremiat. A condição apomórfica extrema corrobora o parentesco de Lathusia e Thalusia (Figs. 79, 80).

Caráter 33. Protórax alargado da margem anterior para a posterior

Protórax tão largo quanto longo, constrito anteriormente, os lados divergentes para trás e com a maior largura após o meio, é uma sinapomorfia de Ischionodonta (Figs. 82, 85).

Caráter 34. Protórax alongado, inerme aos lados e sulcado na base do pronoto

Protórax cilíndrico-alongado, constrito anteriormente, com os lados abaulados e inermes e presença de sulco em forma de "V" invertido na região posterior do pronoto, é sinapomórfico para o grupo Closteropus+. Neste grupo, Disaulax + Cosmisoma e Closteropus + Gurubira apresentam outras condições distintas, tratadas nos Caracteres 35 e 36, respectivamente.

\section{Caráter 35. Protórax: padrão Cosmisoma}

Os gêneros Cosmisoma (Figs. 86, 284) e Disaulax (Figs. 87, 287) apresentam gibosidades pronotais pouco aparentes, lados do protórax regulares e levemente arredondados, constritos nas regiões anterior e posterior, e sulco em "V" na base do pronoto pouco acentuado. Em C. ammirallis, o protórax é mais globoso, porém com as mesmas características que as demais espécies do grupo.

\section{Caráter 36. Protórax: padrão Closteropus}

Em Closteropus e Gurubira (Figs. 83, 84) o protórax tem lados subparalelos, a largura basal é maior que a anterior, a constrição posterior é pouco acentuada, o sulco basal em "V" do pronoto é acentuado e o pronoto apresenta quatro gibosidades, sendo duas anteriores e duas posteriores.

Caráter 37. Protórax alongado, inerme aos lados e estreitado na região anterior

Protórax cilíndrico, abaulado aos lados, sem tubérculos laterais e mais constrito na região anterior é sinapomórfico para Rhopalophora (Figs. 91, 92, 286), e também para Coremia (Figs. 90, 93) (homoplasia).

Caráter 38. Protórax alongado, aspecto sub-retilíneo

Protórax muito alongado, com aspecto sub-retilíneo, é uma autapomorfia de Cycnoderus (Figs. 88, 89). Em Lissozodes o protórax também é cilíndrico-alongado, mas difere por ser constrito na região posterior (Caráter 39).

Caráter 39. Protórax alongado, constrito na região basal

Protórax cilíndrico-alongado, sem tubérculos laterais, pouco arredondado na metade posterior e região basal com constrição acentuada é condição única de Lissozodes (Fig. 97).

Caráter 40. Protórax nitidamente alargado entre as constrições anterior e posterior

Protórax com as regiões anterior e posterior estreitadas, com larguras subiguais, delimitadas por constrições acentuadas e região mediana nitidamente alargada aos lados, corrobora o parentesco de Ozodes + Neozodes (Fig. 94), assim como o de Parozodes + Argyrodines (Figs. 95, 96).

\section{Caracteres 41 - 43. Cavidade coxal anterior}

De acordo com NAPP (1994), cavidades coxais anteriores fortemente angulosas aos lados e abertas atrás é condição plesiomórfica em Cerambycidae, também presente no plano básico dos Cerambycinae. Lacordaire (1869) situou Rhopalophorini no grupo com cavidades coxais anteriores não angulosas aos lados entre as tribos em que as cavidades podem 
ser fechadas ou abertas atrás. Nos Cleomenini estudados (Cleomenes, Fig. 100, Dihammaphora e Listroptera), as cavidades são arredondadas aos lados e fechadas atrás. Em Glaucytes, também são arredondadas aos lados, mas abertas atrás.

Em Rhopalophorini (Figs. 101-108, 110-113), as cavidades podem ser desde algo transversas, subangulosas aos lados e abertas atrás, até arredondadas lateralmente e fechadas atrás. Além disso, na região posterior, as cavidades podem ser fechadas por expansão do processo prosternal, do proepimero ou de ambos. O processo prosternal também é variável, sendo: estreito, com lados subparalelos, não expandido no ápice; alargado, com lados subparalelos; largo na base e no ápice, um pouco estreitado entre as coxas anteriores ou fortemente expandido no ápice.

A variabilidade dentro do grupo em estudo e também nos grupos externos permitiu que apenas as seguintes condições apomórficas fossem consideradas:

Caráter 41. Cavidade coxal anterior: transversa, fortemente angulosa aos lados - 0; transversa e angulosa aos lados - 1; arredondada, levemente angulosa a fechada aos lados - 2

Cavidade coxal anterior com aspecto arredondado, levemente angulosa a fechada aos lados, é uma sinapomorfia do grupo Elaphopsis+. O grupo Coremia+ (Figs. 103-105) apresenta cavidades coxais com aspecto transverso, sendo um pouco angulosas aos lados, condição que ocorre também em Ischionodonta (Figs. 110, 111).

Embora em Lissozodes, Ozodes (Figs. 114, 115) e Neozodes as cavidades coxais tenham aspecto arredondado, observa-se que são bem mais desenvolvidas do que nos demais gêneros de Rhopalophorini. Este padrão é característico dos grupos que têm as coxas anteriores cônicas e projetadas, aspecto já salientado por Giesbert \& ChemsaK (1993), quando da transferência de Ozodes e Neozodes para Necydalopsini. Por esta razão, as cavidades coxais arredondadas, nesses gêneros, foram consideradas não homólogas às cavidades arredondadas dos demais Rhopalophorini.

Tendo em vista a variabilidade encontrada no grupo em estudo, é possível que cavidades coxais anteriores fechadas e arredondadas aos lados tenham sido eventos independentes em Cleomenini e em Rhopalophorini, como ocorre em diferentes tribos de Cerambycinae (NAPP, dados não publicados).

Caráter 42. Cavidade coxal anterior, na região posterior: aberta - 0; quase fechada por expansão do processo prosternal e do proepimero - 1; fechada por forte expansão apical do processo prosternal - 2

No grupo Closteropus+ (Fig. 108), o processo prosternal é alargado na base e no ápice e o proepimero projeta-se até além da metade do diâmetro da cavidade cotilóide que é quase fechada, condição sinapomórfica que ocorre paralelamente em Rhopalophora (Fig. 102). Em Cycnoderus (Figs. 106,107), verifica-se uma forte expansão do processo prosternal no ápice, condição autapomórfica. As cavidades coxais anteriores fechadas de Argyrodines e Parozodes foram interpretadas como não homólogas às dos gêneros acima, considerando que a conformação do protórax é totalmente distinta (Caráter 43).

Caráter 43. Cavidade coxal anterior fechada por forte expansão do processo prosternal

Em Parozodes e Argyrodines (Figs. 112, 113), a região apical do processo prosternal é fortemente expandida, sobrepondose às extremidades internas do proepimero, condição única entre os Rhopalophorini.

Caráter 44. Cavidade coxal anterior fechada por forte expansão do proepimero

O processo prosternal de Lissozodes, Ozodes (Figs. 114, 115) e Neozodes é muito estreito entre as coxas anteriores e pouco dilatado no ápice, e a cavidade coxal é fechada posteriormente apenas pelo proepimero, fortemente expandido, sinapomorfia deste grupo.

Caráter 45. Proendosternito: fusionado apenas no ápice - 0; fusionado em todo o comprimento -1

Segundo NAPP (1994), esta estrutura é pouco pesquisada em Coleoptera. Apenas MARINONI (1979) destacou a importância do seu estudo para a definição de grupos em Lamiinae. Em Cerambycinae, o proendosternito usualmente não é fusionado na linha média (NAPP, dados não publicados). Em Ozodes, Lissozodes (Figs. 118, 119) e Elaphopsis é fusionado apenas no ápice, mesma condição observada em Cleomenes e Glaucytes (Figs. 116, 117). Proendosternito totalmente fusionado na linha média (Figs. 120-123, 126, 127), é uma sinapomorfia dos demais Rhopalophorini. O proendosternito de Cycnoderus foi considerado não comparável, tendo em vista sua extrema redução (Caráter 46).

Caráter 46. Proendosternito: desenvolvido - 0; reduzido - 1

O proendosternito em Cycnoderus (Figs. 124, 125) é formado por duas projeções muito reduzidas e não fusionadas, condição interpretada como autapomórfica.

\section{Mesotórax e metatórax. Caracteres 47-53}

Caráter 47. Escutelo: plano - 0; côncavo -1

Escutelo côncavo na região mediana é condição exclusiva de Ozodes + Neozodes, corroborando o parentesco destes gêneros.

Caráter 48. Processo mesosternal: mais estreito que a cavidade coxal média - 0; tão a pouco mais largo que a cavidade coxal média -1; mais largo que a cavidade coxal média - 2

Em Rhopalophorini, o processo mesosternal varia desde muito estreito até mais largo que a cavidade coxal, possibilitando o estabelecimento de uma série de transformação linear.

Lissozodes, Ozodes (Figs. 130, 132) e Neozodes apresentam esse processo muito estreito, quase laminar, condição completamente distinta da observada nos demais Rhopalophorini. Nestes, o processo mesosternal é, pelo menos, 
quase tão largo quanto o diâmetro de uma coxa média, acoplando-se no ápice à projeção intercoxal do metasterno.

Em Argyrodines, Parozodes, Cycnoderus (Fig. 133) e Ischionodonta (Fig. 131), o processo mesosternal é quase tão largo quanto uma coxa média, mesma condição verificada em Cleomenes e Glaucytes (Figs. 128, 129). Processo mesosternal tão a pouco mais largo que a cavidade coxal média (Figs. 134136) é indicado como sinapomórfico para o grupo Closteropus+, ocorrendo também em Rhopalina (Figs. 300, 301) ou corrobora o parentesco de Rhopalina+ (com reversão em Ischionodonta) (Fig. 302). Processo mesosternal mais largo que a cavidade coxal corrobora a monofilia do grupo Rhopalophora+ (Figs. 138, 139), ocorrendo homoplasicamente em Gurubira (Fig. 140).

Elaphopsis (Fig.137) também apresenta processo mesosternal pouco mais largo que a cavidade coxal média, porém difere pela presença de projeções laterais para encaixe nas mesocoxas, sendo, por isso, considerado como não comparável (Caráter 49).

Caráter 49. Processo mesosternal com projeções laterais

Processo mesosternal com projeções laterais arredondadas que se encaixam em depressões nas mesocoxas é autapomórfico para Elaphopsis (Fig. 137). Além disso, o sistema de acoplamento com o metasterno também difere por apresentar entalhe mediano para encaixe da projeção anterior do metasterno.

Caráter 50. Mesendosternito: fusionado à parede interna do mesepimero, projeções laterais presentes - 0 ; fusionado à parede interna do mesepimero, projeções laterais ausentes - 1; não fusionado, projeções laterais ausentes - 2

No plano básico de Cerambycinae, o mesendosternito é anguloso, pouco esclerotinizado, com projeções desenvolvidas para implante de tendões, região basal tão longa quanto a distal e esta não fusionada no ápice à parede interna do mesepimero (NAPP 1994).

Em Cleomenes (Fig. 141), Glaucytes (Fig. 144) e em quase todos os Rhopalophorini (Figs. 145-150), o mesendosternito é fusionado à parede interna do mesepimero, tornando-se mais oblíquo e esclerotizado, com a região basal encurtada. Cleomenes distingue-se por apresentar projeções laterais desenvolvidas, embora a região basal seja reduzida. EmOzodes, Lissozodes (Figs. 151, 153, 154) e Elaphopsis (Fig. 152), estas projeções são ainda mais desenvolvidas e a região basal mais alongada do que em Cleomenes.

Considerando-se estes aspectos, a perda das projeções laterais foi interpretada como sinapomórfica para Rhopalophorini. Em Cycnoderus e Disaulax (Figs. 142, 143), as extremidades do mesendosternito são livres. Tendo em vista a ausência das projeções laterais e a semelhança com o mesendosternito dos demais Rhopalophorini, a condição encontrada nestes dois gêneros foi interpretada como reversão secundária.

Caráter 51. Metendosternito: braços laterais e lâminas nãofusionados - 0; braços laterais e lâminas fusionados -1
Em Cleomenes, Glaucytes (Figs. 157 - 160) e na maioria dos Rhopalophorini (Figs. 155, 156, 161-166, 174-177), o metendosternito tem lâminas alongadas e cilíndricas não fusionadas aos braços e o pedúnculo é livre, condição também presente no plano básico de Cerambycinae. Metendosternito com braços fusionados às lâminas, estas curtas e arredondadas, e pedúnculo totalmente fusionado à parede interna do metasterno (Figs. 167 -170), é uma sinapomorfia que corrobora o parentesco de Rhopalophora com o grupo Coremia+.

Caráter 52. Metendosternito: projeções para implante dos tendões anteriores: desenvolvidas - 0 ; reduzidas - 1

Presença de projeções medianas desenvolvidas para implante dos tendões anteriores ocorre em Cleomenes (Figs. 157, 158), Ozodes e Lissozodes (Figs. 178, 179). Nos Rhopalophorini (Figs. 155, 161, 163, 165, 174, 176), estas projeções são reduzidas, condição sinapomórfica.

Caráter 53. Braços laterais em relação às lâminas: verticais - 0; horizontais -1

Braços laterais alongados e direcionados mais verticalmente são considerados plesiomórficos por se aproximarem mais do padrão hilecetóide (CROwson 1955), forma que também ocorre no plano básico dos Cerambycinae (NAPP 1994) e em Ozodes (Figs. 171, 178), Lissozodes (Figs. 173, 179) e Elaphopsis (Fig. 172). Metendosternito com braços laterais curtos e perpendiculares às lâminas é sinapomórfico para os demais gêneros de Rhopalophorini (Figs. 155, 156, 161-166, 174-177).

Rhopalophora e o grupo Coremia + foram codificados como não comparáveis para este caráter já que, nestes gêneros, os braços laterais do metendosternito são fusionados às lâminas (Caráter 51).

Em Cleomenes e Glaucytes verificam-se duas condições: Cleomenes (Fig. 158) tem braços horizontais e alongados, enquanto em Glaucytes (Fig. 160) os braços laterais são curtos e oblíquos. O metendosternito dos Rhopalophorini é semelhante ao de Glaucytes, diferindo apenas pelos braços horizontais.

\section{Élitros e asas. Caracteres 54-60}

Caráter 54. Élitros: sem faixas de pêlos dourados - 0; com faixas de pêlos dourados - 1

Dentre os Rhopalophorini, apenas Cosmisoma batesi e $C$. scopulicorne (Fig. 284) possuem uma faixa longitudinal de pêlos dourados em cada élitro, condição sinapomórfica.

Caráter 55. Élitros: não adelgaçados e sem carena - 0; adelgaçados e carenados - 1

Élitros adelgaçados ao nível do meio, com carena dorsolongitudinal até a região apical, acompanhada de sulco raso, é uma autapomorfia de Lathusia.

Caráter 56. Asas. Área carenada na base da Radial: ausente - 0; presente - 1

Em Cleomenes, Glaucytes (Figs. 180, 181) e em grande parte 
dos Cerambycinae, inexiste área carenada na base da Radial. Em todos os Rhopalophorini (Figs. 182-191) e também em Ozodes e Lissozodes, a base da Radial apresenta uma área carenada.

Caráter 57. Asas. Lobo anal: desenvolvido - 0; reduzido - 1

Na grande maioria dos Rhopalophorini (Figs. 182-191), verifica-se uma redução no lobo anal que pode ser acompanhada, ou não, da redução da veia $2 \mathrm{Ab}$ em diferentes graus. Entretanto, a redução do lobo anal e/ou da $2 \mathrm{Ab}$ é bastante variável entre e dentro dos gêneros e/ou grupos de gêneros, impossibilitando o estabelecimento de uma série de transformação. Por esta razão, no momento, apenas a tendência à redução do lobo anal e da veia $2 \mathrm{Ab}$ está sendo considerada como sinapomórfica, em Rhopalophorini, para o grupo Argyrodines+ (com reversão em Rhopalina). Os diferentes graus de redução nos diversos gêneros deverão ser avaliados quando de um estudo revisivo dos mesmos.

Nos grupos externos duas situações são observadas: em Glaucytes (Fig. 181), o lobo anal e a veia 2 Ab são desenvolvidos, condição que ocorre no plano básico dos Cerambycinae e também em Ozodes e Elaphopsis. Já Cleomenes (Fig.180), apresenta o lobo anal ainda mais reduzido do que em Rhopalophorini.

Redução do lobo anal e/ou da venação alar parece ocorrer independentemente em diferentes tribos de Cerambycinae (NAPP, dados não publicados) como, por exemplo, em Necydalopsini e Rhinotragini. É possível, portanto, que a redução em Cleomenes e em Rhopalophorini sejam eventos independentes. O mesmo é válido para Lissozodes que compartilha várias apomorfias com Ozodes e Neozodes e nenhuma com os demais Rhopalophorini.

Caráter 58. Asas. Veia Plical: presente - 0; ausente - 1

A presença da Plical (P) é recorrente em Cerambycinae, sendo mantida em Cleomenes, Glaucytes (Figs. 180, 181) e na grande maioria dos Rhopalophorini. Em Cleomenes e Glaucytes, esta veia é bem alongada, atingindo a Cubital, enquanto nos Rhopalophorini (Figs. 186-191), a Plical tem comprimento variado, desde curta até alongada, ligando-se à Cubital.

A ausência da Plical, condição sinapomórfica, corrobora o parentesco do grupo Coremia+ (Figs. 182-185).

Caráter 59. Asas. Veia Empusal: unida à Plical - 0; unida à 1A -1

A condição mais comum e presente no plano básico dos Cerambycinae é a Empusal separar-se da $1 \mathrm{~A}$ e ligar-se à Plical, com o ramo Ea unido a esta. No grupo Coremia + (Figs. 182, 184, 185), a Empusal permanece unida à 1A, separando-se desta próximo à $2 \mathrm{Aa}$, condição sinapomórfica. Coremia plumipes (Fig.183) foi codificada como não comparável, uma vez que nesta espécie ocorre perda tanto da Ea, como da Plical. É possível, contudo, que a perda da Ea nesta espécie seja uma condição mais apomórfica em relação à observada nos demais representantes do grupo Coremiat, considerando o seu parentesco com este grupo.

Nos demais Rhopalophorini (Figs.186-191), há a perda da
Ea, mas esta mesma condição é verificada em Cleomenes e Glaucytes (Figs. 180, 181).

Caráter 60. Asas. Transversa s-m sinuosa, ângulo entre Cubital e Média Posterior, aberto - 0; s-m retilínea, ângulo entre Cubital e Média Posterior, fechado - 1

No plano básico de Cerambycinae, a Média Anterior (MA) está presente, a Média Posterior (MP) é afastada da Cubital (CU) e a s-m é variável, desde angulosa a retilínea. Nos grupos externos ocorrem duas situações: em Cleomenes (Fig.180), o ângulo entre MP+CU é fechado e em Glaucytes (Fig.181), aberto. Em ambos a MA está ausente, sendo a s-m sinuosa. A perda da MA parece acontecer com freqüência e de forma independente em vários grupos de Cerambycinae (tribos e/ou gêneros).

Nos Rhopalophorini (Figs. 186-188, 190, 191), a s-m é pouco a fortemente sinuosa, o ramo basal da MA pode estar ou não presente e nota-se, também, uma grande variação no ângulo formado entre $\mathrm{MP}+\mathrm{CU}$. Na revisão do gênero Coremia (Marques 1994), constatou-se em todas as espécies pertencentes aos gêneros Coremia, Dirocoremia, Merocoremia, Thalusia (Figs. 182-185) e Lathusia, um padrão invariável envolvendo esse conjunto de veias, ou seja: s-m alongada e retilínea, ausência da MA e ângulo fechado formado entre MP+CU. Neste estudo, este padrão foi observado também para as espécies de Rhopalophora (Fig. 189) e considerado sinapomórfico para este grupo de gêneros. A condição apomórfica deverá ser confirmada para as demais espécies de Rhopalophora.

\section{Pernas. Caracteres 61 - 83}

Caráter 61. Pernas médias: mais curtas que as posteriores - 0; tão longas quanto as posteriores - 1

O mais comum em Cerambycinae é o alongamento progressivo das pernas, sendo as posteriores um terço mais longas que as anteriores, condição apresentada por Cleomenes e Glaucytes. Pernas médias tão longas quanto as posteriores é uma autapomorfia de Rhopalophora (Figs. 192, 193).

Caráter 62. Pernas posteriores: sem asperosidades - 0; com asperosidades - 1

Ischionodonta (Fig.290) é o único gênero de Rhopalophorini que tem o pedúnculo dos metafêmures e também as metatíbias com pontos ásperos, biselados, condição autapomórfica. Argyrodines (Fig.292) e Parozodes também apresentam espículos nas pernas posteriores, mas a conformação destas é totalmente diversa da observada em Ischionodonta (Vide caracteres 68, 71). Em Ischionodonta, os metafêmures são pouco deprimidos e unicarenados e as metatíbias mais conspicuamente deprimidas e sem carenas.

Caráter 63. Metafêmures: pedúnculo curto a reduzido, clava alongada - 0; pedúnculo alongado, clava curta - 1

Fêmures pedunculados e clavados são considerados como apomórficos em Cerambycinae. Nos Rhopalophorini, existe uma 
grande variação quanto a: 1) comprimento do pedúnculo em relação ao comprimento total do fêmur; 2) comprimento do pedúnculo em relação à clava; 3 ) conformação da clava, desde alongada e pouco abrupta, até curta e fortemente abrupta. Ozodes (Fig. 198), Neozodes e Lissozodes (Fig. 199) têm metafêmures com pedúnculo reduzido e clava bastante alongada, estendendo-se pela maior parte do comprimento total do fêmur, e pouco distinta do pedúnculo. Elaphopsis, Argyrodines e Parozodes (Figs. 200-202) apresentam um padrão que se assemelha ao anterior, porém com o pedúnculo mais longo e a clava não tão alongada, sendo, na sua forma geral, bastante distinto do observado nos gêneros restantes de Rhopalophorini. As condições acima foram consideradas plesiomórficas.

Metafêmures com pedúnculo bem alongado e clava proporcionalmente curta, distinta e bem definida (Figs. 203207, 290, 291 293-299), é uma sinapomorfia do grupo Cycnoderust.

Caráter 64. Metafêmures: pedúnculo cilíndrico, delgado e muito alongado, clavas curtas e pouco abruptas.

Autapomorfia de Coremia (Fig. 294).

Caráter 65. Metafêmures, clavas: alongadas, pouco abruptas 0 ; curtas, abruptas e largas - 1 ; curtas, fortemente abruptas e bem alargadas -2

Como comentado anteriormente (caráter 63), os gêneros de Rhopalophorini apresentam uma grande variabilidade em relação ao tipo de clava dos metafêmures, o que induziu à consideração de apenas alguns tipos na análise final. Metafêmures com clavas curtas, abruptas e alargadas (Fig. 296), condição sinapomórfica inicial, sustenta a monofilia do grupo Dirocoremia+. Em Thalusia + Lathusia (Figs. 297-299), as clavas dos metafêmures também são curtas, porém mais alargadas e fortemente abruptas, condição sinapomórfica extrema. Em Cleomenes, Glaucytes e nos demais Rhopalophorini (Figs. 203-207), as clavas dos metafêmures são menos alargadas e abruptas.

Caráter 66. Fêmures, pedúnculo: sem sulcos e carenas - 0; com sulcos e/ou carenas - 1

Fêmures cilíndricos, destituídos de sulcos e/ou carenas é a condição plesiomórfica em Cerambycinae e apresentada por Cleomenes e Glaucytes. Nos Rhopalophorini ocorre grande variabilidade quanto à presença/ausência, número e tipos de sulcos e carenas no pedúnculo dos fêmures, bem como em relação à conformação destes.

Neste caráter, foi considerada apenas a presença de sulcos e/ou carenas, condição sinapomórfica para o grupo Argyrodines + , com reversões em Cycnoderus tenuatus e no grupo Coremia + (exceto Dirocoremia). As variações quanto à conformação do metafêmur, tipo e número de sulcos e carenas foram tratadas em caracteres distintos (67 e 68).

Caráter 67. Fêmures: pedúnculo não deprimido, sem sulcos ou carenas - 0 ; pedúnculo deprimido, sulcado e bicarenado - 1
A condição apomórfica corrobora a monofilia do grupo Closteropus+. Nos gêneros Closteropus, Gurubira (Fig.291), Disaulax e Cosmisoma, o pedúnculo dos meso- e metafêmures é deprimido, com duas carenas paralelas desde a base e sulcado entre as carenas. Em Argyrodines e Parozodes, o pedúnculo dos metafêmures é semelhante mas, pelas características mencionadas no caráter 68 , foi aqui considerado como não homólogo.

Caráter 68. Metafêmures: pedúnculo cilíndrico, sem espículos -

0 ; pedúnculo deprimido, com espículos - 1

Argyrodines e Parozodes (Figs. 201, 202) possuem espículos proeminentes no pedúnculo dos metafêmures que é deprimido, alargado e provido de duas carenas. Ao contrário do que ocorre nos gêneros citados no caráter anterior (67), as carenas em Argyrodines e Parozodes iniciam-se após a base e são quase unidas, divergindo para os ápices. Também pela conformação do pedúnculo, a presença dos espículos foi considerada não homóloga à presença de asperosidades nos fêmures de Ischionodonta (Vide caráter 62).

Caracteres 69 - 77. Metatíbias.

Metatíbias simples, cilíndricas e retilíneas, com pilosidade curta, indiferenciada, estão presentes no plano básico de Cerambycinae e também em Cleomenes e Glaucytes, condição plesiomórfica. Nos Rhopalophorini, as metatíbias são deprimidas, desde pouco até fortemente, e variáveis quanto à: 1) curvatura; 2) presença/ausência de carenas e/ou sulcos; 3 ) pilosidade, esparsa ou formando diferentes tipos de escovas e/ou tufos. Esta variabilidade, a exemplo dos metafêmures e da conformação do protórax, inviabilizou a formulação de séries de transformação e, em muitos casos, o reconhecimento de sinapomorfias para grupos maiores de gêneros. As seguintes condições foram consideradas apomórficas.

\section{Caráter 69. Metatíbias deprimidas}

Como mencionado acima, em todos os Rhopalophorini, inclusive Ozodes e Lissozodes, as metatíbias são deprimidas, condição sinapomórfica.

\section{Caráter 70. Metatíbias curvas na metade posterior}

Metatíbias curvas, mais notadamente na metade posterior, é uma sinapomorfia do grupo Coremia+. A seguinte sequiência foi estabelecida: 1- metatíbias pouco curvas na metade posterior, condição apomórfica inicial, presente em Coremia (Fig. 294); 2 - com curvatura mais acentuada, condição apomórfica intermediária, em Merocoremia, Dirocoremia e Thalusia (Figs. 295 -297); 3 - metatíbias fortemente curvas, condição apomórfica extrema, no gênero Lathusia (Figs. 298-299).

Caráter 71. Metatíbias fortemente deprimidas, com espículos e pilosidade diferenciada

Metatíbias fortemente deprimidas, levemente arqueadas na metade posterior, providas de espículos marginais bem conspícuos e, na face inferior, com numerosos pêlos muito alongados são exclusivas de Argyrodines (Fig.292) e 
Parozodes.

Caráter 72. Metatíbias deprimidas, com aspecto lamelar Closteropus e Gurubira (Fig. 291) apresentam metatíbias deprimidas e alargadas, com aspecto lamelar e arqueadas na metade apical. Além disso, são bicarenadas e sulcadas, condição sinapomórfica.

Caracteres 73 - 75. Tufos de pilosidade das metatíbias.

Metatíbias com tufos de pêlos foi sempre considerada uma característica do gênero Coremia aucttorum. MARQUES (1994) constatou diferenças significativas na conformação e disposição dos tufos de pêlos, desde alongados (Coremia) até arredondados (Thalusia), ou pouco adensados, até quase ausentes (Lathusia ferruginea). Inicialmente, a presença de tufos de pilosidade foi considerada um evento único, mas os resultados das análises indicaram, pelo conjunto dos demais caracteres, que os diferentes tufos de pêlos são, provavelmente, eventos independentes. Em conseqüência, o caráter "metatíbias com tufos de pêlos" foi, a posteriori, desdobrado em três caracteres descritos a seguir.

Caráter 73. Tufos de pêlos alongado, pouco compacto

Coremia (Fig. 294) apresenta um tufo de pêlos bastante alongado, não compacto, estende-se por quase a metade do comprimento das metatíbias, condição autapomórfica.

Caráter 74. Tufos de pêlos arredondado, compacto

Em Thalusia (Fig. 297), o tufo de pêlos é compacto, com aspecto arredondado, não em pincéis, e ocupa pouco menos da metade do comprimento das metatíbias, condição autapomórfica.

Caráter 75. Tufos de pêlos formado por pincéis

Dirocoremia (Fig. 296), exceto D. simplicipes (Fig. 289), tem um tufo de pêlos desenvolvido, formado por pincéis de pêlos longos, negros e adensados, ocupando cerca da metade do comprimento das metatíbias, condição autapomórfica.

Caráter 76. Metatíbias com franjas de pêlos

Metatíbias com pilosidade em forma de franja bem longa e densa que recobre apenas as faces laterais, é caráter autapomórfico de Cycnoderus barbatus (Fig. 293). Este mesmo tipo de franja está presente no metatarsômero I.

Caráter 77. Metatíbias com pilosidade longa e esparsa

Pêlos alongados, eretos e esparsos em toda a superfície das metatíbias e ausência de pilosidade curta é condição sinapomórfica para o grupo Ischionodonta+ (Ischionodonta, Fig. 213; Disaulax, Fig. 212; Cosmisoma, Figs. 210, 214; Gurubira, Fig. 211 e Closteropus).

Caráter 78. Tarsos. Escova tarsal dos metatarsômeros: com pêlos curtos e compactos - 0; com pêlos alongados e esparsos-1 Escovas tarsais compactas e uniformes, formadas por pêlos curtos, ocorre em Cleomenes, Glaucytes e na maioria dos
Rhopalophorini. Em Lissozodes, Ozodes (Figs. 215, 216) e Neozodes, a pilosidade da face ventral dos metatarsômeros é alongada e pouco densa, sem o aspecto de escova, condição sinapomórfica. Deve ser observado que, neste grupo, o metatarsômero I é curto, enquanto em outros grupos de Cerambycinae em que a pilosidade da face ventral é semelhante à da dorsal, o metatarsômero I é muito alongado.

Caráter 79. Tarsos. Escova tarsal dos metatarsômeros: desenvolvida - 0 ; reduzida - 1

Escova tarsal reduzida a duas fileiras laterais de pilosidade curta com a região mediana glabra, é condição autapomórfica de Coremia (Fig. 217).

Caráter 80. Tarsos. Face ventral dos metatarsômeros: com pêlos curtos - 0; com pêlos alongados - 1

Cycnoderus barbatus (Fig. 218) apresenta, na face ventral dos metatarsômeros, pêlos bem longos e esparsos, sem formar escova uniforme, caráter autapomórfico.

Caráter 81. Tarsos. Face dorsal dos metatarsômeros: sem pêlos alongados - 0; com pêlos alongados - 1

A face dorsal dos metatarsômeros I-II é revestida de pilosidade curta decumbente, em Cleomenes (Fig.219), Glaucytes e na maioria dos gêneros de Rhopalophorini. Metatarsômeros I-II com pêlos laterais alongados, muito evidentes, porém sem formar franjas é uma autapomorfia de Coremia (Figs. 227, 294). Cycnoderus barbatus (Fig. 293) também possui pilosidade alongada nos metatarsômeros I-II, porém o metatarsômero II é curto, não alongado como em Coremia, e considerado, portanto, como não comparável.

Caráter 82. Tarsos. Metatarsômero I mais longo que II+III+IV:

De acordo com NAPP (1994), “... tarsômeros curtos e subiguais nas três pernas são considerados plesiomórficos; tarsômeros progressivamente alongados e tarsômeros posteriores muito mais longos que os anteriores, os estados apomórficos". O metatarsômero I de Cycnoderus barbatus (Figs. 218, 293) é fortemente alongado, cerca de 2,5 vezes tão longo quanto os II+III+IV somados, condição autapomórfica.

Caráter 83. Tarsos. Metatarsômeros: um terço mais longos que os protarsômeros - 0; com o dobro do comprimento dos protarsômeros - 1

Tarsos posteriores com o dobro do comprimento dos anteriores é uma sinapomorfia do grupo Coremia+ (Figs. 225230, 294-296). Cleomenes (Figs. 219,220), Glaucytes e os demais Rhopalophorini (Figs. 221-224) têm a condição plesiomórfica.

\section{Terminália. Caracteres 84-91}

As estruturas da terminália do macho, segundo NAPP (1994), são extremamente variáveis dentro das subfamílias, sendo difícil defini-las neste nível. Esta situação de grande diversidade também foi constatada nos Rhopalophorini, limitando sua utilização às condições apomórficas descritas nos caracteres 
84 a 89.

Caráter 84. Tégmen, peça anelar arredondada

O tégmen apresenta grande variabilidade inter- e intragenérica quanto à conformação da peça anelar que pode ser convergente, arredondada, com ou sem projeções laterais (Figs. 233-236, 239-242). Peça anelar convergente e/ou com projeções laterais é o mais comum em Cerambycinae. Peça anelar arredondada, sem projeções laterais e com os braços ligados no ápice por uma membrana, é uma sinapomorfia que corrobora a monofilia do grupo Rhopalophora+ (Figs. 243245).

\section{Caráter 85.Tégmen: pilosidade reduzida}

A pilosidade do tégmen em Cleomenes (Fig. 231), Glaucytes (Fig. 232) e na maioria dos Rhopalophorini (Figs. 233-236, 239245) pode variar desde curta a alongada, esparsa a adensada. Somente em Lissozodes e Ozodes (Figs. 237, 238) a pilosidade é bastante reduzida, formada por pêlos extremamente curtos, condição sinapomórfica.

\section{Caráter 86. Tégmen: reduzido}

Tégmen com aspecto reduzido, inclusive dos parâmeros, com peça anelar arredondada, totalmente fusionada no ápice e aparência de peça única, é autapomórfico para Ozodes (Fig. 238).

\section{Caráter 87. Lobo médio encurtado}

Em Ischionodonta, o lobo médio (Figs. 247, 248) diferenciase dos de Cleomenes (Fig. 246), Glaucytes e dos demais Rhopalophorini (Figs. 249-254, 256) pelo aspecto encurtado com a região mediana mais dilatada, as apófises basais alargadas e arredondadas no ápice, caráter autapomórfico.

Caráter 88. Lobo médio: lobo ventral com ápice bífido

Lobo ventral com ápice bífido é uma autapomorfia de Rhopalophora (Figs. 249, 250). Em Coremia plumipes, o lobo ventral é bífido, porém mais estreito na região apical, dando uma outra conformação ao lobo ventral, considerado como não homólogo.

Caráter 89. Lobo médio: alargado e retilíneo

Lobo médio desenvolvido, com apófises basais alargadas e retilíneas, e lobo ventral acuminado para o ápice, é uma sinapomorfia que corrobora o parentesco dos gêneros Disaulax, Cosmisoma, Closteropus e Gurubira (Figs. 251-254). Em Cleomenes (Fig. 246), Glaucytes e em Rhopalophorini (Figs. 247-250, 256) não se verifica este padrão de lobo médio.

Caráter 90. Fêmea. Esternito VIII: tão a mais longo que largo, apódema alongado - 0; mais largo que longo, apódema encurtado - 1; fortemente transverso, apódema curto - 2

Esternito VIII mais largo que longo com apódema encurtado (Figs. 262, 263), é sinapomórfico para o grupo Merocoremia+, ocorrendo homoplasicamente em Coremia signaticollis. Dirocoremia (Figs. 264-266) é o único gênero em que o esternito é fortemente transverso e o apódema é curto, condição autapomórfica. Em Cleomenes (Fig. 257), Glaucytes e demais Rhopalophorini (Figs. 258-261), o esternito é tão a mais longo que largo e o apódema é alongado.

Caráter 91. Fêmea. Ovipositor: região proximal mais longa que a distal: 0; região proximal pouco mais longa que a distal - 1; regiões proximal e distal curtas, transversas - 2

Em Cleomenes (Fig. 267), Glaucytes e na grande maioria dos Rhopalophorini (Figs. 268-270), o ovipositor tem a região proximal nitidamente mais longa que a distal. Ovipositor com região proximal encurtada, pouco mais longa que a distal (Figs. 271, 272, 276, 277), condição sinapomórfica, corrobora o parentesco dos gêneros do grupo Rhopalophora+. Neste grupo, apenas em Dirocoremia (Figs. 273-275) o ovipositor é encurtado e transverso, com redução tanto da região proximal quanto da distal, condição autapomórfica.

\section{DISCUSSÃOECONCLUSÕES}

Pela revisão bibliográfica observa-se que os diferentes autores utilizaram basicamente os mesmos caracteres para definir Rhopalophorini, ou seja, antenas alongadas, palpos maxilares curtos, fêmures pedunculados e clavados, cavidades coxais anteriores arredondadas e as médias fechadas aos lados. Se, por um lado, este conjunto de caracteres contribuiu para manter Rhopalophorini como um grupo relativamente homogêneo, também permitiu a inclusão de gêneros com afinidades apenas aparentes, fato demonstrado pelo estudo mais detalhado de sua morfologia.

O relacionamento do grupo Lissozodes + com os demais Rhopalophorini, em todas as análises, foi estabelecido por caracteres referentes à conformação dos olhos, antenas alongadas, asas com área carenada na base da Radial e metatíbias deprimidas $(6.1,7.1,10.2,56.1,69.1)$ (Figs. 300, 302). Embora estas condições sejam apomórficas se considerado o plano básico dos Cerambycinae (NAPP 1994), sua condição de sinapomorfia, no nível aqui considerado, é questionável, uma vez que antenas longas são observadas na maioria dos Cerambycinae e a conformação dos olhos, presença de área carenada na base da Radial e metatíbias deprimidas são caracteres bastante plásticos, variando entre e dentre as tribos. Além disso, este grupo apresenta peças bucais como no plano básico de Cerambycinae (NAPP 1994): mandíbulas sem franja de pêlos, maxilas com basistipe e dististipe fusionados, gálea reduzida e lígula pouco desenvolvida e não-bilobada. Embora tenham as cavidades coxais anteriores arredondadas aos lados e fechadas atrás, observa-se que são bem desenvolvidas, pois as procoxas são cônicas e projetadas e, neste grupo, o proepimero, muito desenvolvido, fecha as cavidades coxais, enquanto o processo intercoxal é estreito e sublaminar e o processo mesosternal é estreito e afilado entre as mesocoxas. Os fêmures são clavados, porém, o pedúnculo é reduzido e a clava bastante alongada, pouco distinta do pedúnculo. $\mathrm{O}$ metendosternito apresenta as projeções para implante dos tendões anteriores desenvolvidas, condição apontada por NAPP 
(l.c.) como plesiomórfica em Cerambycinae. O pro- e mesendosternitos são fusionados mas possuem características distintas dos demais Rhopalophorini; o proendosternito tem aspecto triangular, fusionado apenas no ápice, enquanto o mesendosternito conserva o aspecto anguloso com projeções laterais bem desenvolvidas. De acordo com NAPP (dados não publicados) a fusão do pro- e mesendosternito pode ocorrer em diferentes gêneros e/ou tribos de Cerambycinae (p. ex. Callichroma Latreille,1816, Tillomorpha Blanchard, 1851, Rhinotragini Thomson, 1864, Hybodera LeConte, 1873, Xistrocera Audinet-Serville, 1834 e Tropocalymma Thomson, 1860).

Os resultados das análises corroboram GIESBERT \& CHEMSAK (1993) que excluíram Ozodes e Lissozodes de Rhopalophorini. Estes gêneros ficam mantidos, provisoriamente, em Necydalopsini Lacordaire, 1869, como proposto por aqueles autores e Neozodes, grupo-irmão de Ozodes, é transferido para essa tribo. A manutenção desses gêneros em Necydalopsini deverá ser avaliada em futuros estudos, já que a proposta de GIESBERT \& CHEMSAK (l.c.) foi fundamentada no estudo de apenas um gênero centro-americano, Eucharassus Bates, 1885, não levando em conta Necydalopsis Blanchard, 1851, gênero-tipo, descrito do Chile.

O relacionamento de Elaphopsis com os demais Rhopalophorini sustenta-se apenas por dois caracteres: cavidades coxais anteriores arredondadas e quase fechadas atrás (41.2) e metendosternito com as projeções medianas para implante dos tendões, reduzidas (52.1) (Figs. 300, 302). A condição do metendosternito é, mais provavelmente, uma simplesiomorfia já que ocorre na grande maioria dos Cerambycinae (NAPP 1994) e cavidades coxais arredondadas e quase fechadas atrás podem ocorrer em diferentes tribos. Além disso, este gênero não compartilha as sinapomorfias assinaladas para Rhopalophorini como: metafêmures com pedúnculo muito alongado e clava relativamente pequena, abrupta e bem definida; maxilas com gálea mais longa que o palpo maxilar, este com o artículo apical pouco alongado, o segundo e terceiro cônicos e subiguais; mento quadrangular com a região membransosa anterior desenvolvida; proendosternito totalmente fusionado na linha média e mesendosternito sem projeções laterais. Em Elaphopsis, o pedúnculo e a clava dos metafêmures são subiguais no comprimento (Fig. 200); a gálea é cilíndrico-capitada, como na maioria dos Cerambycinae, o artículo apical do palpo maxilar é fortemente dilatado e mais longo que os demais, sendo o segundo e terceiro cilíndro-alongados e o basal, curto (Fig. 60); mento fortemente transverso com a região membranosa anterior reduzida (Fig. 68), condição presente no plano básico de Cerambycinae; proendosternito fusionado apenas no ápice e mesendosternito com projeções laterais (Fig. 152). Como observado por LACORDAIRE (1869), Elaphopsis apresenta, ainda, granulação ocular grossa (Fig.281). Pelos caracteres mencionados, este gênero, a exemplo do grupo Lissozodes+, está mal alocado em Rhopalophorini. Corroborando THOMSON (1860), propõe-se a transferência de Elaphopsis para a tribo Ibidionini Thomson, 1860. De acordo com MARTINS (1967),
Elaphopsis apresenta algumas características das Divisões III e IV, como: cavidades coxais anteriores abertas atrás; escapo cilíndrico; artículo antenal IV curto e artículos apicais dos palpos alongados e dilatados para o ápice, podendo, eventualmente, ser incluído na Divisão IV de Ibidionini.

Rhopalophorini, como definida no presente trabalho, ou seja, excluindo-se Elaphopsis e o grupo Lissozodes + , tem sua monofilia justificada por caracteres relativos às peças bucais, à venação alar e, principalmente, aos endosternitos. Alguns desses caracteres já haviam sido mencionados por outros autores e confirmados como sinapomórficos, outros foram redefinidos e vários acrescidos. No momento, as seguintes sinapomorfias definem Rhopalophorini (Fig. 300):

- Gálea cilíndrica até mais longa que o palpo maxilar, dilatada e obliquamente truncada no ápice (27.1, Figs. 61-66). Gálea alongada foi referida para alguns gêneros de Rhopalophorini (Audinet-Serville 1833, 1834; LeConte 1850; Thomson 1860). O presente estudo confirmou este caráter como sinapomórfico para a tribo, ressaltando-se que, além de alongada, é dilatada e obliquamente truncada no ápice.

- Palpos maxilares com artículo apical encurtado, atenuado para o ápice, tão longo quanto o basal e artículos $2^{\circ}$ e $3^{\circ}$ cônicos e subiguais (30.1). Palpos maxilares mais curtos que a gálea e até mais curtos que os labiais, com o artículo apical ovóide, também foram referidos pelos mesmos autores e ainda por BLANCHARD (1845) e LACORDAIRE (1869). Observa-se que, embora a gálea seja alongada, os artículos 2-4 dos palpos maxilares em Rhopalophorini são encurtados, os 2-3 cônicos e curtos e o $4^{\circ}$ tão longo quanto o basal e distintamente atenuado no ápice. Como mencionado pelos autores acima, os artículos apicais dos palpos labiais são semelhantes aos maxilares.

- Mento com aspecto quadrangular e região anterior membranosa desenvolvida (31.1, Figs. 70-74).

- Proendosternito totalmente fusionado na linha média (45.1, Figs. 120-123, 126, 127). Esta estrutura, usualmente, não é fusionada nos Cerambycinae, podendo ocorrer fusão de diferentes formas em grupos aparentemente não relacionados.

- Mesendosternito oblíquo, fortemente esclerotizado, fusionado à parede interna do mesepimero, sem projeções laterais (50.1, Figs. 145-150). As considerações sobre o proendosternito aplicam-se ao mesendosternito. Vale destacar que, nos Rhopalophorini estudados, verifica-se um alargamento da região apical do mesendosternito e uma fusão completa à uma projeção, igualmente larga, da parede interna do mesepimero. Além disso, os braços do mesendosternito são robustos, ocorrendo a perda das projeções laterais. Em outros grupos em que o mesendosternito também é fusionado, inclusive em Cleomenes, Glaucytes (Figs. 141, 144), no grupo Lissozodes + (Figs. 151, 153, 154) e em Elaphopsis (Fig. 152), não se observa este alargamento da região apical, bem como da projeção interna do mesepimero, e as projeções laterais são mantidas. Em outros grupos onde o mesendosternito é fusionado à parede do mesepimero, esta estrutura pode ser membranosa, angulosa e com projeções laterais (NAPP, dados não publicados).

- Metendosternito com os braços laterais direcionados 
horizontalmente, perpendiculares às lâminas (53.1, Figs. 156, $162,164,166,175,177)$.

- Asa com o lobo anal e a 2Ab com redução (57.1, Figs. 182191). Como citado na discussão do caráter, a redução do lobo anal e da venação alar parece ocorrer de forma independente entre e dentro de diferentes grupos.

- Fêmures sulcados e carenados (66.1, Fig.291). Embora a tribo tenha sido caracterizada por todos os autores por seus fêmures clavados, não houve menção à ocorrência de sulcos ou carenas. Presença de sulcos e/ou carenas pode ser indicada como característica do plano básico dos Rhopalophorini.

- Metafêmures com pedúnculo alongado, atingindo, ou quase, o ápice elitral e bem distinto da clava que é proporcionalmente curta, abrupta e bem definida (63.1, Figs. 284, 286-288). Todos os autores mencionaram fêmures com clava abrupta para os Rhopalophorini, mesmo quando colocados em grupos distintos (p. ex., Audinet-SERVILLE 1833, 1834; Thomson 1860). O caráter, como redefinido, aplica-se a todos os Rhopalophorini, exceto Argyrodines +Parozodes.

- Escapo antenal com sulcos e/ou depressões (13.1). Como o anterior, este caráter está presente em todos os integrantes do grupo Cycnoderust, revertendo apenas em Coremia signaticollis e Merocoremia monnei.

Com relação à conformação das cavidades cotilóides anteriores e médias, caracteres básicos na classificação de LACORDAIRE (1869), no momento, parecem não ser mais efetivos para definir Rhopalophorini. Cavidades coxais anteriores arredondadas e pouco angulosas aos lados são indicadas como sinapomórficas para o plano básico da tribo (Fig. 301, caráter 41.2). Entretanto, Ischionodonta, grupo já estabelecido por Chevrolat (1859) quando da proposta de classificação de LACORDAIRE (l.c), e os gêneros do grupo Coremia + apresentam cavidades cotilóides anteriores angulosas aos lados e as médias abertas, mas compartilham todas as sinapomorfias assinaladas na presente análise para a tribo. Embora vários gêneros tenham as cavidades coxais médias fechadas, este caráter, a exemplo do que se observa em outras tribos de Cerambycinae, parece não ser sinapomórfico para a tribo. Como mencionado anteriormente, as cavidades coxais anteriores podem ser fechadas atrás de distintas maneiras, aspecto que deve ser levado em conta quando da utilização deste caráter em estudos de outras tribos.

Um outro conjunto de caracteres pode, eventualmente, constituir sinapomorfias para Rhopalophorini, ficando na dependência de um estudo mais abrangente que possa definir o seu nível de universalidade (Fig. 301):

- Conformação dos olhos e antenas longas $(6.1,7.1,10.2)$. Estas estruturas são extremamente variáveis entre e dentro das tribos. Antenas longas, se comparadas às de Cleomenini, podem ser sinapomórficas no plano básico dos Rhopalophorini. Já a conformação dos olhos em Rhopalophorini difere tanto de Cleomenini como de Glaucytes. A diferente conformação dos olhos em Glaucytes já havia sido apontada por LACORDAIRE (1869).

- Presença da área carenada na base da Radial (56.1, Figs. 182-191). Área carenada na base da Radial está ausente em
Cleomenes (fig.180), Glaucytes (fig.181) e na maioria dos Cerambycinae, embora tenha sido constatada no grupo Lissozodes + e em Elaphopsis.

- Metatíbias deprimidas (69.1, Fig. 291). Diferentes grupos de Cerambycinae apresentam tíbias deprimidas. Já Cleomenini e Glaucytini têm tíbias cilíndricas, o que indica a possibilidade de que tíbias deprimidas possam ocorrer de forma independente.

Diversos caracteres ou estados de caracteres hipotetizados como apomórficos em Cerambycinae (p. ex. redução da venação alar, empódio reduzido ou sem cerdas, processos intercoxais largos, aspectos das peças bucais e cavidades cotilóides médias fechadas) não puderam ser utilizados, ou tiveram seu uso limitado, por ocorrerem em outras tribos da subfamília, particularmente em Cleomenini e em Glaucytes. Muitos destes caracteres foram descartados por não ter sido possível, no momento, defini-los como sinapomórficos para o nível considerado.

Como demonstrado pelo estudo, os gêneros de Rhopalophorini apresentam uma grande riqueza e diversidade nos caracteres da morfologia externa, os quais, notadamente, foram de maior utilidade na definição dos gêneros ou de pares de grupos-irmãos, já que a plasticidade, em muitos casos, inviabilizou o reconhecimento de séries de transformação e/ou de sinapomorfias para agrupamentos maiores. Como conseqüência, observa-se que os gêneros ou clados com poucos gêneros estão embasados por várias autapomorfias e/ ou sinapomorfias, enquanto alguns dos grupos maiores são sustentados por poucas condições apomórficas.

Embora vários autores tenham questionado a manutenção de Argyrodines e Parozodes em Rhopalophorini e apontado semelhanças com, por exemplo, Neozodes e Ozodes (Aurivillius 1897; Martins 1975), estes dois gêneros mantiveram inalteradas suas relações de parentesco com os demais Rhopalophorini, já que compartilham as sinapomorfias apontadas para a tribo, exceto quanto à conformação dos metafêmures. Entretanto, é importante ressaltar que Argyrodines e Parozodes também apresentam várias das condições sinapomórficas do grupo Lissozodes +, como: conformação da cabeça e do protórax; élitros encurtados e ornamentados com faixas tegumentares e pilosidade alongada, esparsa e ereta das antenas e tíbias. No momento, Argyrodines e Parozodes são mantidos em Rhopalophorini, mas a hipótese de uma realocação em outra tribo não deve, ainda, ser descartada.

Com os dados atuais não foi possível definir o parentesco de Rhopalina que permanece em politomia no nível indicado nas Figs. 300-302. Antenas curtas, com artículos deprimidos e carenados e asas com lobo anal não reduzido (reversão) são indicados como autapomorfias desse gênero.

Os demais gêneros de Rhopalophorini formam dois grandes grupos monofiléticos (Figs. 300-302): Ischionodonta+, embasado por sinapomorfias referentes às antenas e pilosidade das tíbias $(16.1,77.1)$ e Rhopalophora + , justificado por várias sinapomorfias relativas ao processo mesosternal, metendosternito, venação alar, tégmen e ovipositor (48.2, 51.1, 60.1,84.1 e 91.1).

Ischionodonta, portanto, não tem parentesco filogenético 
com Rhopalophora, corroborando a proposta de GIESBERT \& ChemsaK (1993), e seu relacionamento com o grupo que inclui Closteropus e Gurubira, como evidenciado nas análises, confirma a opinião de NAPP \& MARQUES (1999c). Entre as sinapomorfias que sustentam a monofilia do gênero, as asperosidades das antenas e pernas (Fig. 290) e o padrão do protórax estão presentes em todas as espécies conhecidas do gênero (NAPP \& MARQues $l$. c.).

As análises indicaram Disaulax como grupo-irmão de Cosmisoma, confirmando a opinião dos vários autores que trataram destes dois gêneros. LACORDAIRE (1869), inclusive, considerou Disaulax como sinônimo de Cosmisoma, ressaltando que a diferença entre eles se restringia à presença, em Disaulax, de tufos de pêlos nos artículos antenais III-VI, opinião compartilhada por ZAJCIW (1962). AudinET-SERVILLE (1833) comentou que Disaulax teria os artículos apicais dos palpos securiformes, enquanto em Cosmisoma os mesmos seriam cilíndricos, no que foi seguido por vários autores. $\mathrm{O}$ presente estudo confirma a observação de LACORDAIRE (1869): os artículos apicais dos palpos labiais são semelhantes aos maxilares nos dois gêneros. Cosmisoma constitui um dos maiores gêneros da tribo e um dos mais estudados sob o ponto de vista taxonômico (Zajciw 1962; Monné \& Magno 1988; GIESBERT \& CHEMSAK 1993). Devido à variabilidade nos caracteres das quatro espécies estudadas e também pela pequena amostragem do total das espécies, não foi possível, no momento, definir outras sinapomorfias para o gênero. Futuros estudos revisivos são necessários para corroborar a monofilia do gênero e para que alguma decisão possa ser tomada com relação à manutenção, ou não, de Disaulax como gênero distinto. As análises indicaram que este gênero difere de Cosmisoma pela conformação do escapo (Fig.37), mesendosternito não fusionado à parede do mesepimero (Fig. 143), além da pilosidade das antenas (Fig. 287).

Os resultados de todas as análises confirmaram Gurubira como grupo-irmão de Closteropus o que confirma a opinião de NAPP \& MARQUES (1999a) que consideraram este gênero como o mais próximo de Gurubira. Com relação a Closteropus, tornase necessário o estudo de outras espécies para que sua monofilia seja melhor embasada.

Com a presente análise, foi possível confirmar a hipótese de relacionamento entre Rhopalophora e o grupo Coremia $+\mathrm{e}$ corroborar a monofilia deste grupo, como sugerido por MARQUES (1994), assim como sua inclusão em Rhopalophorini (MARQUES \& NAPP 1996). Com relação a Rhopalophora, um futuro estudo poderá indicar novas sinapomorfias e/ou confirmar as já evidenciadas.

A monofilia do grupo Coremia + foi corroborada em todas as análises pelo padrão da venação alar (ausência da Plical e Empusal unida na base à 1a. Anal), metatíbias encurvadas, metatarsômeros muito alongados e apófise do oitavo esternito encurtada. As relações de parentesco entre Merocoremia, Thalusia, Lathusia e Dirocoremia mostram uma certa instabilidade. Nas análises com parte dos caracteres multiestado ordenados, estabelece-se um maior parentesco entre Dirocoremia e Thalusia+Lathusia pela conformação das clavas (65.1). Neste caso, Merocoremia constitui o grupo-irmão de Dirocoremia +Thalusia +Lathusia (Figs. 300, 301). Aceitando-se esta hipótese, deve-se admitir: 1) reversão da condição antenas alongadas (10.2) para antenas pouco alongadas (10.1) no grupo Coremiat, com um novo alongamento em Dirocoremia (10.2); 2) perda de sulcos e/ou carenas nos fêmures do grupo Coremia+ (66.0) e um ganho secundário deste caráter também em Dirocoremia (66.1); 3) homoplasia da condição apódema do oitavo esternito encurtado (90.1) no grupo Merocoremia+ e em Coremia signaticollis. Nas análises com todos os caracteres multiestado não ordenados, Dirocoremia é indicado como grupo-irmão do grupo Coremia+ consitituído pelos gêneros Coremia, Merocoremia, Lathusia e Thalusia (Fig. 302). Nesta hipótese, a monofilia do grupo Coremia+ fica embasada por duas reversões: antenas moderadamente longas e ausência de sulcos e/ou carenas nos fêmures $(10.1,66.0)$; protórax transverso e subtuberculado aos lados (32.1) e clavas abruptas e robustas (65.1) seriam homoplásicos em Direcoremia e Thalusia+Lathusia, ou reverteriam em Coremia; neste gênero ocorreria também reversão no caráter 70 (metatíbias curvas); ainda, o parentesco de Merocoremia fica indefinido.

Como discutido anteriormente (Material e Métodos, pag. 495), Rhopalophorella fasciata e Muxbalia monzoni foram excluídas das análises finais pelo grande número de caracteres não comparáveis já que significativa parte dos caracteres utilizados refere-se à morfologia interna, o que resultou na indefinição do relacionamento destes gêneros dentro de Rhopalophorini. Nas análises preliminares, Rhopalophorella permaneceu em politomia nos níveis de Coremia, Cosmisoma e/ou Rhopalina, com base em reversões e/ou homoplasias.

Com relação a Muxbalia, inicialmente, quando Cleomenes aureicollis, Haenkea atra e Listroptera tenebricosa foram testados como grupos-externos, aquele gênero teve seu relacionamento estabelecido com Cleomenes aureicollis, por caracteres como: lobo ocular contíguo ao tubérculo antenífero; metafêmures curtos atingindo, no máximo, o $4^{\circ}$ esternito abdominal; metatíbias cilíndricas e projeção do $1^{\circ}$ segmento abdominal acuminado, condições observadas unicamente em Cleomenes. Já nas análises utilizando-se um ancestral hipotético, Muxbalia ficou incluído em Rhopalophorini, mas com parentesco indefinito.

Considerando que, apesar da falta de dados, as análises indicaram Rhopalophorella e Muxbalia como pertencentes a Rhopalophorini, esses dois gêneros são mantidos, provisoriamente, na tribo.

O presente estudo corrobora LACORDAIRE (1869) com relação à semelhança entre Cleomenini e Rhopalophorini, uma vez que vários são os caracteres e/ou estados de caracteres apomórficos compartilhados pelos representatantes estudados dessas duas tribos, principalmente no que concerne aos gêneros neotropicais, Haenkea e Listroptera, que compartilham mais sinapomorfias com Rhopalophorini do que com Cleomenes. Isso evidencia a necessidade de um estudo dos Cleomenini neotropicais que poderá resultar na possível transferência desses gêneros para Rhopalophorini. 


\section{Classificação}

Com base no exposto, apresenta-se, para Rhopalophorini, uma proposta de Classificação isomórfica com o cladograma de consenso estrito (Fig. 301), acrescendo-se os gêneros Rhopalophorella e Muxbalia. Adotou-se o método de seqüenciação (Nelson 1972), além das propostas de WILEY $(1979,1981)$ е de АмоRiм (1982), evitando-se propor novos nomes ou categorias para os pontos de dicotomia dos cladogramas.

Rhopalophorini Blanchard, 1845

Rhopalophorini incertae sedis Rhopalophorella Linsley, 1941

Rhopalophorini incertae sedis Muxbalia Giesbert \& Chemsak, 1993

Argyrodines+ Argyrodines Bates, 1867

Parozodes Aurivillius, 1897

Cycnoderus Audinet-Serville, 1834

Rhopalina Monné, 1989, sedis mutabilis Ischionodonta+
Ischionodonta Chevrolat, 1859

Closteropus+

Closteropus Guérin-Meneville, 1844

Gurubira Napp \& Marques, 1999

Disaulax+

Disaulax Audinet-Serville, 1833

Cosmisoma Audinet-Serville, 1834

Rhopalophora+

Rhopalophora Audinet-Serville, 1834

Coremia+

Coremia Aurdinet-Serville, 1834

Merocoremia Marques, 1994

Dirocoremia Marques, 1994

Thalusia+

Thalusia Thomson, 1864

Lathusia Zajciw, 1959

Agradecimentos. Ao Prof. Miguel A. Monné (MNRJ) pelo empréstimo de grande parte do material, Prof. Albino M. Sakakibara (UFPR) pelo trabalho fotográfico e Rosangela I. Marques pela arte final dos desenhos.
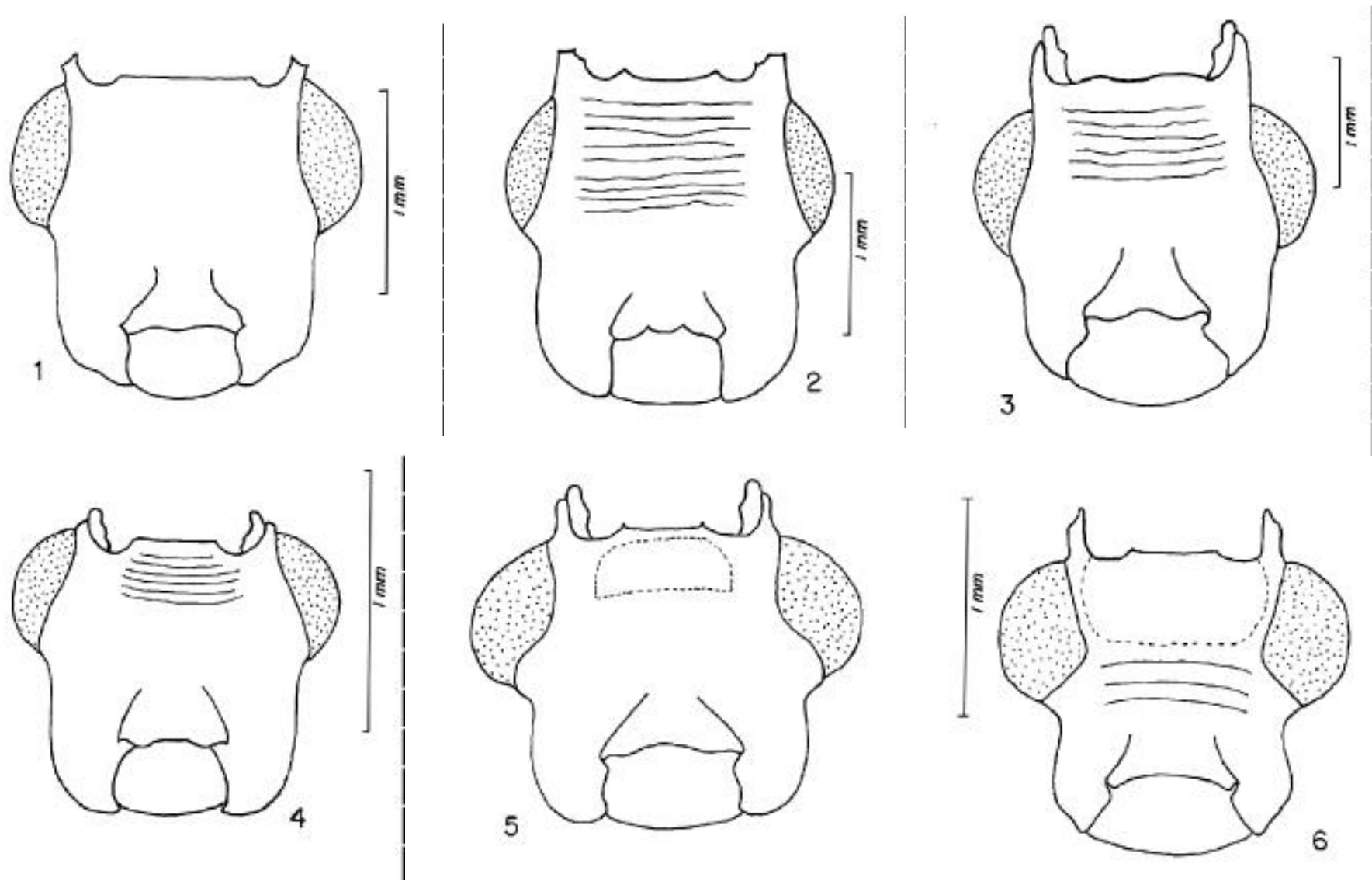

Figs. 1-6. Cabeça, ventral:1, Cleomenes; 2, Rhopalophora collaris; 3, Cosmisoma scopulicorne; 4, Cycnoderus barbatus; 5, Thalusia atrata; 6 , T. erythromera. 

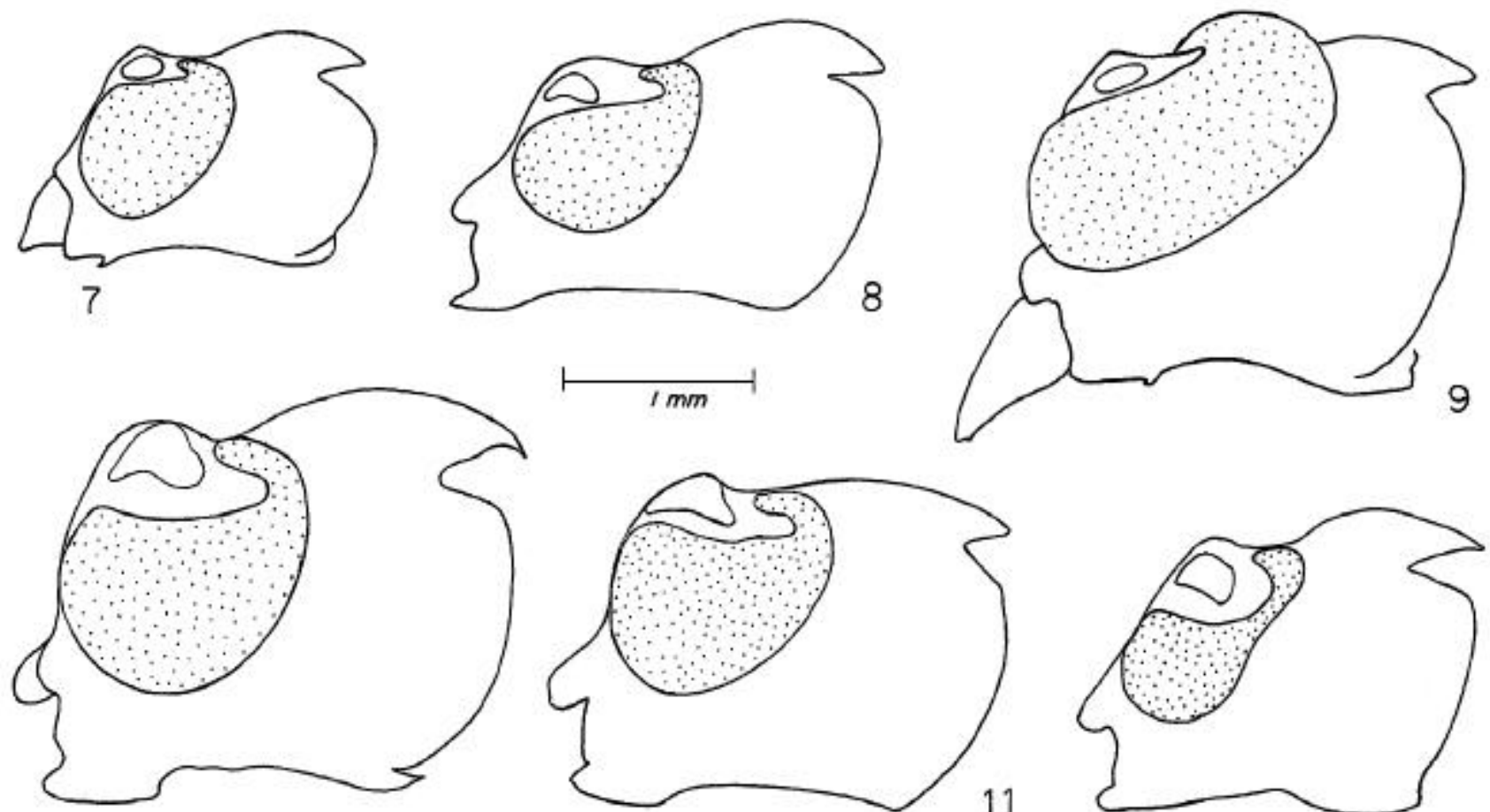

10
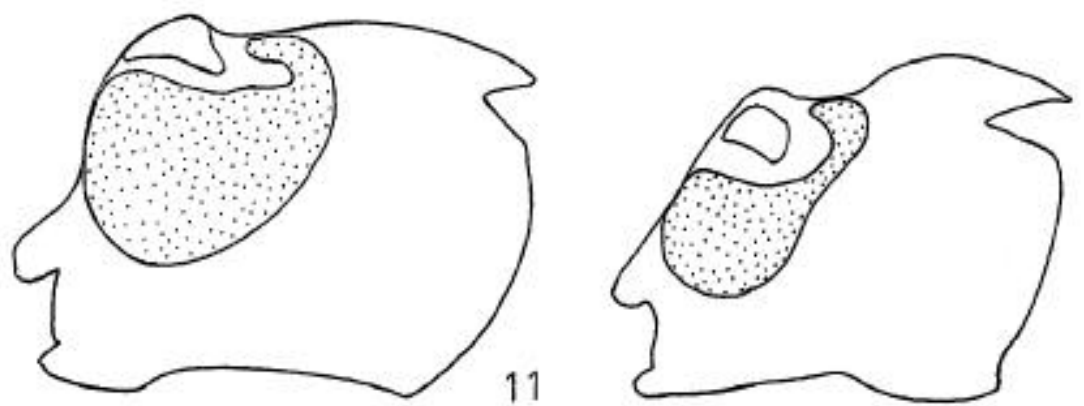

1
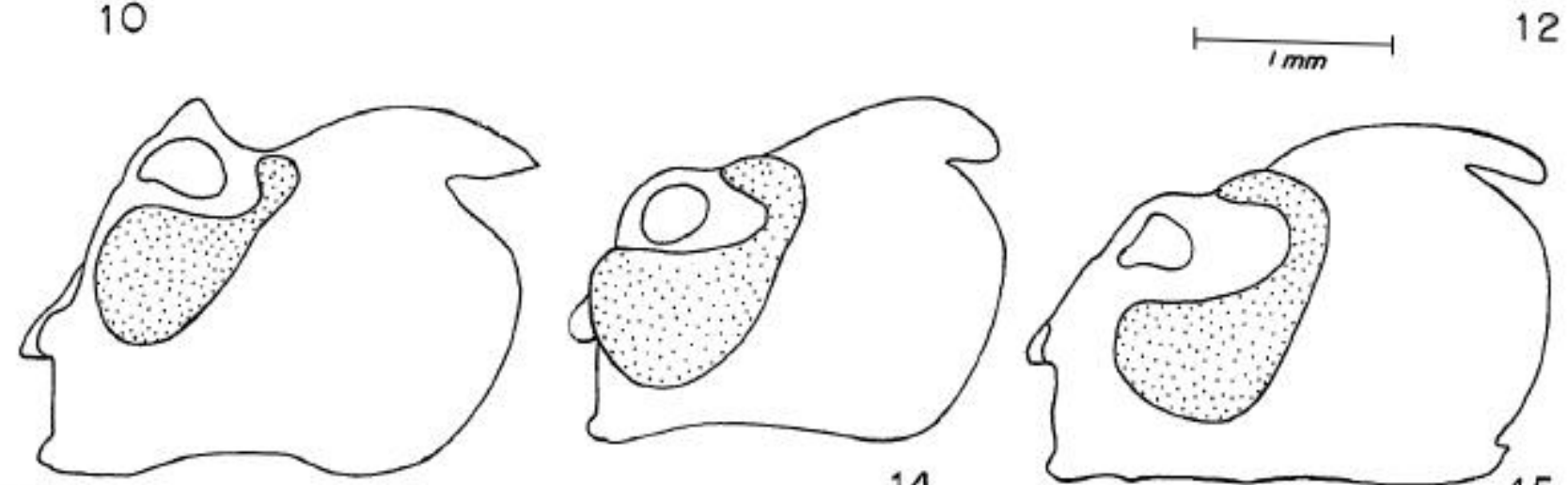

13

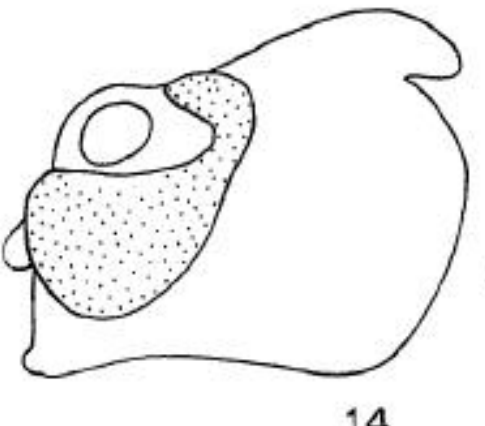

14

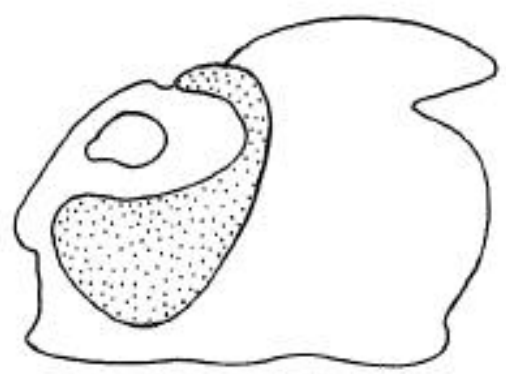

16

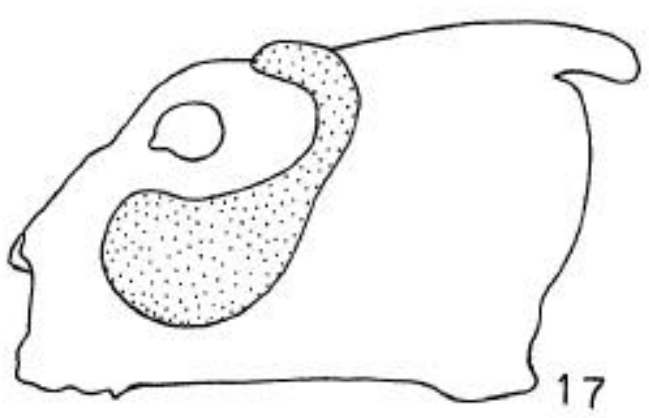

Figs. 7-17. Cabeça, lateral: 7, Cleomenes; 8, Rhopalophora collaris; 9, Glaucytes; 10, Closteropus; 11, Gurubira;12, Argyrodines; 13, Parozodes; 14, Cycnoderus barbatus; 15 , Dirocoremia ingae; 16 , D. simplicipes; 17, D. bruchi. Figs. 7-11; 12,13 e 15-17, respectivamente, na mesma escala. 


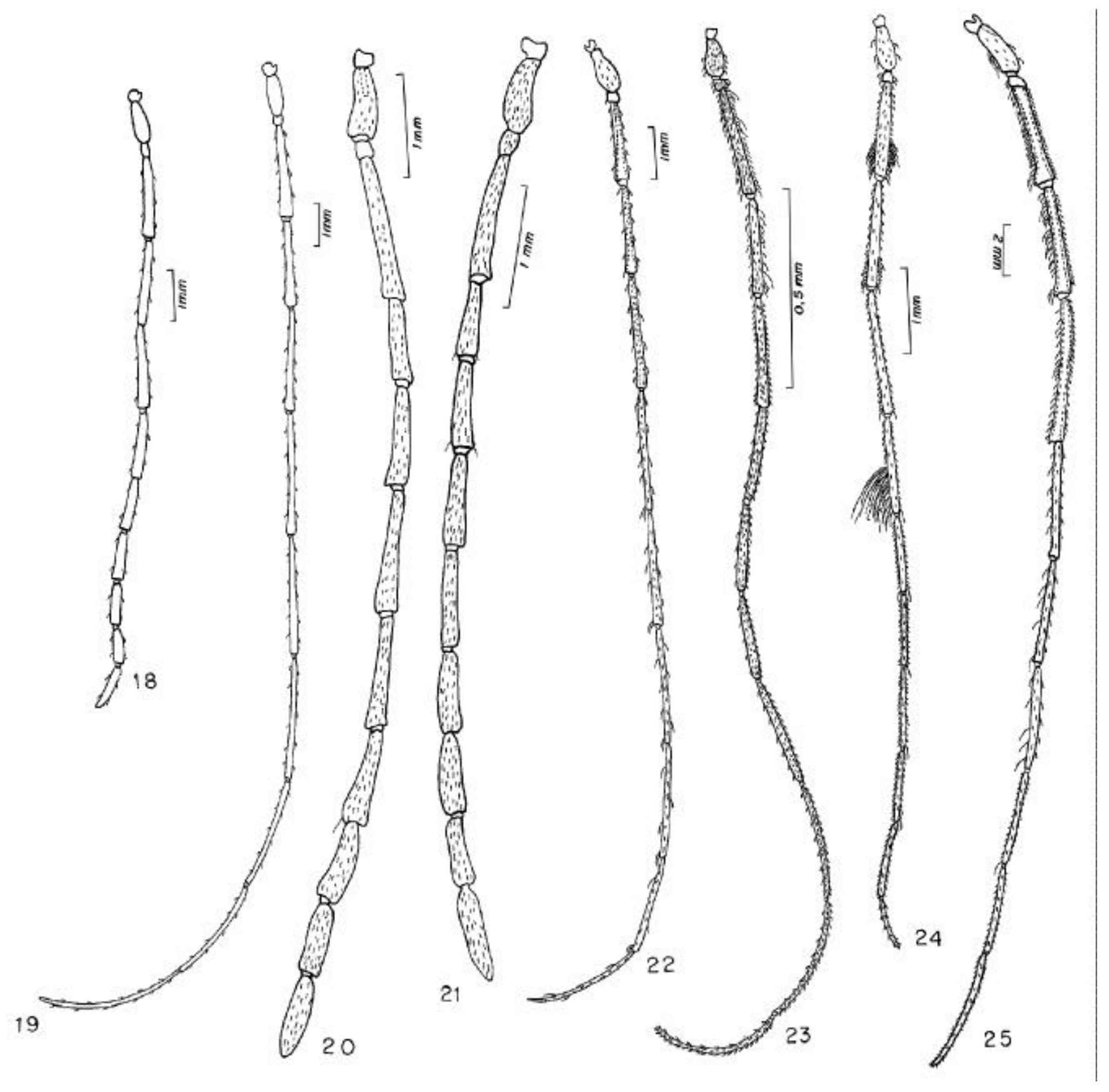

Figs. 18-25. Antenas: 18, Cleomenes; 19, Glaucytes; 20, Coremia plumipes; 21, C. signaticollis; 22, Gurubira; 23, Cycnoderus tenuatus; 24, Cycnoderus barbatus; 25, Closteropus. 

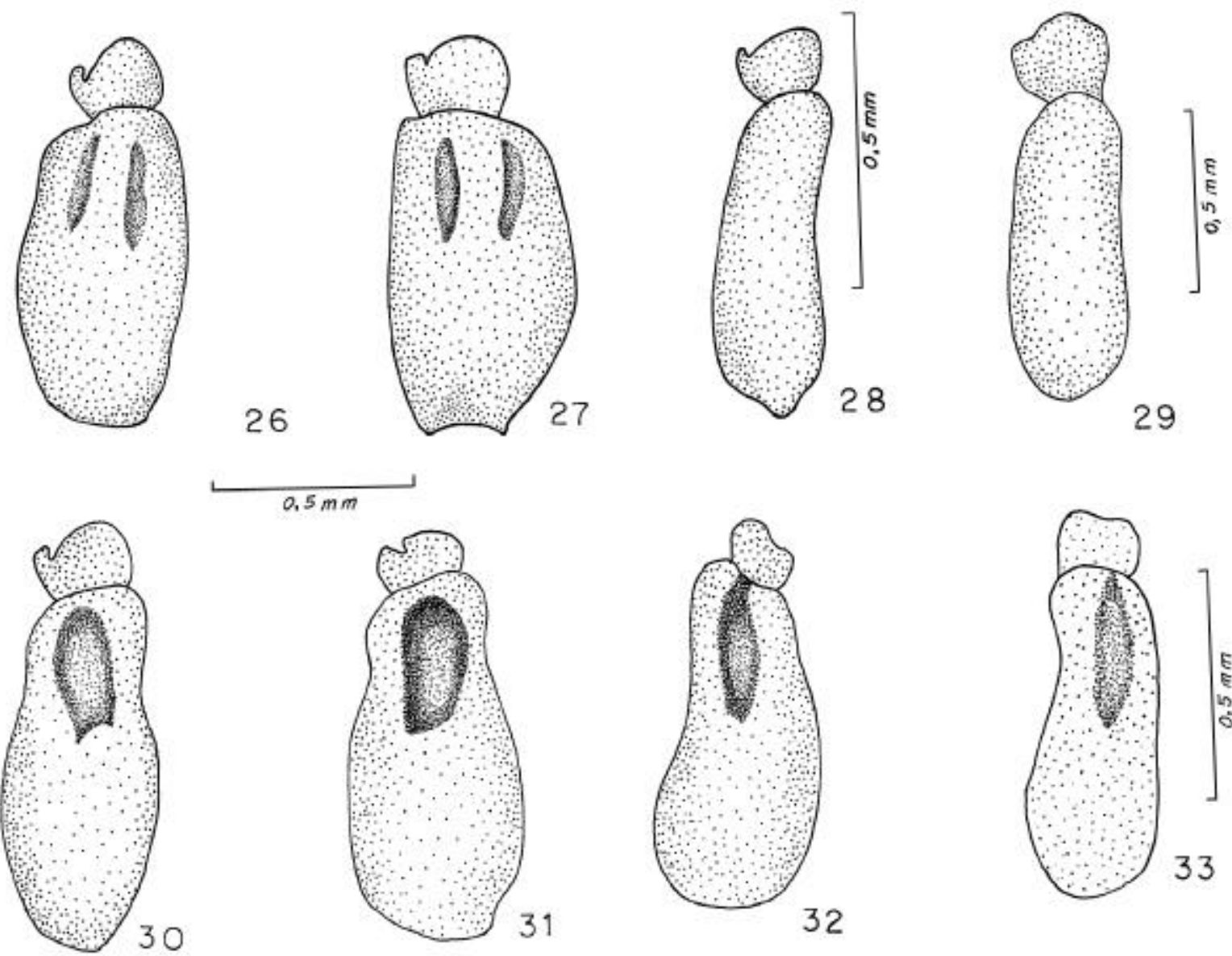

30
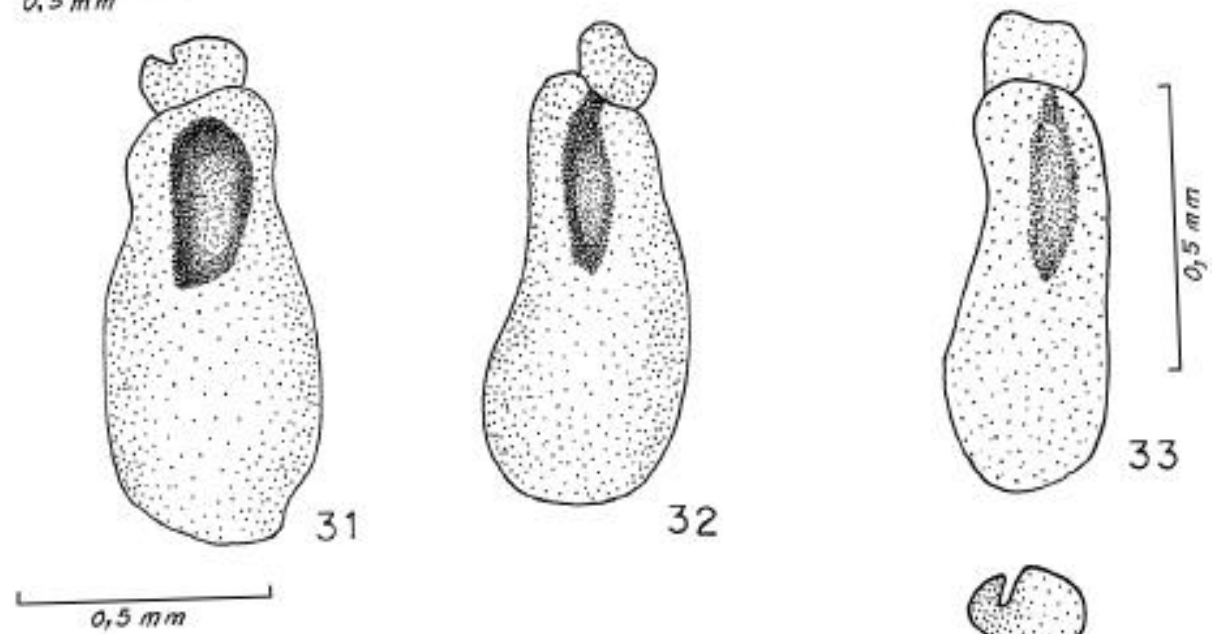

32
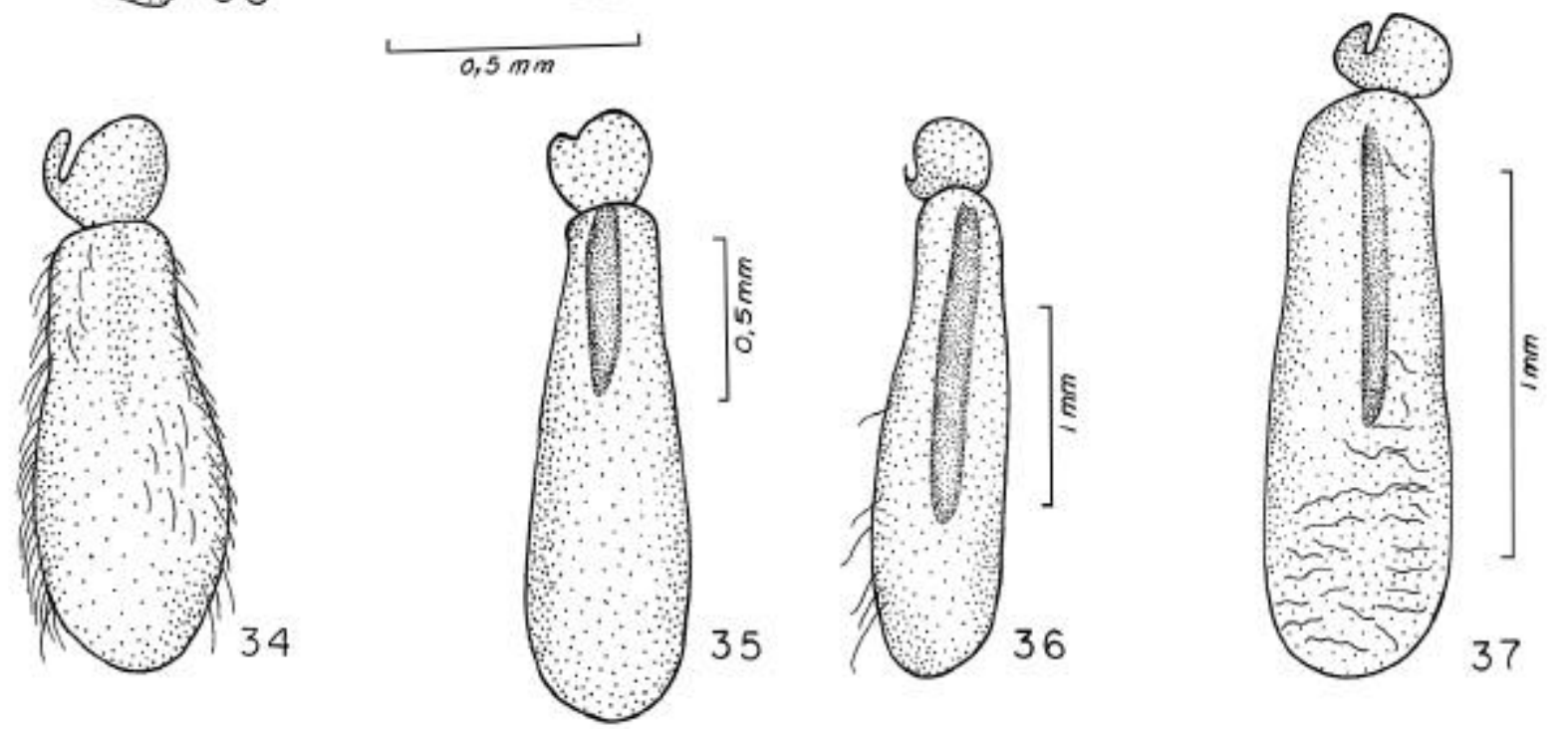

Figs. 26-37. Escapo: 26, Dirocoremia ingae; 27, D. bruchi; 28, Coremia signaticollis; 29, Cleomenes; 30, Dirocoremia simplicipes; 31 , Lathusia ferruginea; 32, Thalusia erythromera; 33, Cosmisoma batesi; 34, Cycnoderus tenuatus; 35, Cosmisoma scopulicorne; 36, C. ammirallis; 37, Disaulax hirsuticornis. Figs. 26,27, 30-32 e 34,37, respectivamente, na mesma escala. 

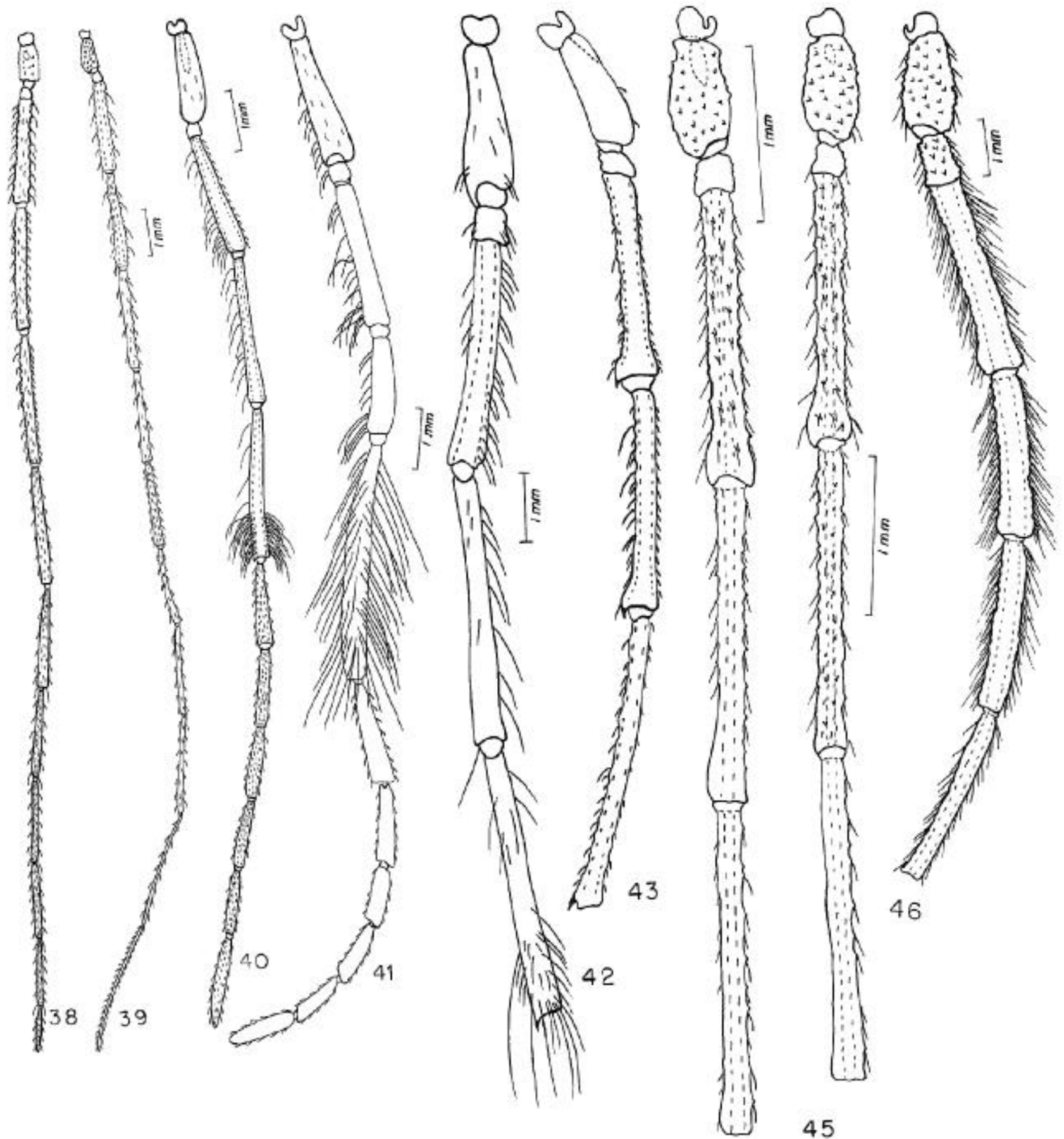

44

Figs. 38-46. Antenas:38, Ischionodonta rufomarginata; 39, I. platensis; 40, Cosmisoma aeneicolle; 41, C. ammirallis; 42, C. aeneicolle, artículos I-V; 43, Closteropus, idem; 44, Ischionodonta platensis, idem; 45, I. rufomarginata, idem; 46, Ozodes, I-VI. 


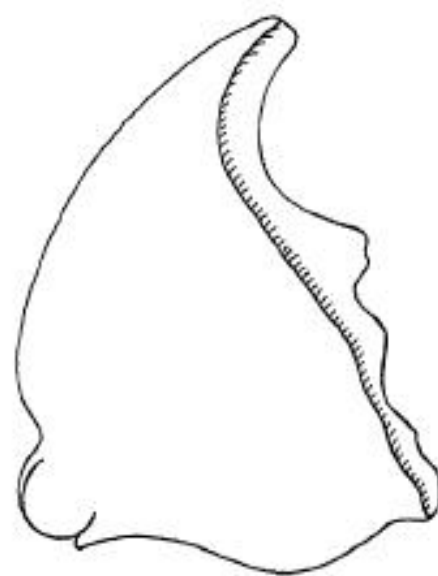

47

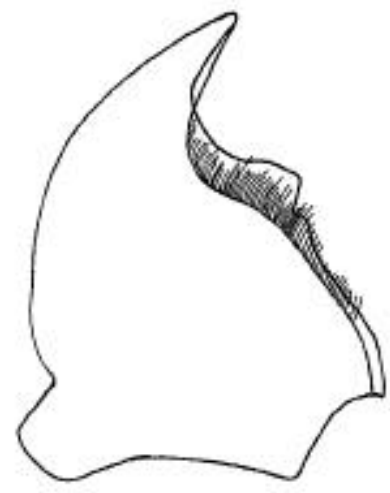

50
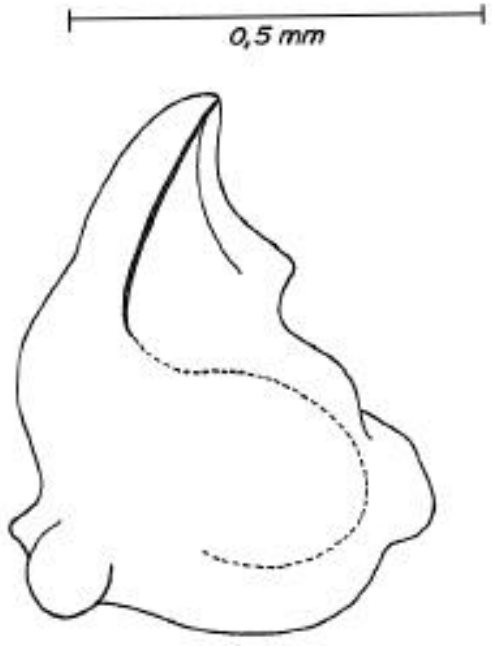

53
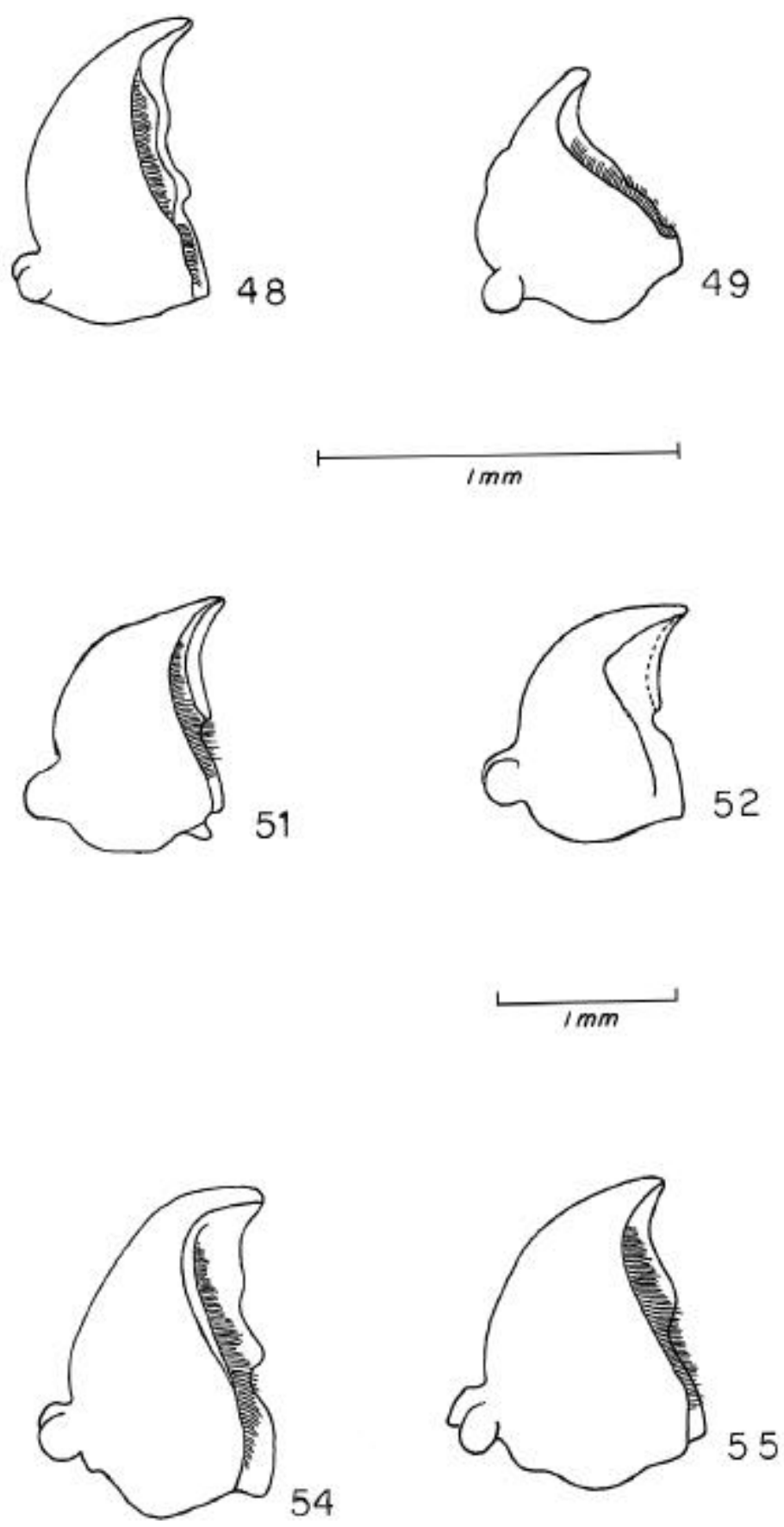

Figs. 47-55. Mandíbulas, face interna: 47, Dirocoremia simplicipes; 48, Cosmisoma scopulicorne; 49, Cleomenes; 50, Dirocoremia bruchi; 51, Cycnoderus tenuatus; 52, Ozodes; 53, Lissozodes; 54, Rhopalophora collaris; 55, Cycnoderus barbatus. Figs. 47,48,50, 53-55 e 49,51, respectivamente, na mesma escala. 

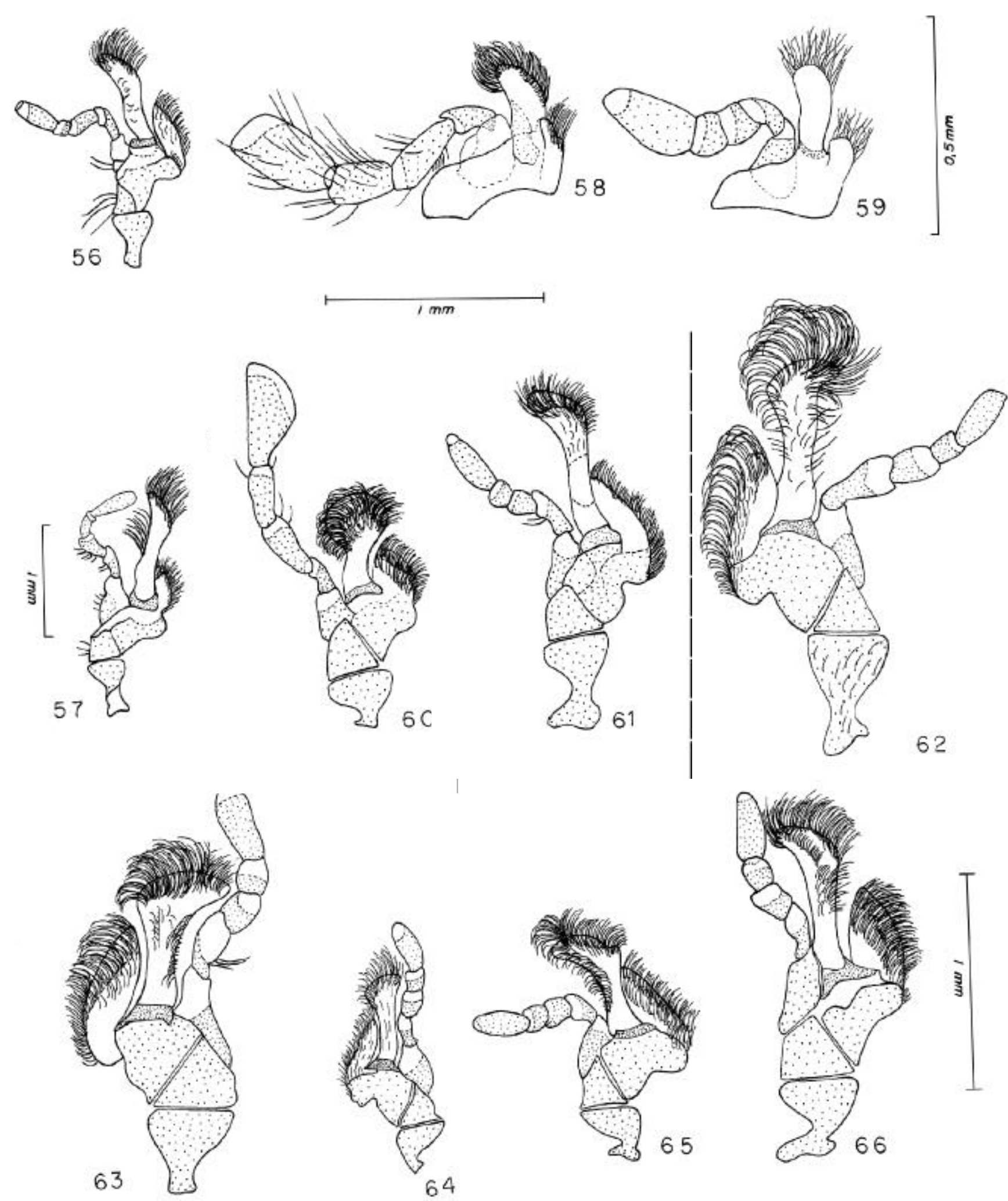

Figs. 56-66. Maxilas: 56, Cleomenes; 57, Glaucytes; 58, Ozodes; 59, Lissozodes; 60, Elaphopsis; 61, Rhopalophora collaris; 62, Gurubira; 63, Closteropus; 64, Ischionodonta platensis; 65, Argyrodines; 66, Parozodes. Figs. 56,58,60 e 61 e 62-66, respectivamente, na mesma escala. 

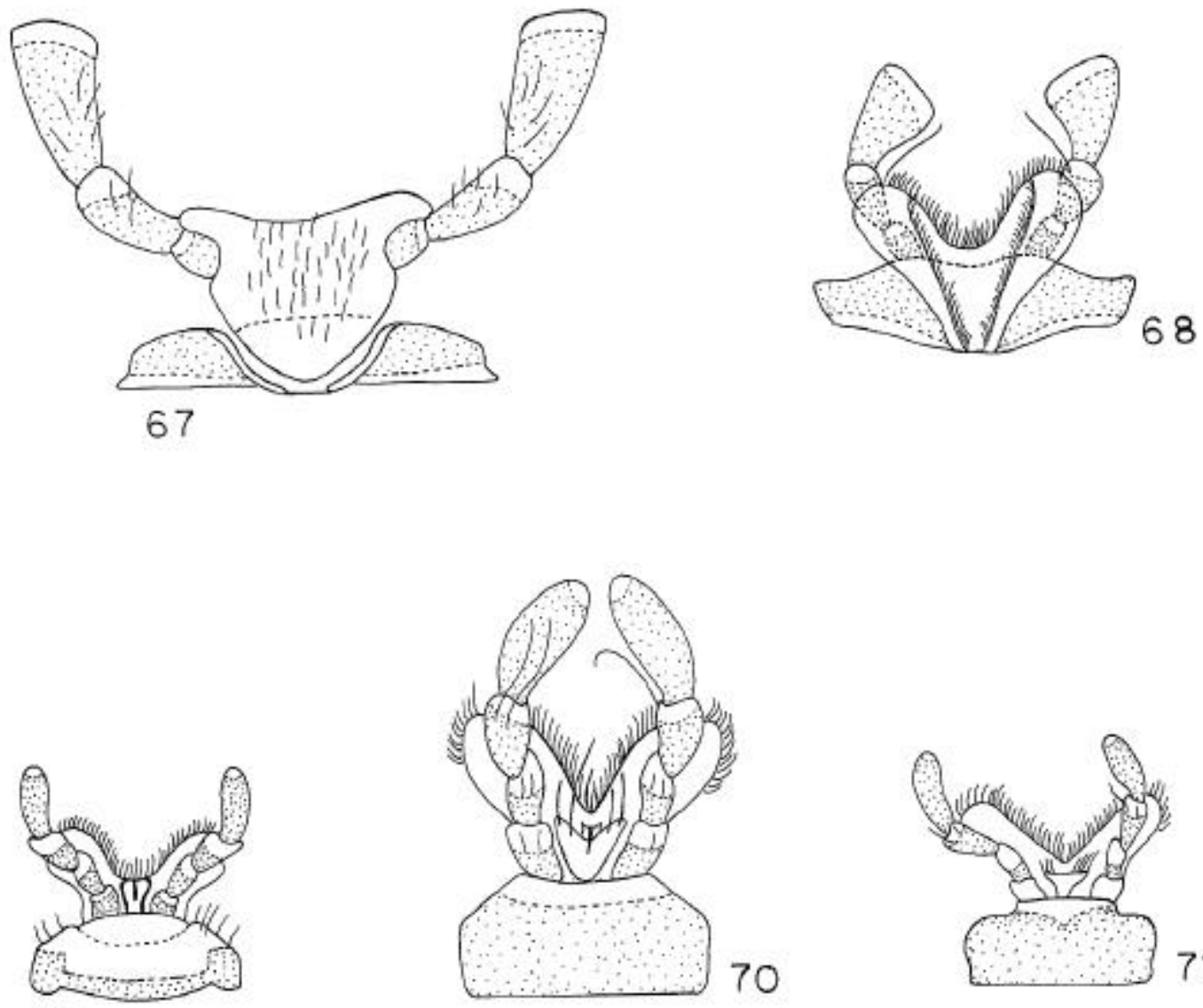

71

69
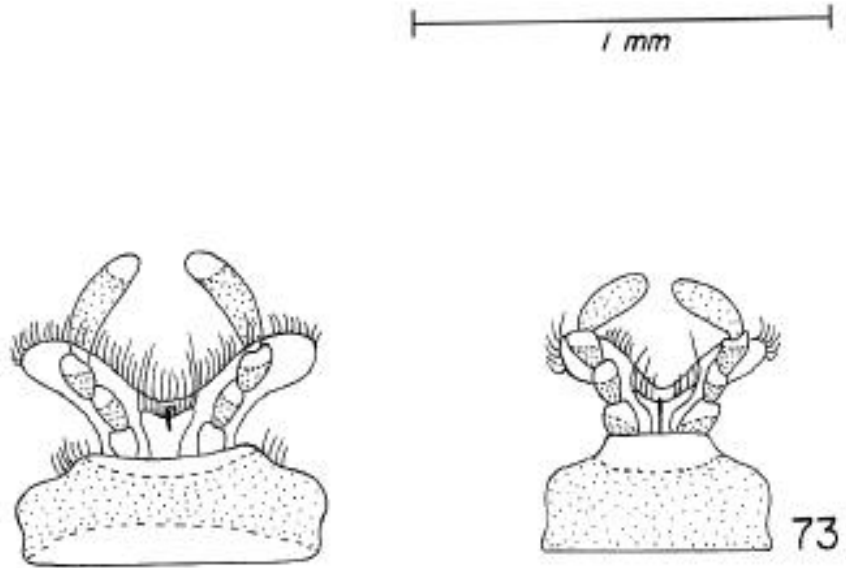

73

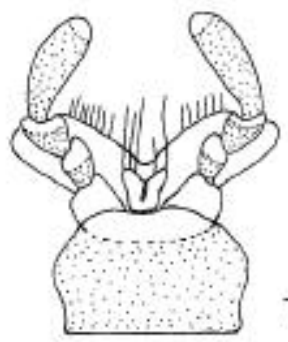

74

72

Figs. 67-74. Lábio, face interna: 67, Ozodes; 68, Elaphopsis. Idem, face externa: 69, Cleomenes; 70, Disaulax; 71, Cycnoderus; 72, Rhopalina; 73, Rhopalophora neivai; 74, Cosmisoma scopulicorne. 

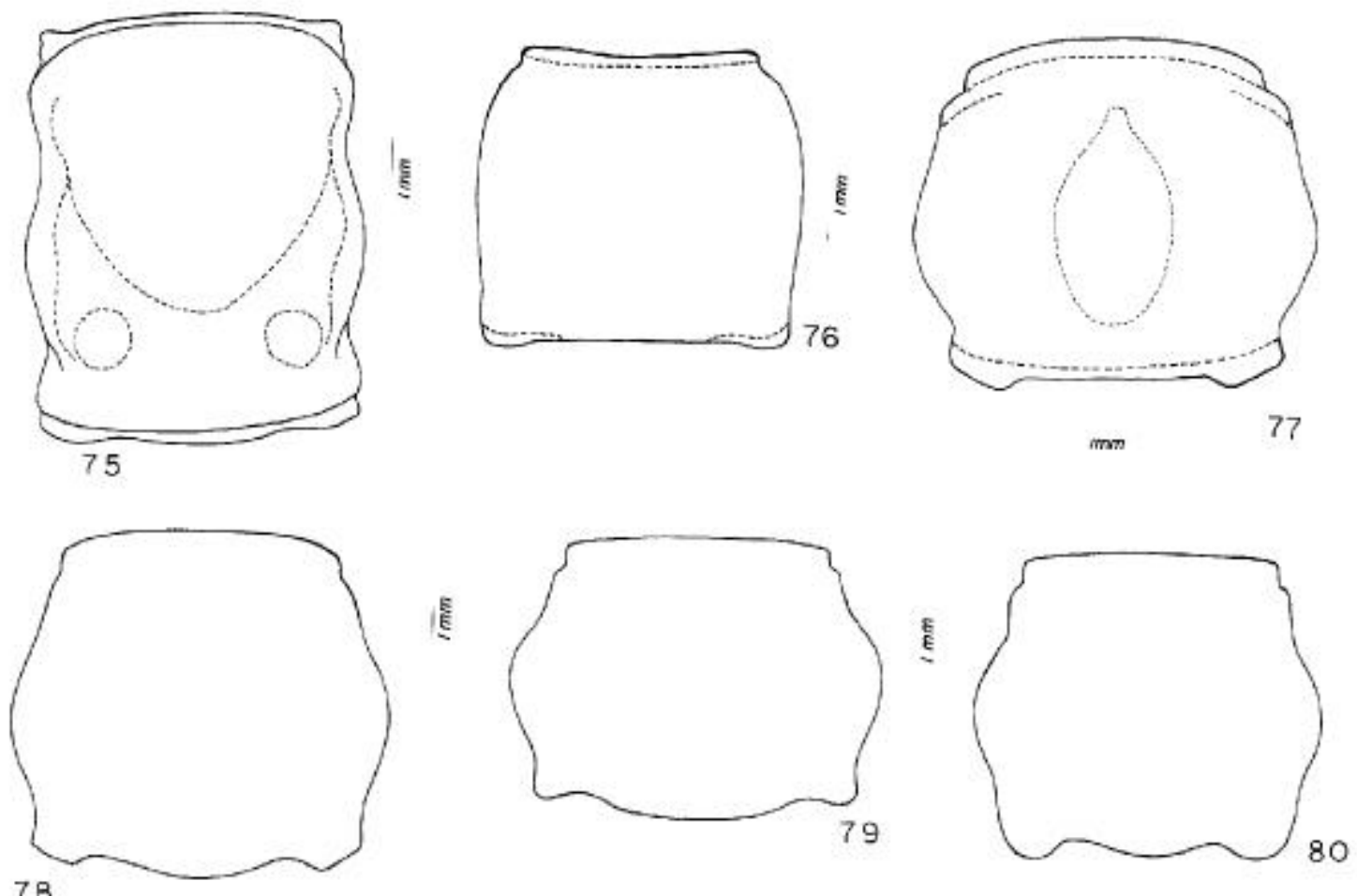

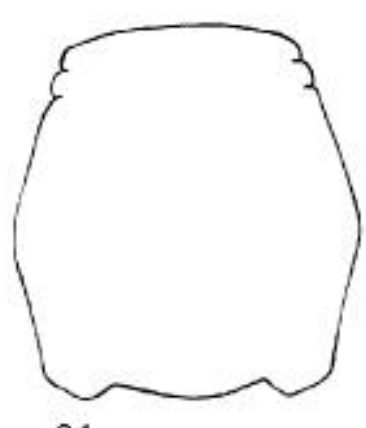

81

78
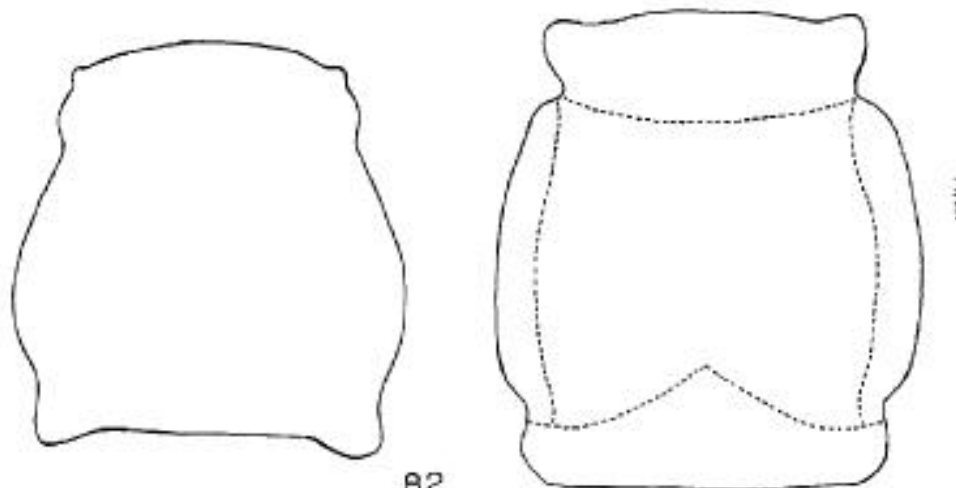

82

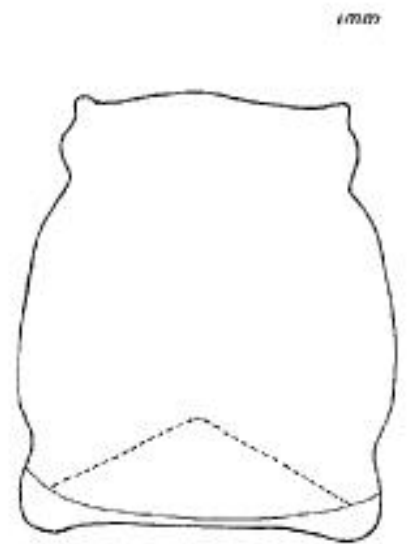

84

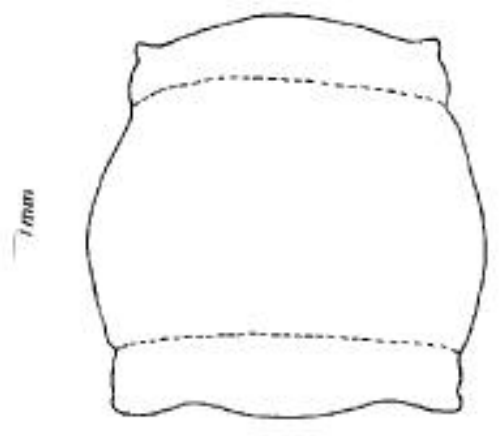

85

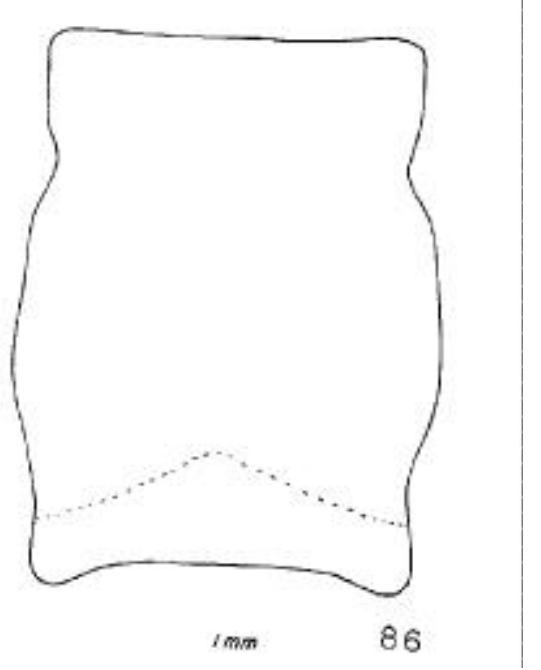

Figs. 75-86. Pronoto: 75, Cleomenes; 76, Glaucytes; 77, Rhopalina; 78, Dirocoremia simplicipes; 79, Lathusia ferruginea; 80, Thalusia erythromera; 81, Dirocoremia ingae; 82, Ischionodonta rufomarginata; 83, Closteropus; 84, Gurubira; 85, Ischionodonta platensis; 86, Cosmisoma scopulicorne. Figs.79,80 e 81,82, 85, respectivamente, na mesma escala. 


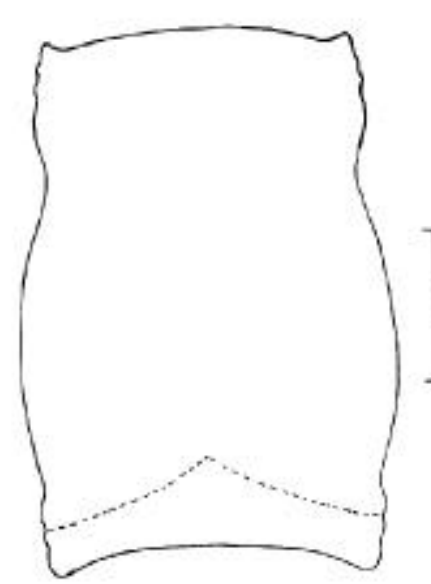

87

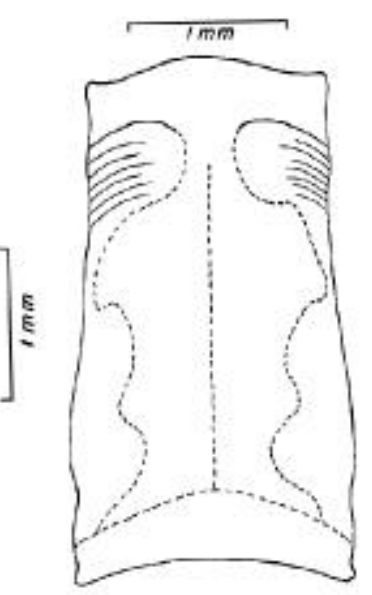

88

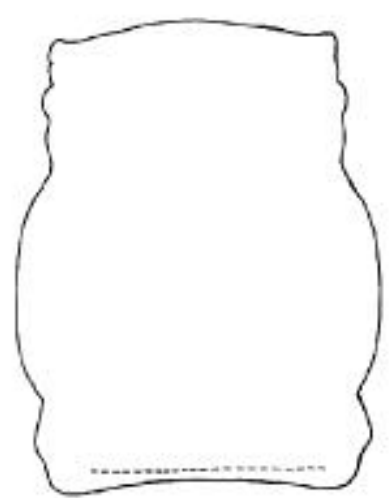

91
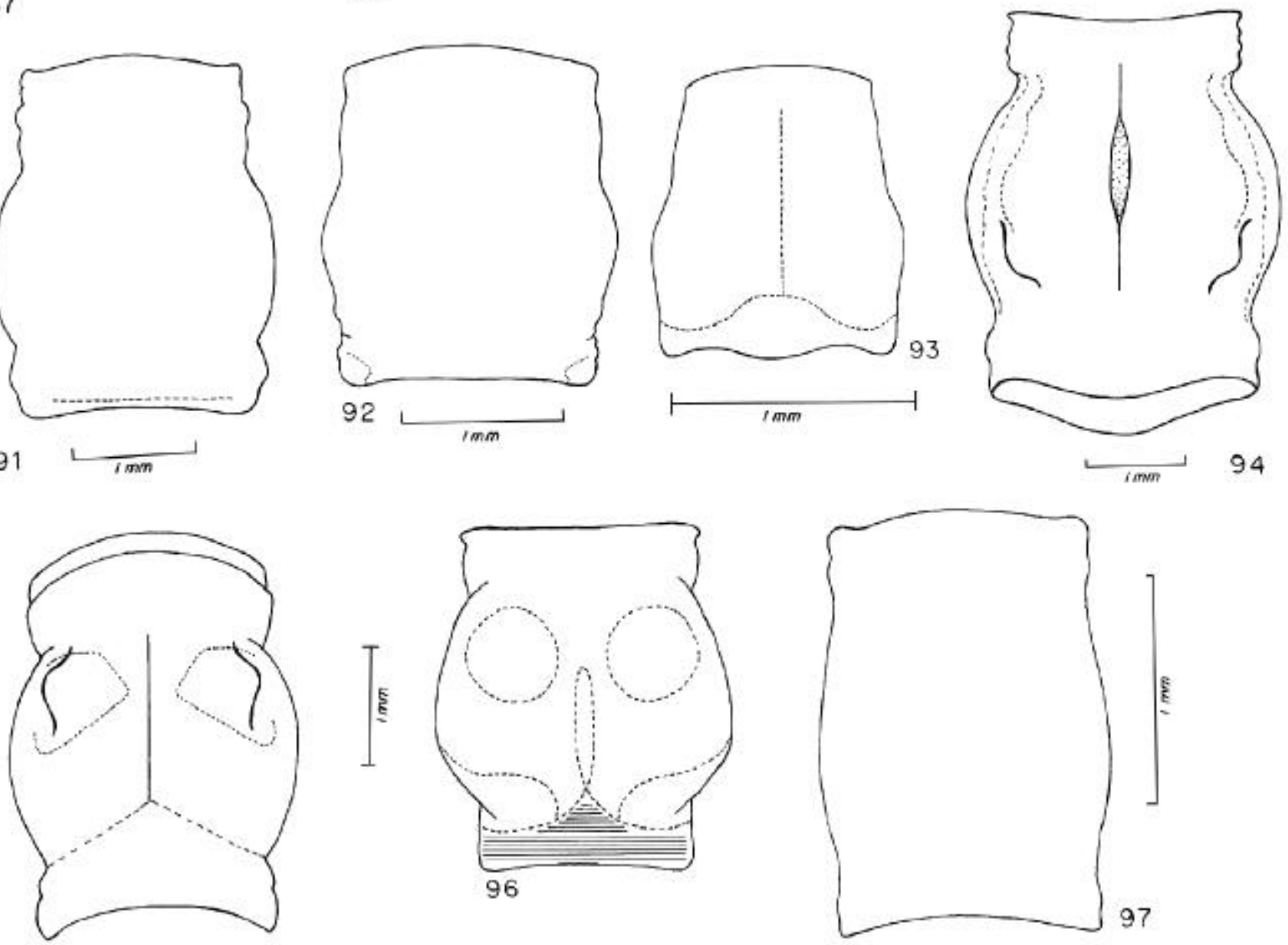

95

Figs. 87-97. Pronoto: 87, Disaulax; 88, Cycnoderus tenuatus; 89, C. barbatus; 90, Coremia plumipes; 91, Rhopalophora collaris; 92. R. neivae; 93, Coremia signaticollis; 94, Ozodes; 95, Parozodes; 96, Argyrodines; 97, Lissozodes. Figs. 90,93 e 95,96, respectivamente, na mesma escala. 

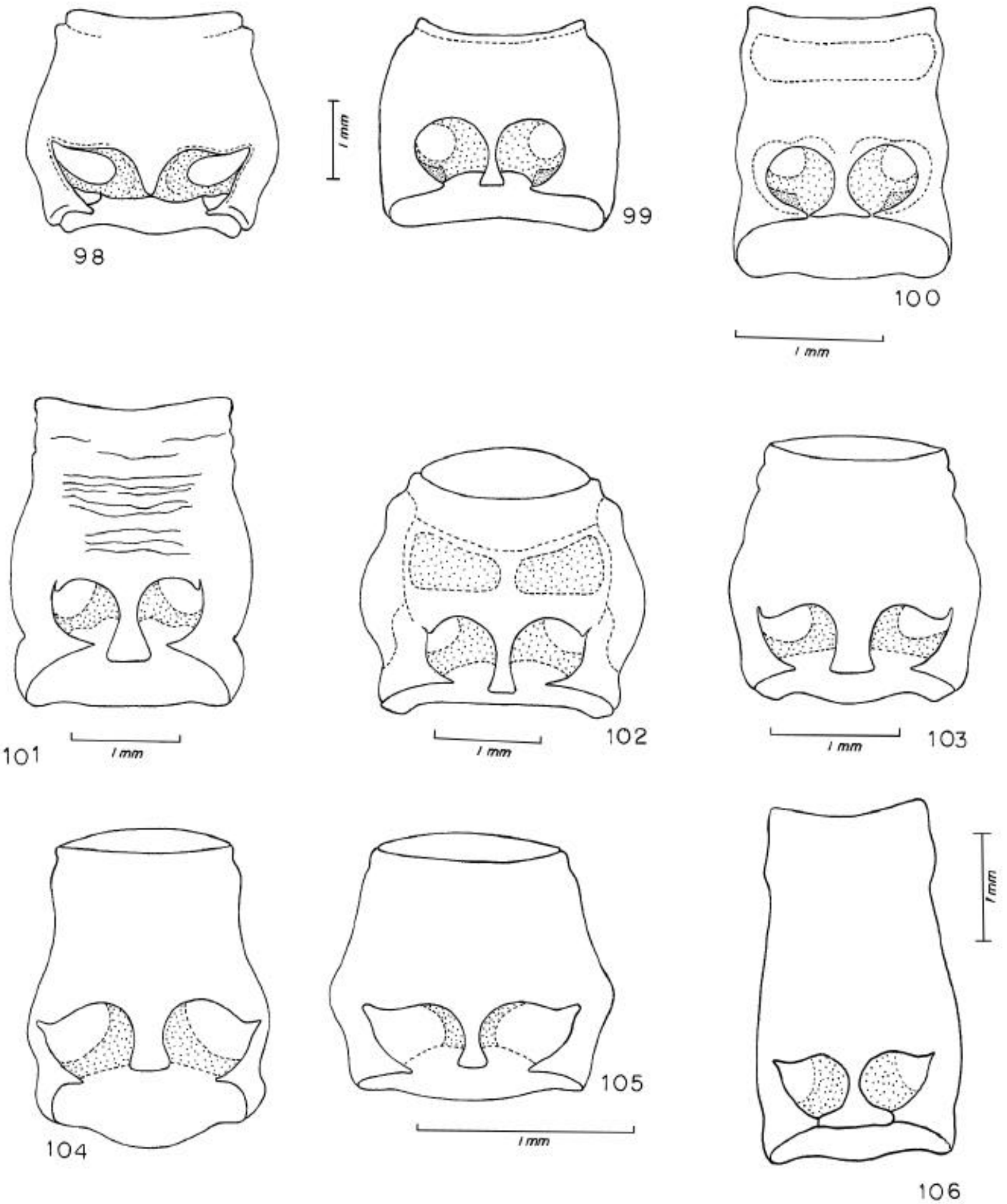

Figs. 98-106. Prosterno: 98, Compsocerus violaceus; 99, Glaucytes; 100, Cleomenes; 101, Rhopalophora collaris;102, Rhopalina; 103, Dirocoremia ingae; 104, Coremia plumipes; 105, Merocoremia; 106, Cycnoderus tenuatus. Figs. 98 e 99, 104 e 105, respectivamente, na mesma escala. 


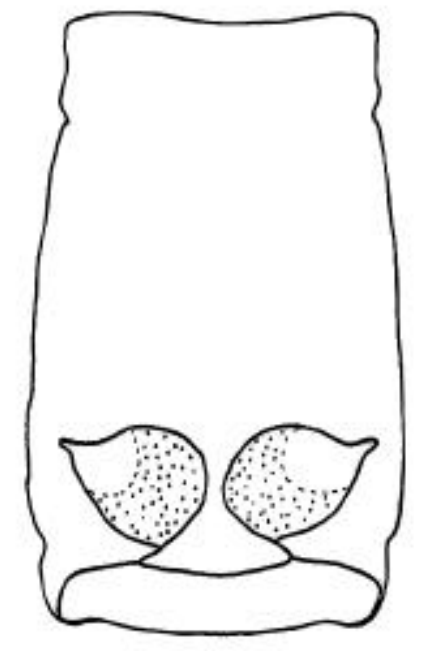

107
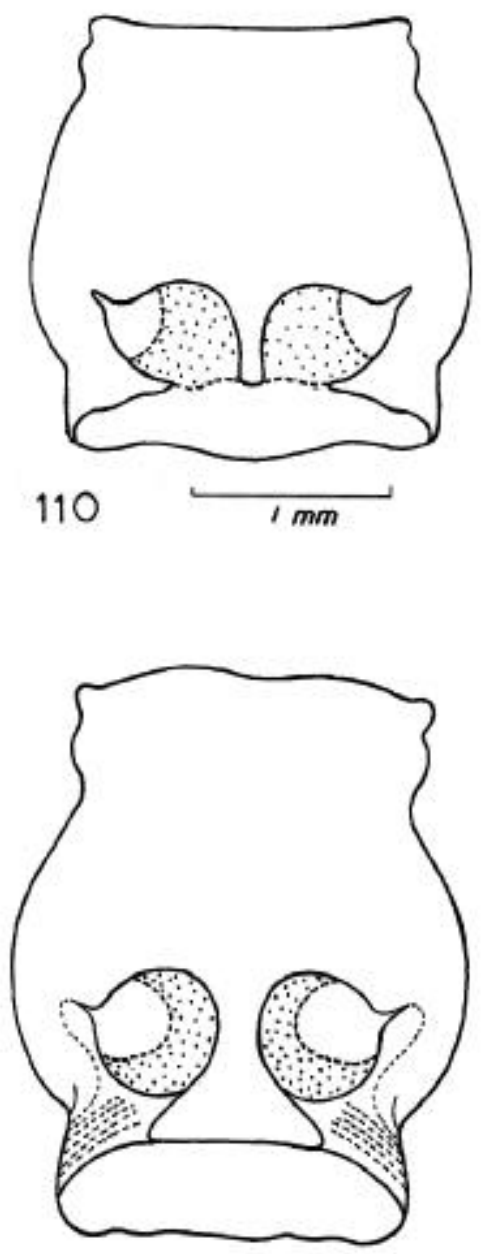

113
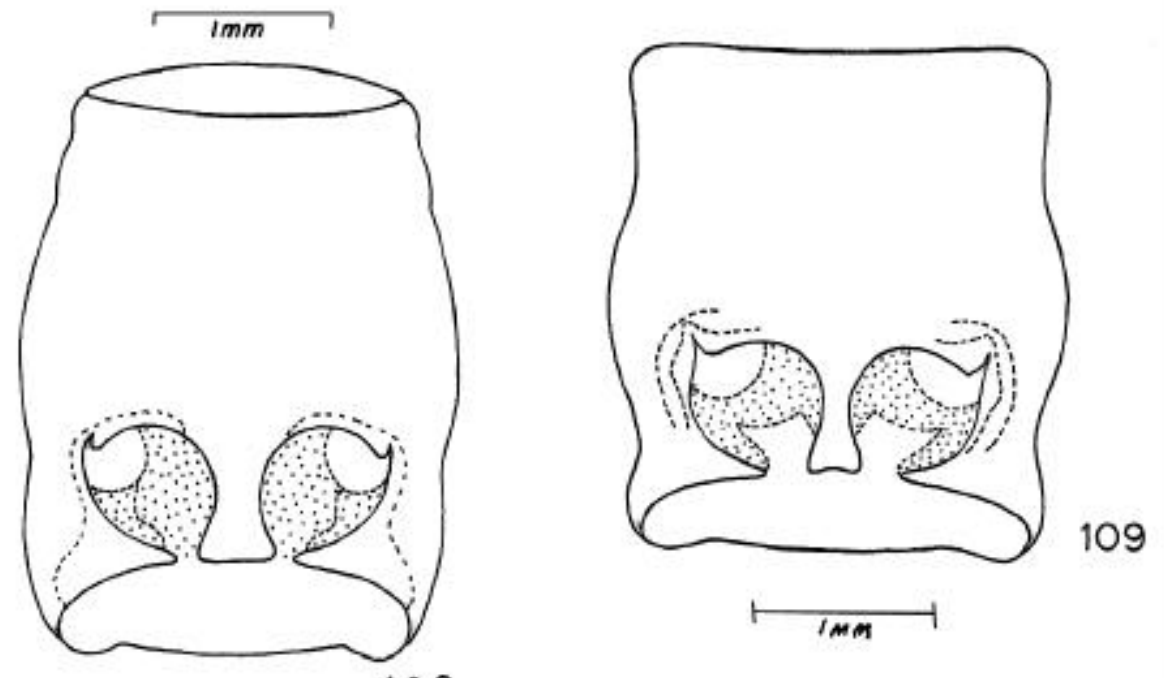

108
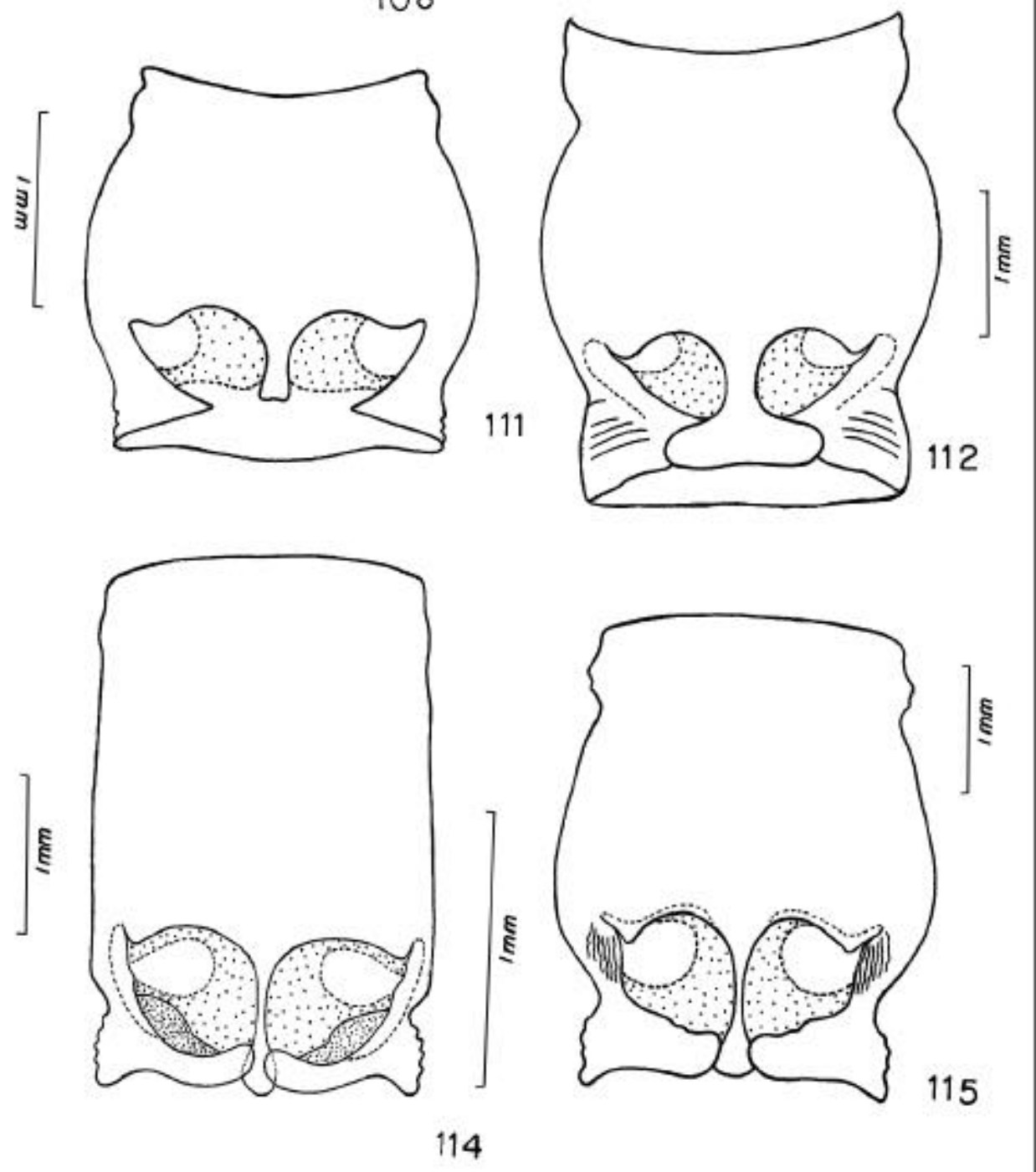

Figs. 107-115. Prosterno: 107, Cycnoderus barbatus; 108, Cosmisoma batesi; 109, Elaphopsis; 110, Ischionodonta rufomarginata; 111, I. platensis; 112, Parozodes; 113, Argyrodines; 114, Lissozodes; 115, Ozodes. Figs. 107 e 109, respectivamente, na mesma escala. 

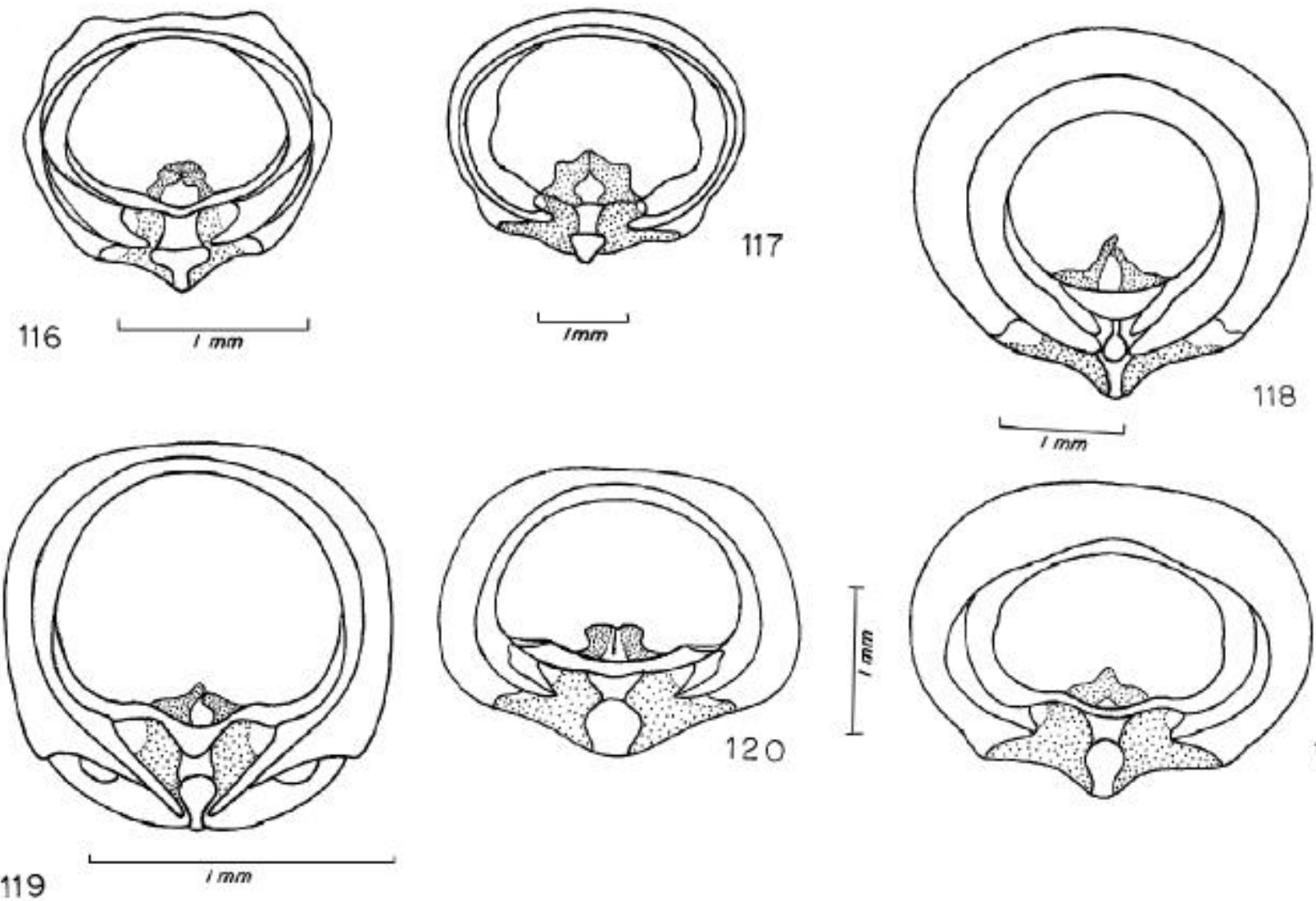

121
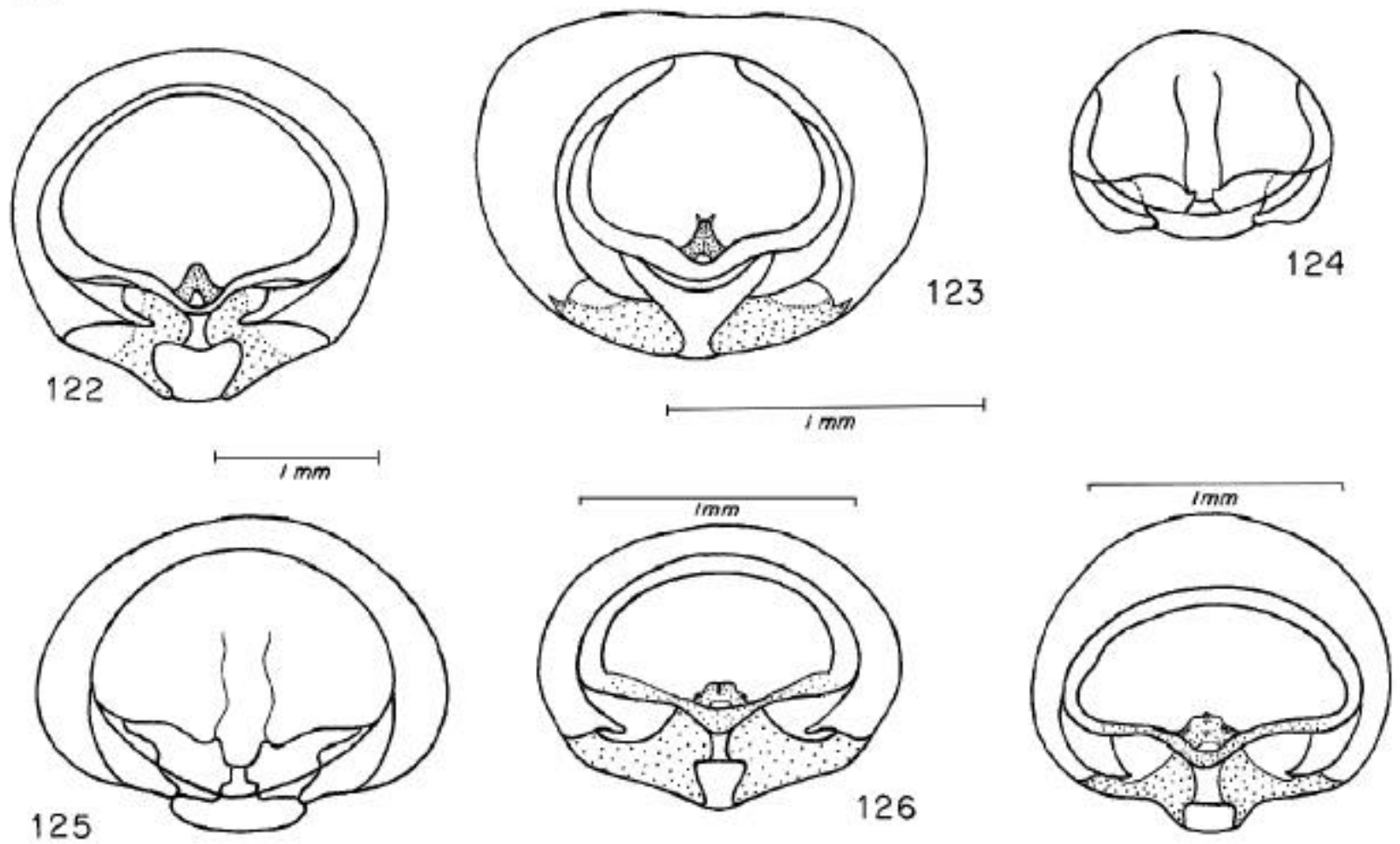

Figs. 116-127. Protórax, proendosternito: 116, Cleomenes; 117, Glaucytes; 118, Ozodes; 119, Lissozodes; 120, Rhopalophora collaris; 121, Rhopalina; 122, Disaulax; 123, Argyrodines; 124, Cycnoderus tenuatus; 125, C. barbatus; 126, Coremia plumipes; 127, Dirocoremia ingae. Figs. 120,121 e 122,124 e 123,125 , respectivamente, na mesma escala. 


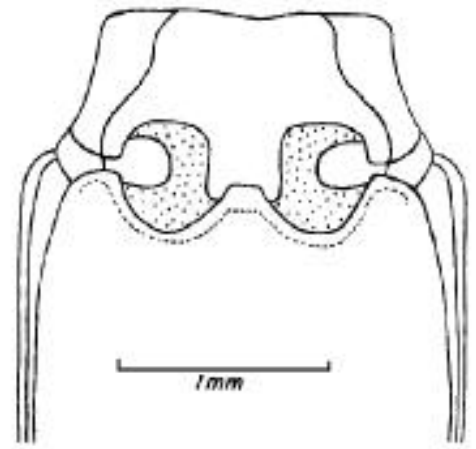

128
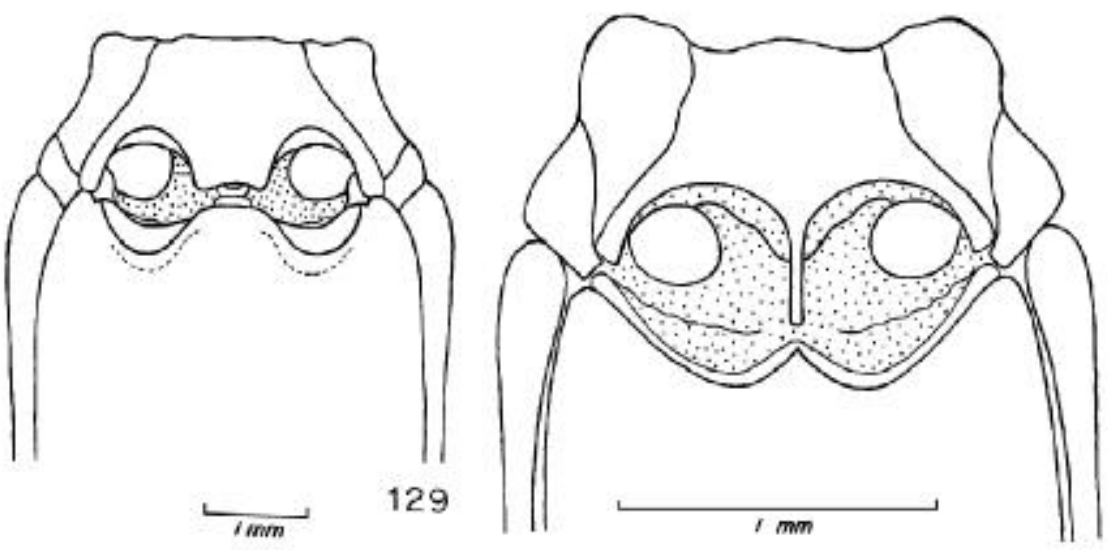

130
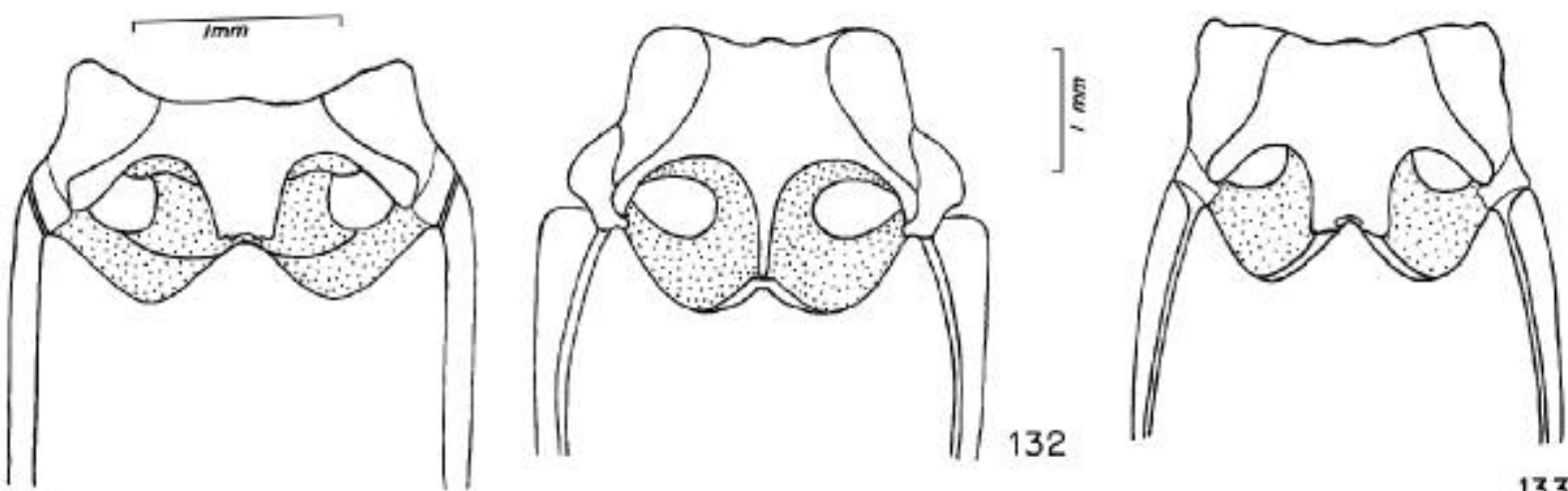

131
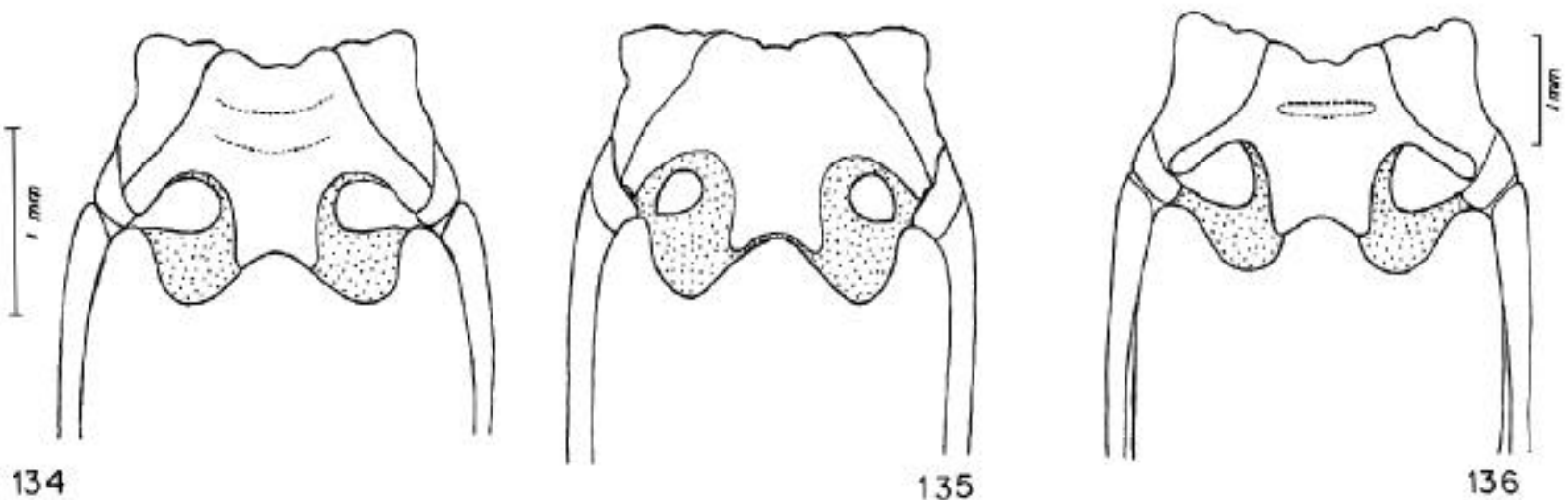

134

135

Figs. 128-136. Processo mesosternal: 128, Cleomenes; 129, Glaucytes; 130, Lissozodes; 131, Ischionodonta platensis; 132, Ozodes;133, Cycnoderus tenuatus; 134, Cosmisoma scopulicorne; 135, Disaulax; 136, Clostreopus. 


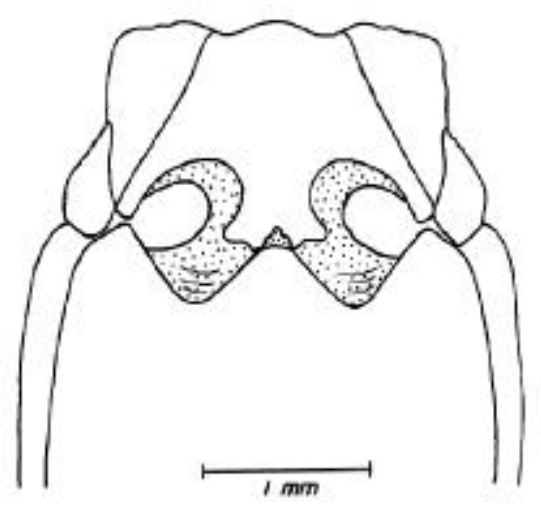

137
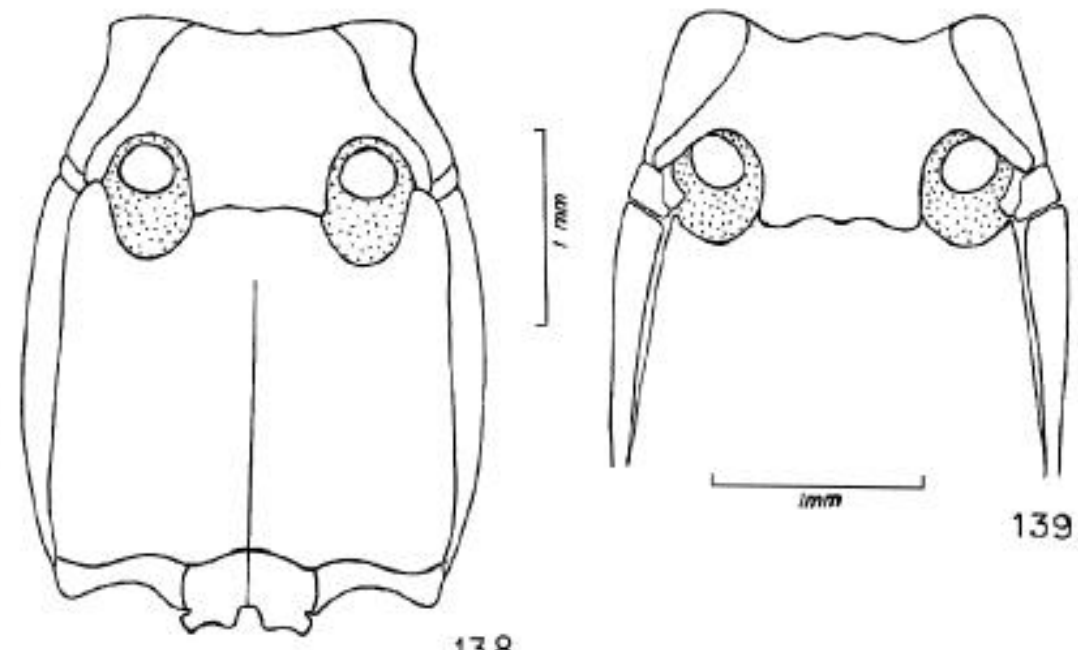

138

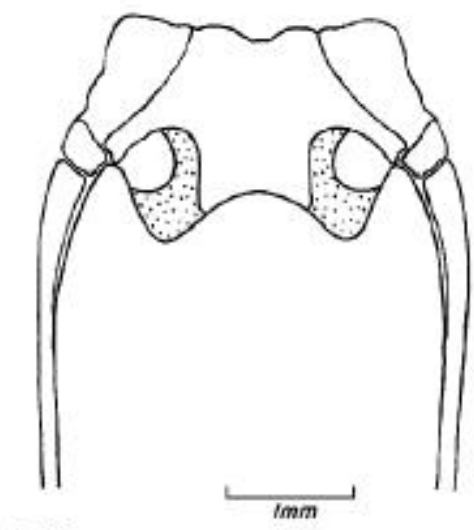

140

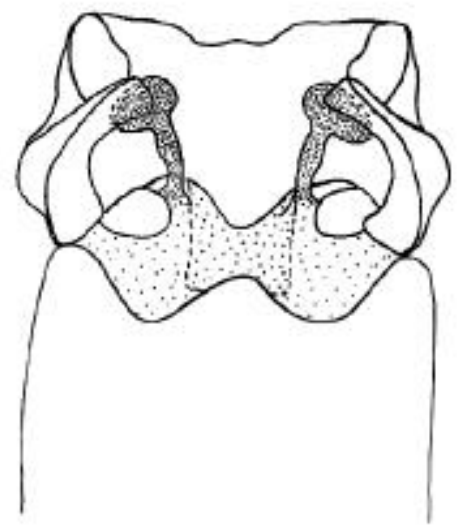

143
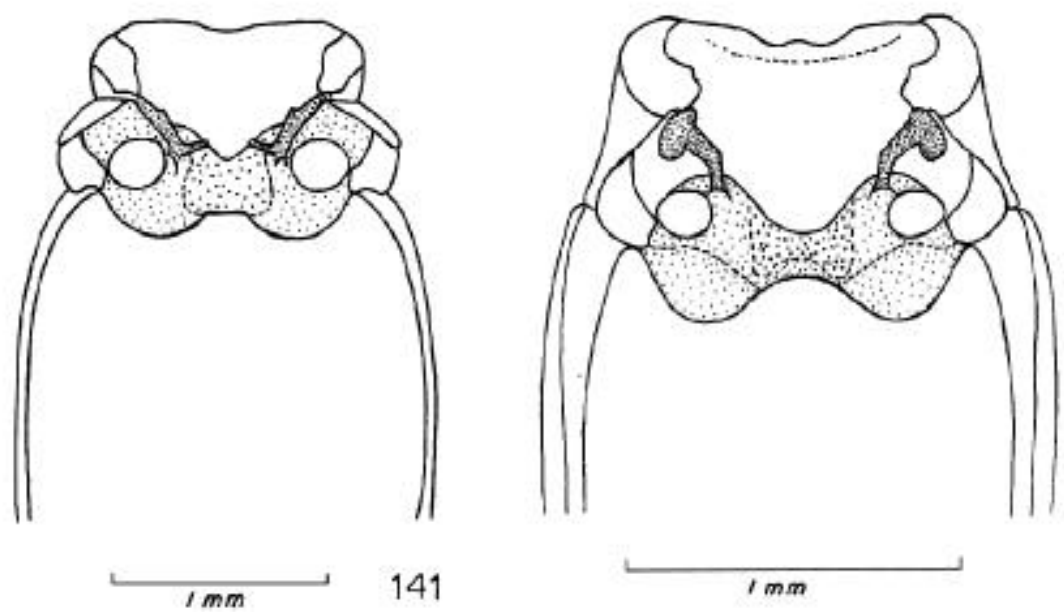

142

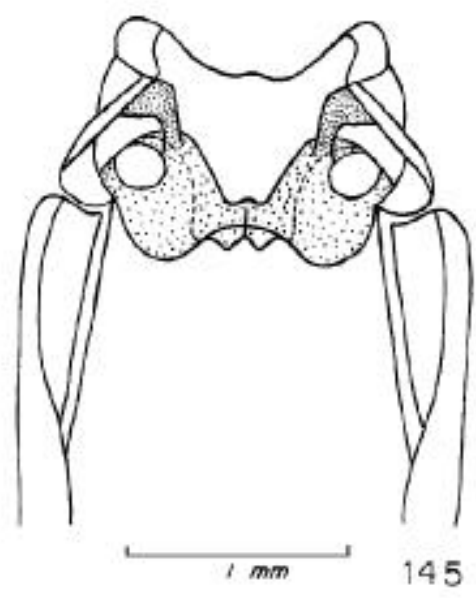

Figs. 137-140. Processo mesosternal: 137, Elaphopsis;138, Rhopalophora collaris; 139, Coremia plumipes; 140, Gurubira. Figs. 141-145. Mesosterno e mesendosternito: 141, Cleomenes; 142 , Cycnoderus barbatus; 143, Disaulax; 144, Glaucytes; 145, Coremia plumipes. 

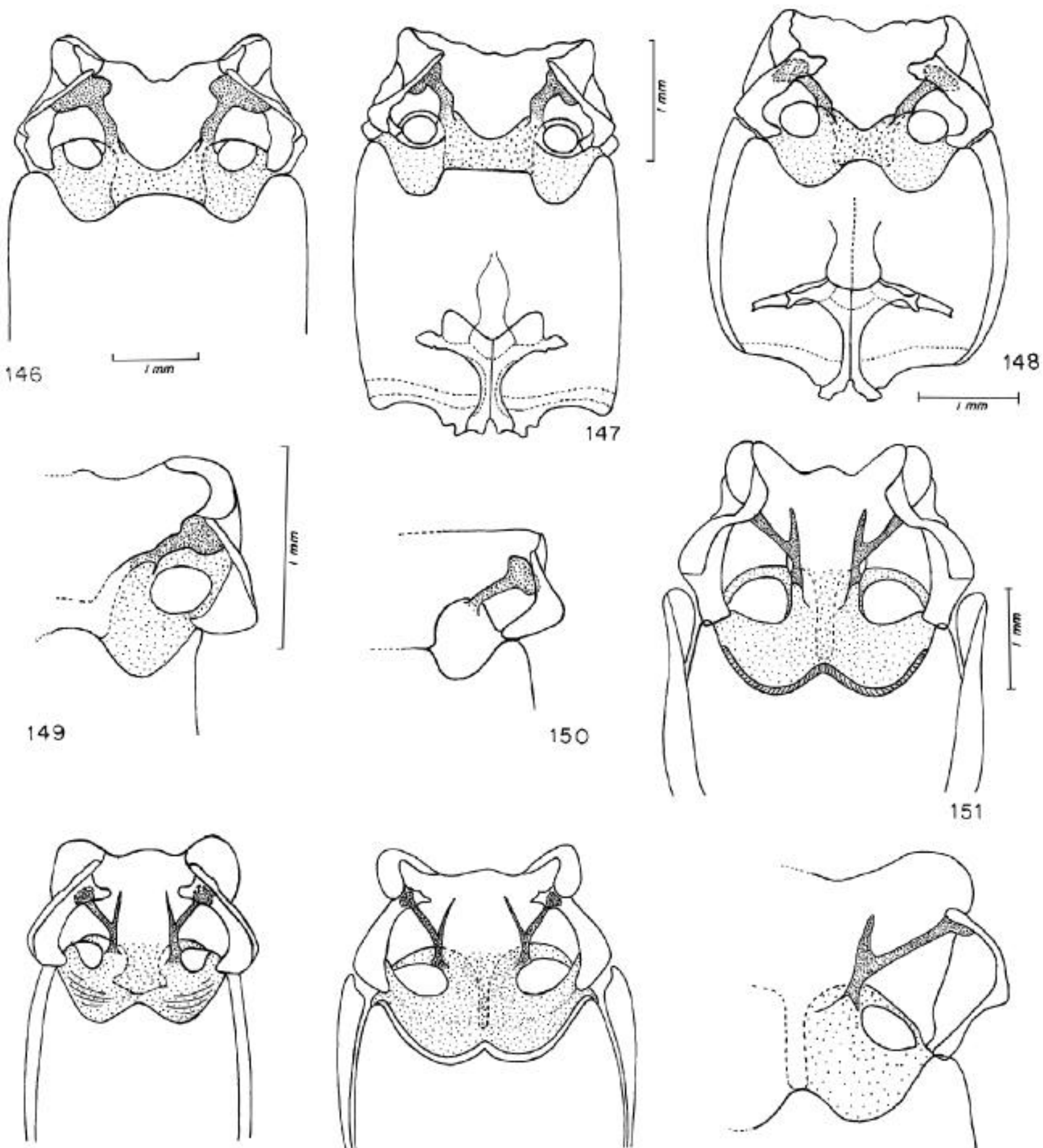

152
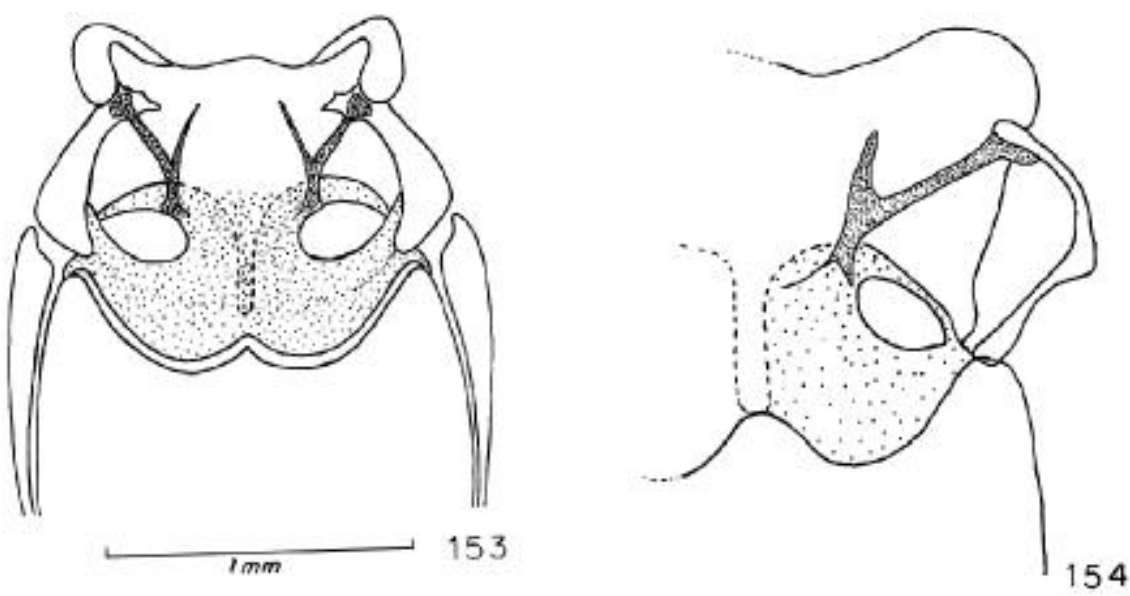

Figs. 146-148. 146, Gurubira, mesendosternito; 147, Rhopalophora colaris, mesosterno, mesendosternito e metasterno, metendosternito; 148, Cosmisoma batesi, idem. Figs. 149-154. Mesosterno, mesendosternito: 149, Coremia plumipes; 150, Cosmisoma scopulicorne; 151, Ozodes; 152, Elaphopsis; 153, Lissozodes; 154, Ozodes. Figs.148,150 e 151,152 e 154, respectivamente, na mesma escala. 

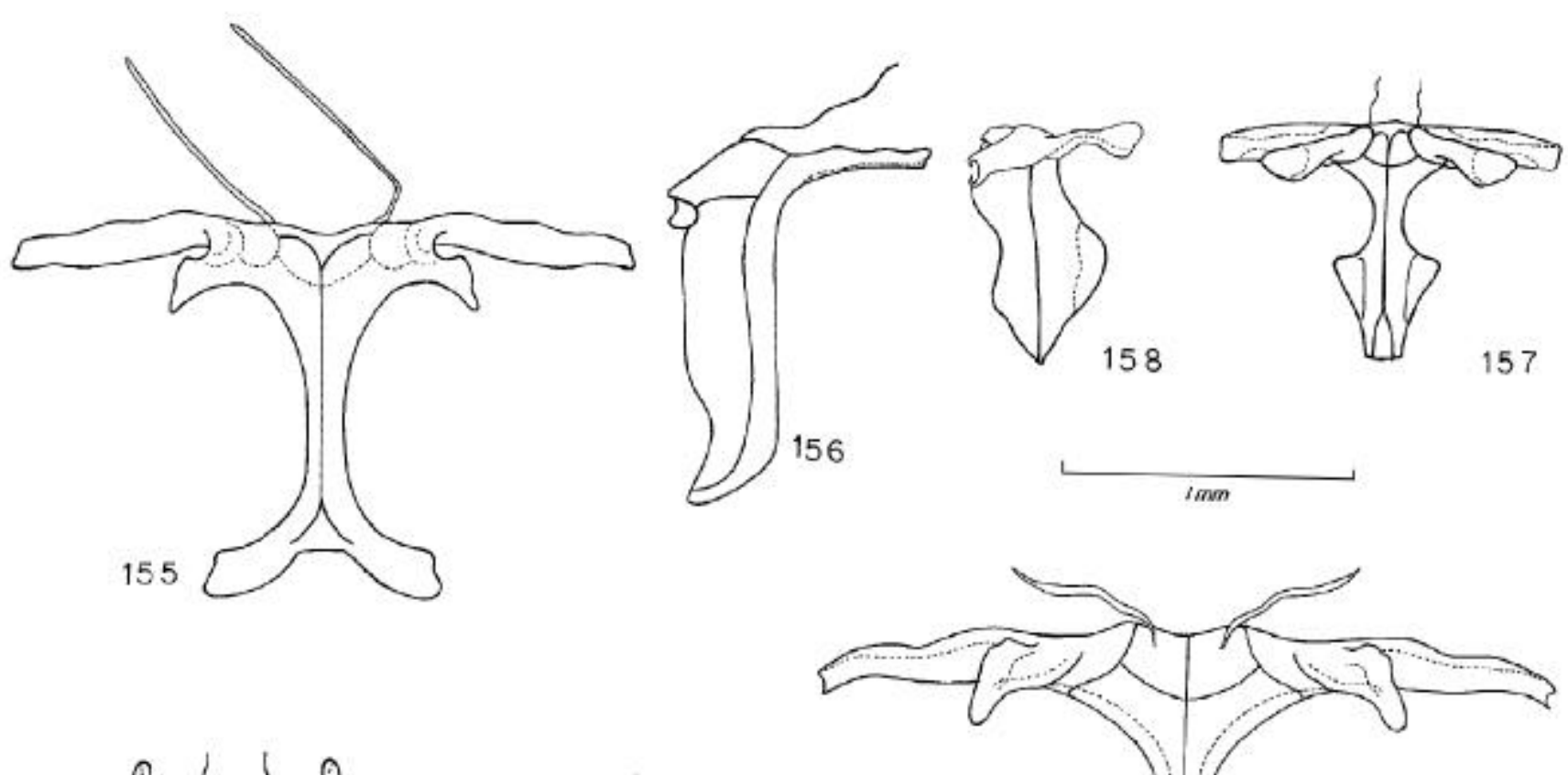

158

157
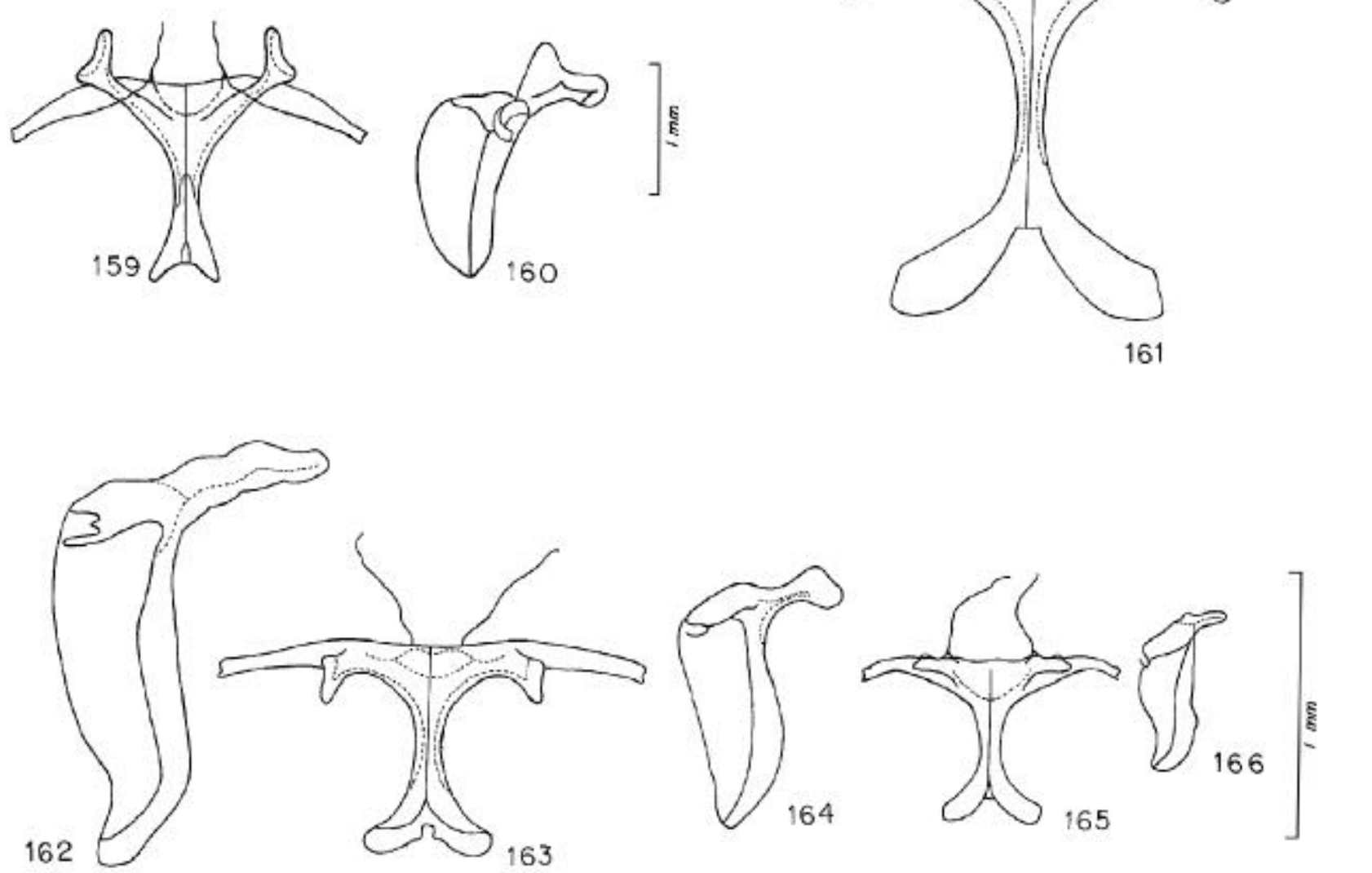

Figs. 155-166. Metendosternito, vistas dorsal e lateral: 155-156, Disaulax; 157-158, Cleomenes; 159-160, Glaucytes; 161-162, Gurubira; 163164, Cosmisoma scopulicorne; 165-166, Cycnoderus barbatus. Figs. 155-158, 159,160 e 161-166, respectivamente, na mesma escala. 

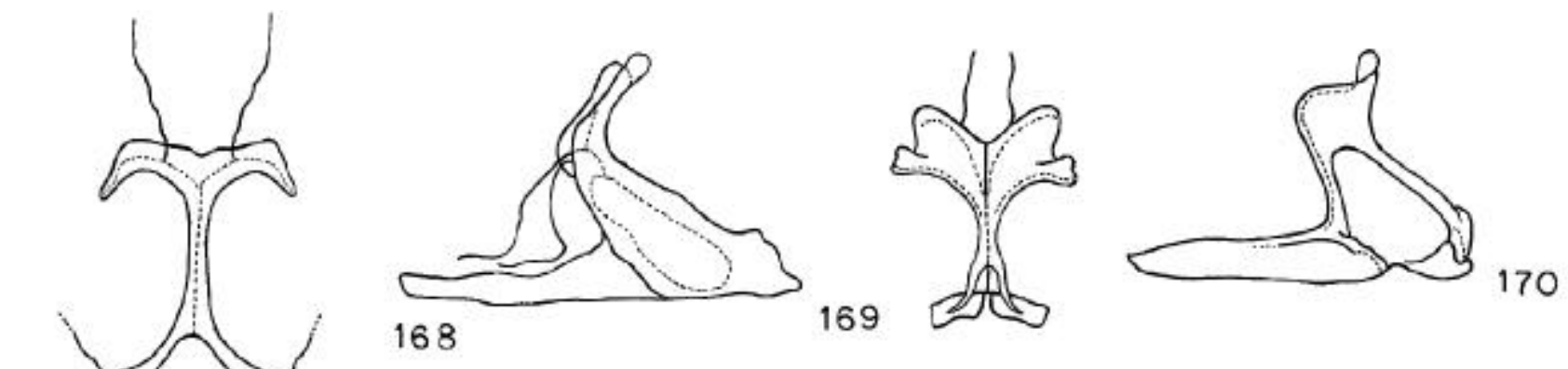

167

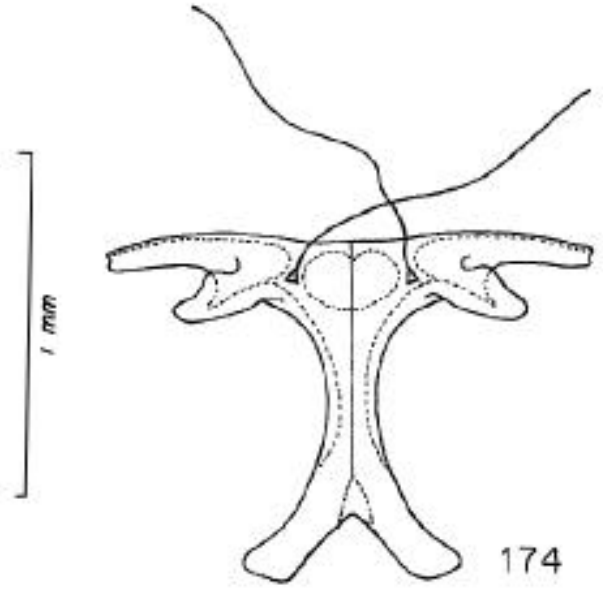

171

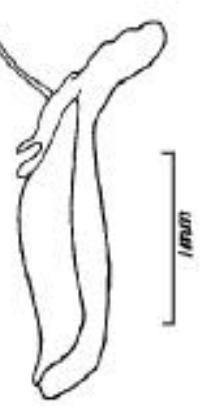

172

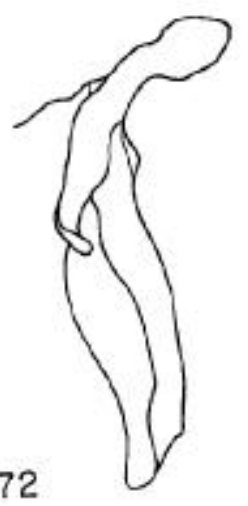

173

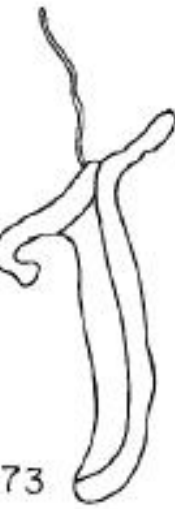

176
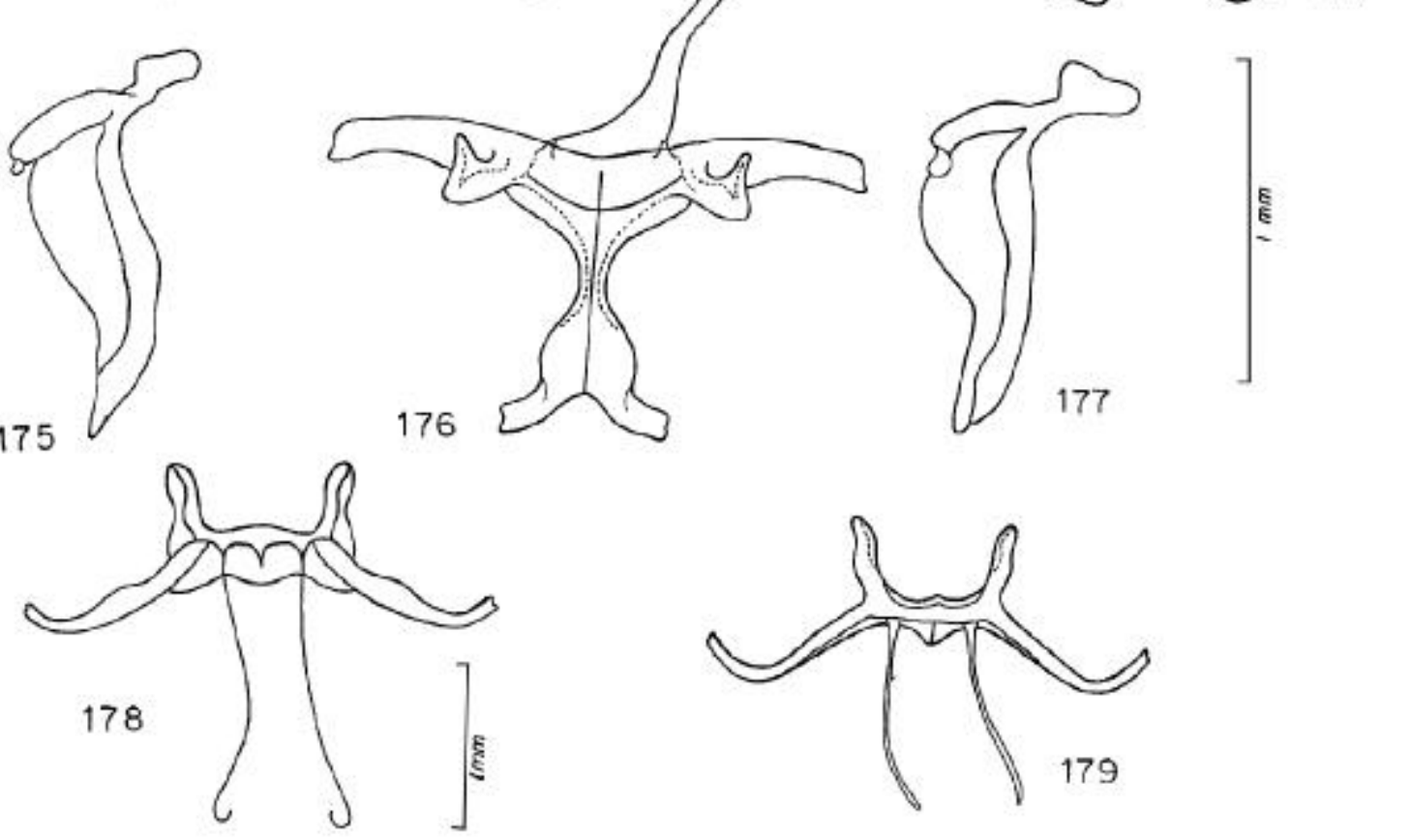

Figs. 167-179. Metendosternito. 167-168, C. plumipes, vistas dorsal e lateral; 169-170, Rhopalophora collaris,idem; 171, Ozodes, vista lateral; 172, Elaphopsis,idem; 173, Lissozodes, idem; 174-175, Ischionodonta rufomarginata, vistas dorsal e lateral; 176-177, I. platensis, idem; 178, Ozodes, vista anterior; 179. Lissozodes, idem. Figs. 167-170, 172 e 173, 174-177 e 179, respectivamente, na mesma escala. 


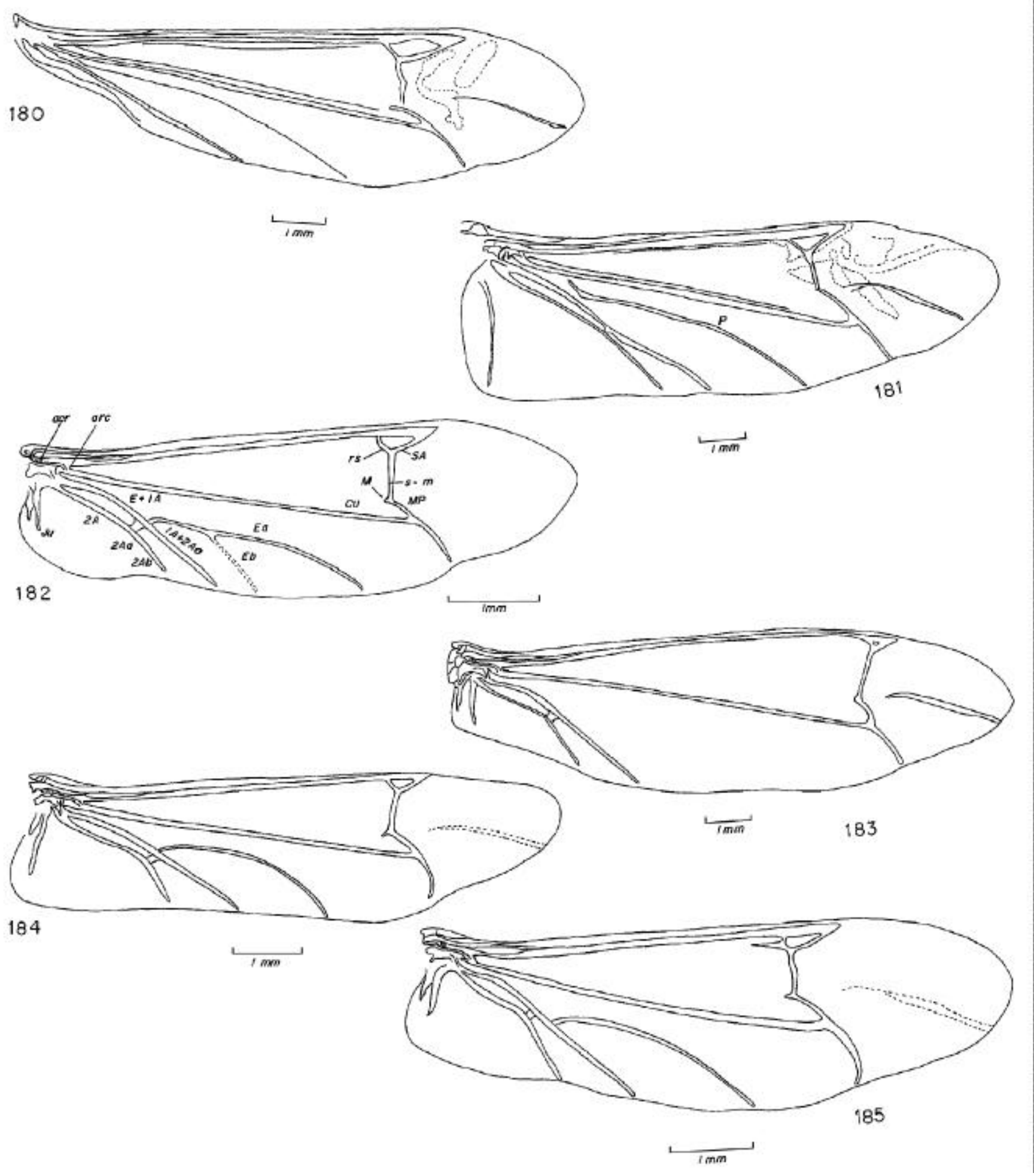

Figs. 180-185. Asa: 180, Cleomenes; 181 , Glaucytes; 182, Coremia signaticollis; 183, C. plumipes; 184 , Dirocoremia ingae; 185 , Thalusia erythromera. Acr=área carenada; arc=árculo; $\mathrm{Cu}=\mathrm{Cubital} ; \mathrm{E}=\mathrm{Empusal} ; \mathrm{Eb}=\mathrm{ramo}$ b da Empusal; Ju=Jugal;M=Média; $\mathrm{MP}=\mathrm{Média} \mathrm{Posterior;} \mathrm{P}=\mathrm{Plical} ; \mathrm{r}-$ $\mathrm{s}=$ veia transversa rádio setor; $\mathrm{SA}=$ Setor Anterior; $\mathrm{s}-\mathrm{m}=\mathrm{veia}$ transversa setor média; $1 \mathrm{~A}=1^{\mathrm{a}}$ anal; $2 \mathrm{~A}=2^{\mathrm{a}}$ anal; $2 \mathrm{Aa}=\mathrm{ramo}$ anterior da $2 \mathrm{~A} ; 2 \mathrm{Ab}=\mathrm{ramo}$ posterior da $2 \mathrm{~A}$. 


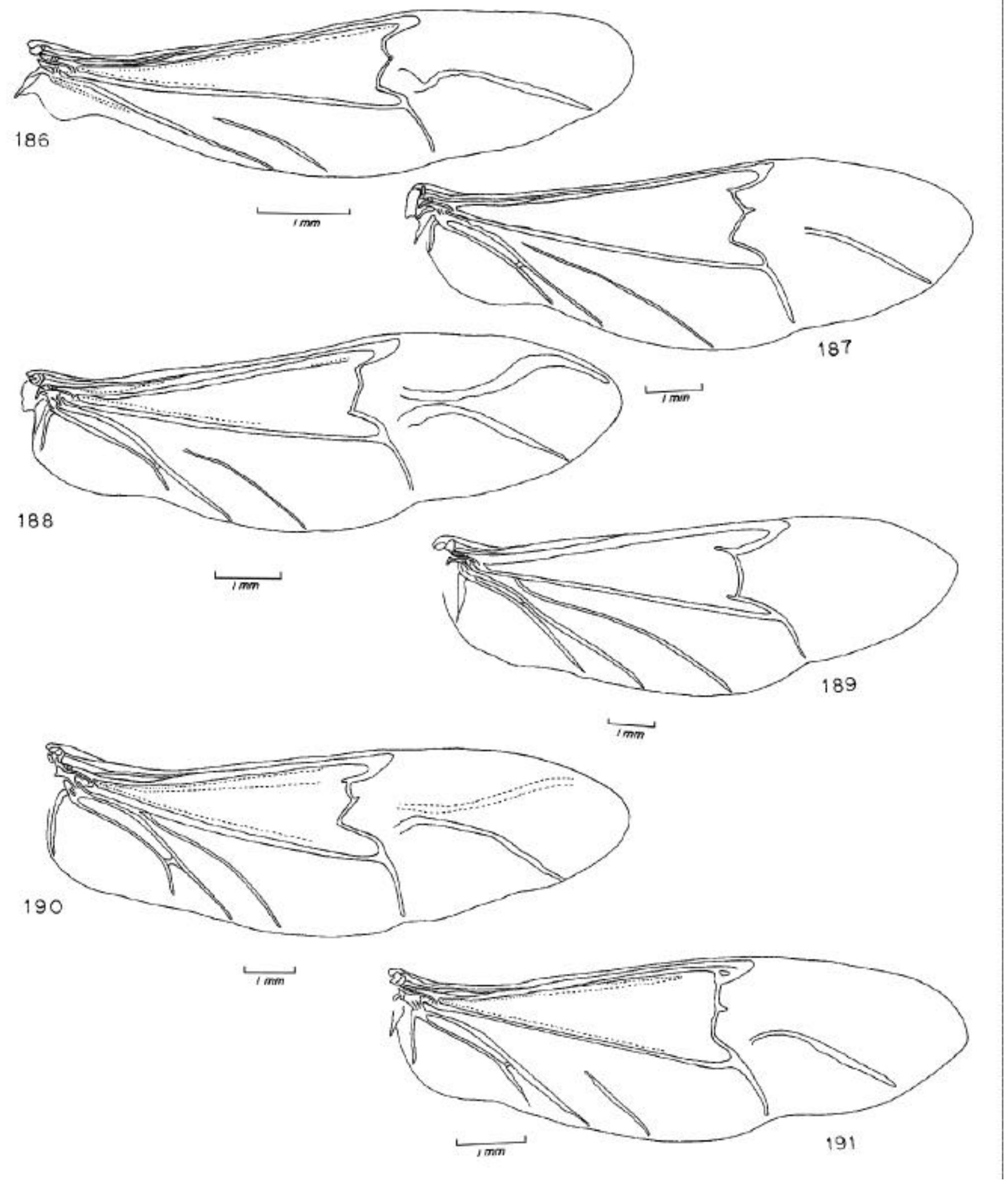

Figs. 186-191. Asa. 186, Cycnoderus barbatus;187, C. tenuatus; 188, Ischionodonta rufomarginata; 189, Rhopalophora collaris; 190, Parozodes; 191, Cosmisoma scopulicorne. 

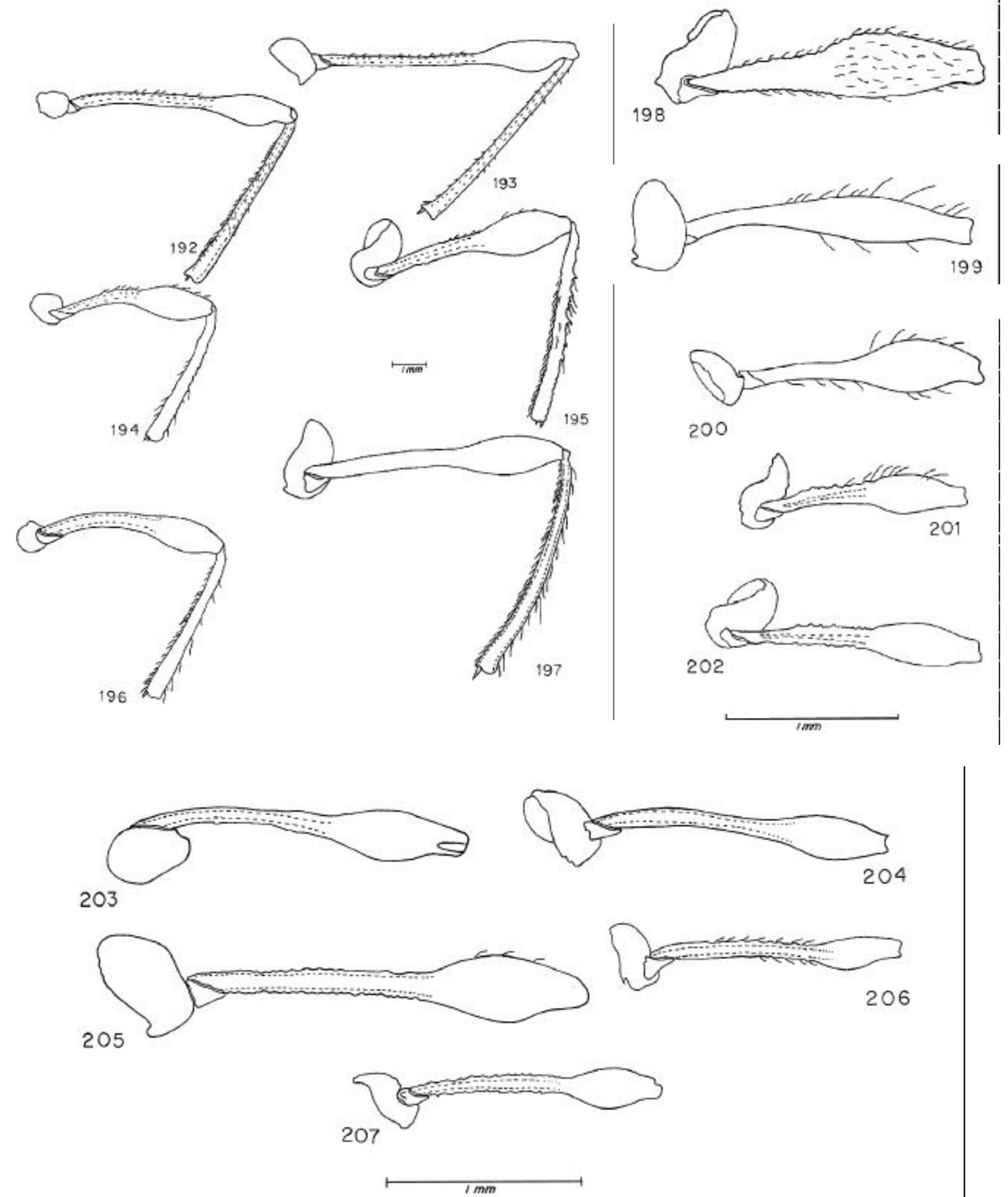

Figs. 192-197. Pernas médias e posteriores.192-193, Rhopalophora collaris; 194-195, Parozodes; 196-197, Gurubira. Figs. 198-207. Metafêmures: 198, Ozodes; 199, Lissozodes; 200, Elaphopsis; 201, Argyrodines; 202, Paraozodes; 203, Cosmisoma ammirallis; 204, Disaulax; 205, Closteropus; 206, Ischionodonta rufomarginata; 207, I. platensis. Figs.198-202 e 203-207, respectivamente, na mesma escala. 

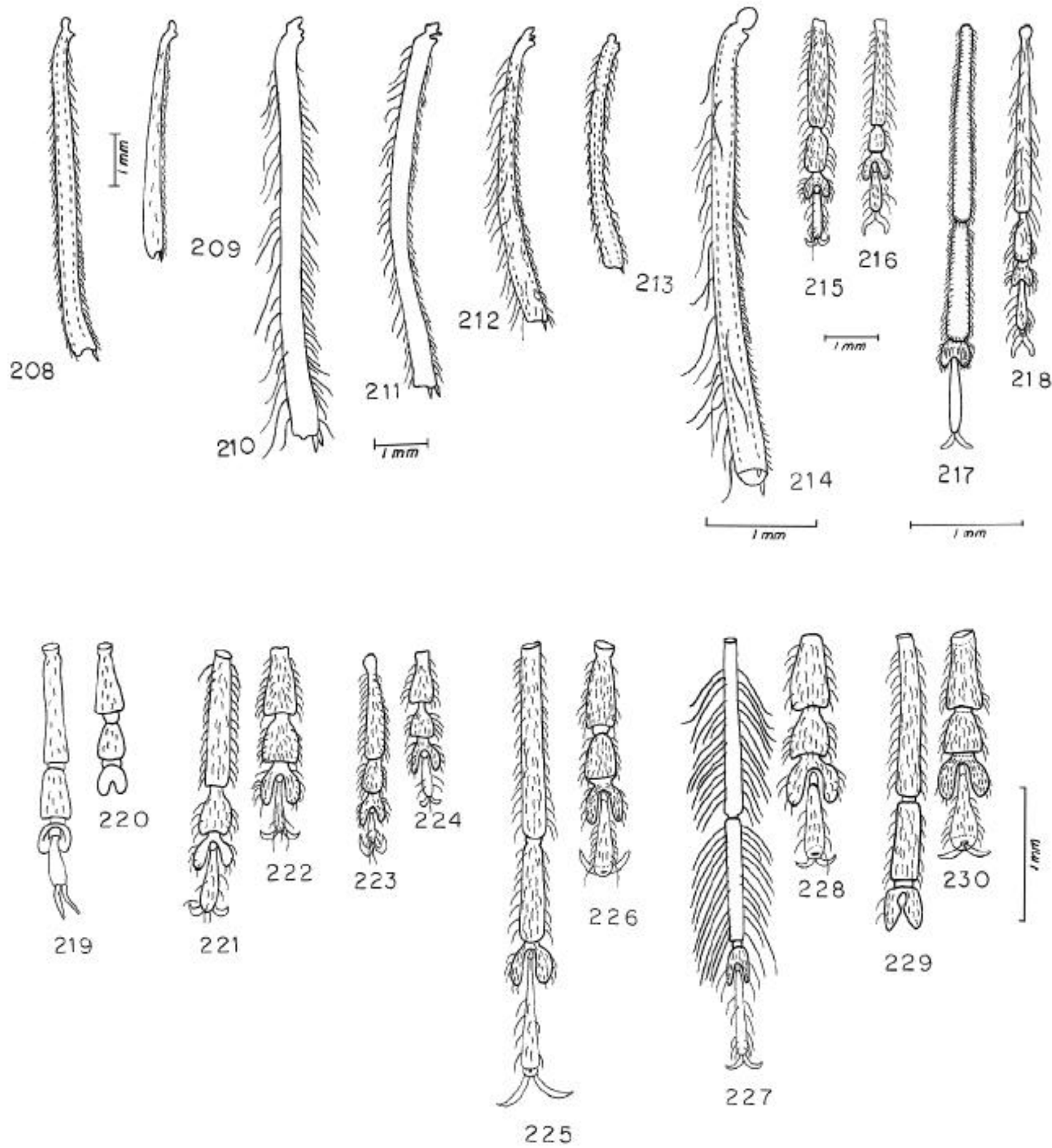

Figs. 208-214. Metatíbias. 208, Rhopalophora collaris; 209, Cleomenes; 210, Cosmisoma aeneicolle; 211, Gurubira; 212, Disaulax; 213, Ischionodonta platensis; 214, Cosmisoma scopulicorne. Figs. 215-218. Metatarsômeros, face ventral: 215, Ozodes; 216, Lissozodes; 217, Coremia plumipes; 218, Cycnoderus barbatus. Figs. 219-230. Metatarsômeros e protarsômeros, vista dorsal. 219-220, Cleomenes; 221-222, Gurubira; 223-224, Rhopalophora collaris; 225-226, Dirocoremia bruchi; 227-228, Coremia signaticollis; 229-230, Lathusia ferruginea. Figs. 208,209, 210-213, 215-216, 217-220, 221-224 e 225-228, respectivamente na mesma escala. 

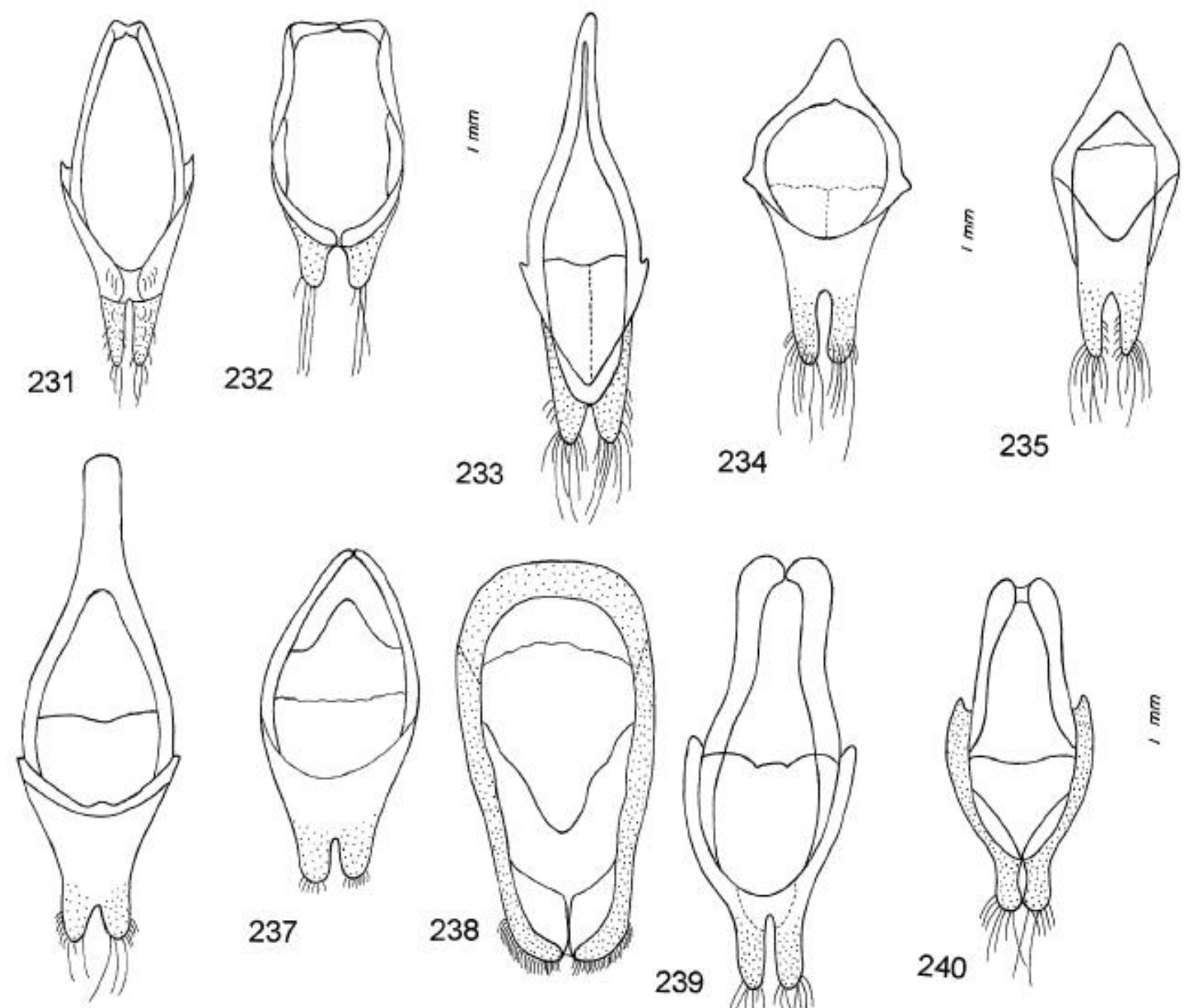

236
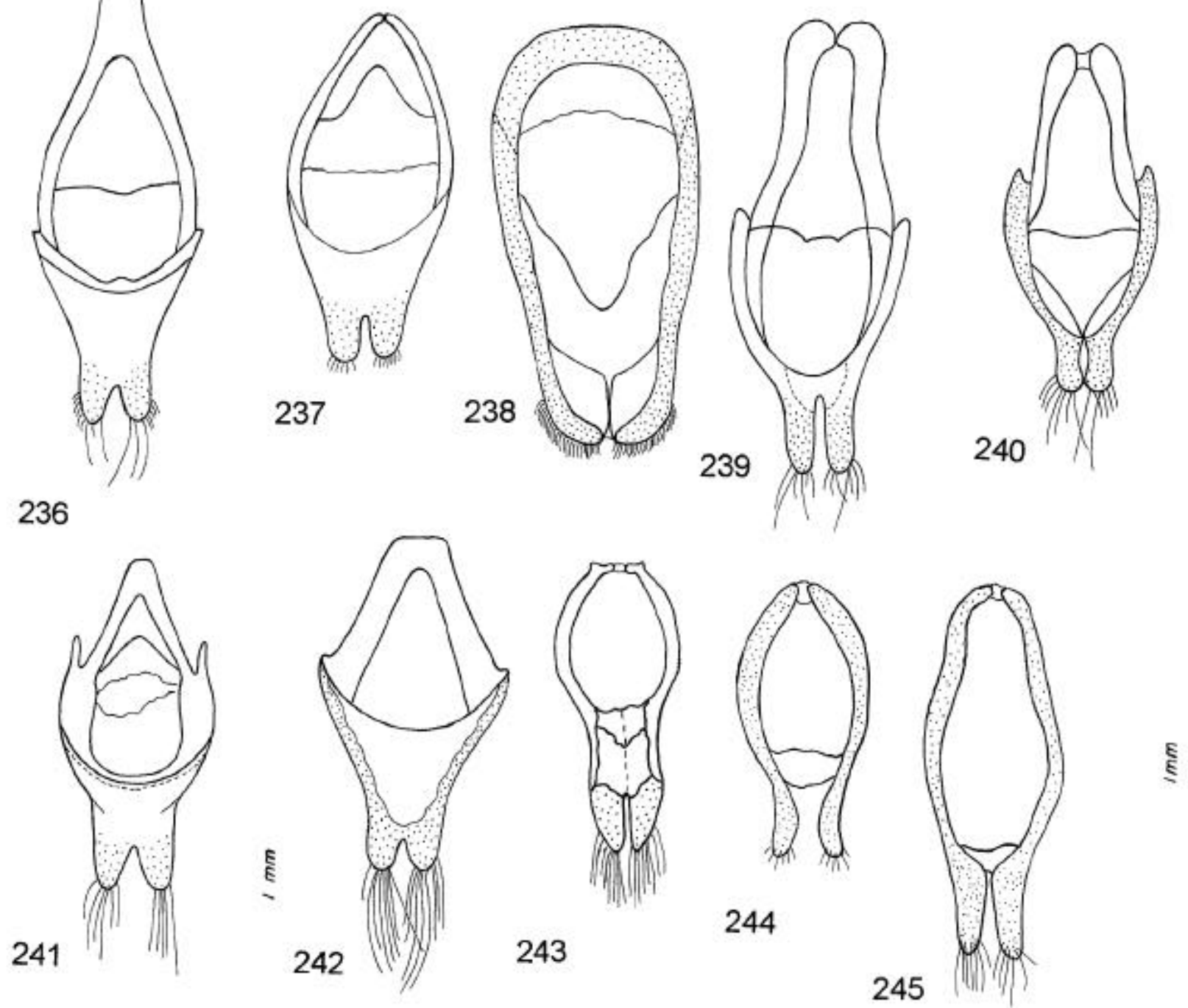

Figs. 231-245.Terminália masculina, tégmen: 231, Cleomenes; 232, Glaucytes; 233, Disaulax; 234, Ischionodonta platensis; 235, I. rufomarginata; 236, Rhopalina; 237, Lissozodes; 238, Ozodes; 239, Cycnoderus tenuatus; 240, C. barbatus; 241, Argyrodines; 242, Parozodes; 243, Rhopalophora collaris; 244, Thalusia erythromera; 245, Merocoremia. Figs.231,233-236, 237-240, 241,242 e 243-245, respectivamente, na mesma escala. 

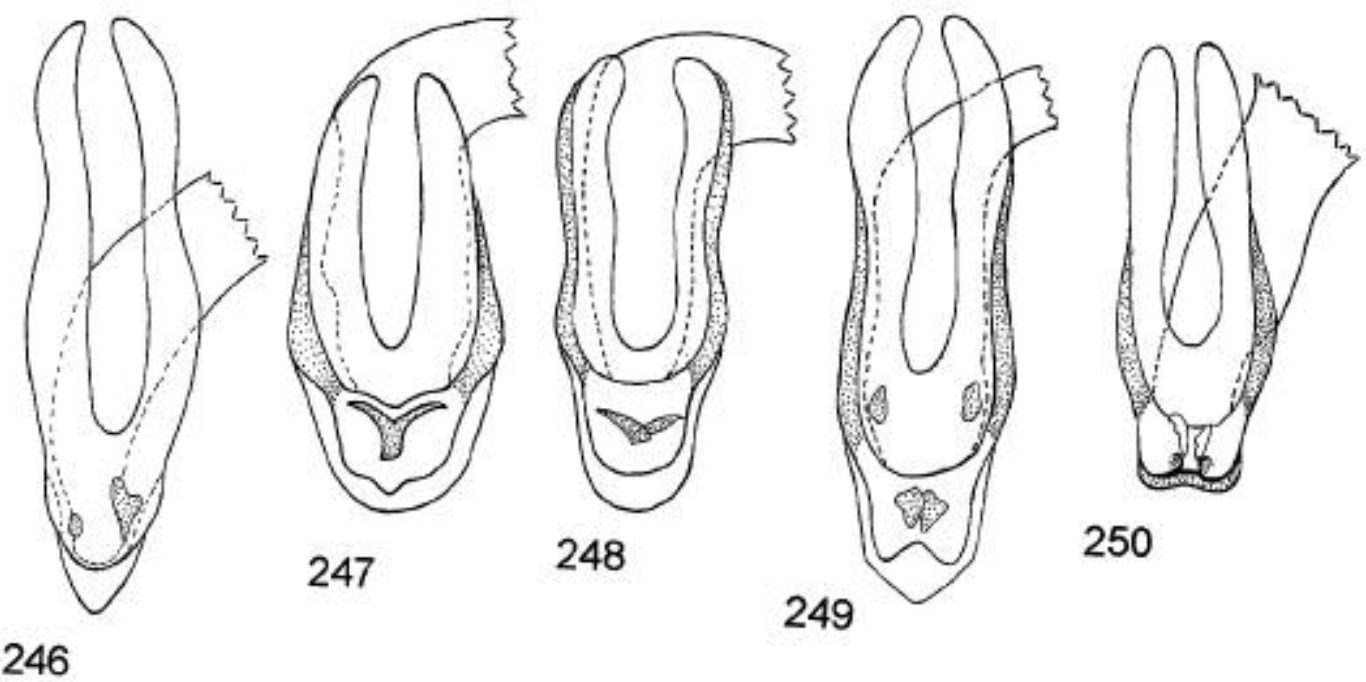

\section{6}
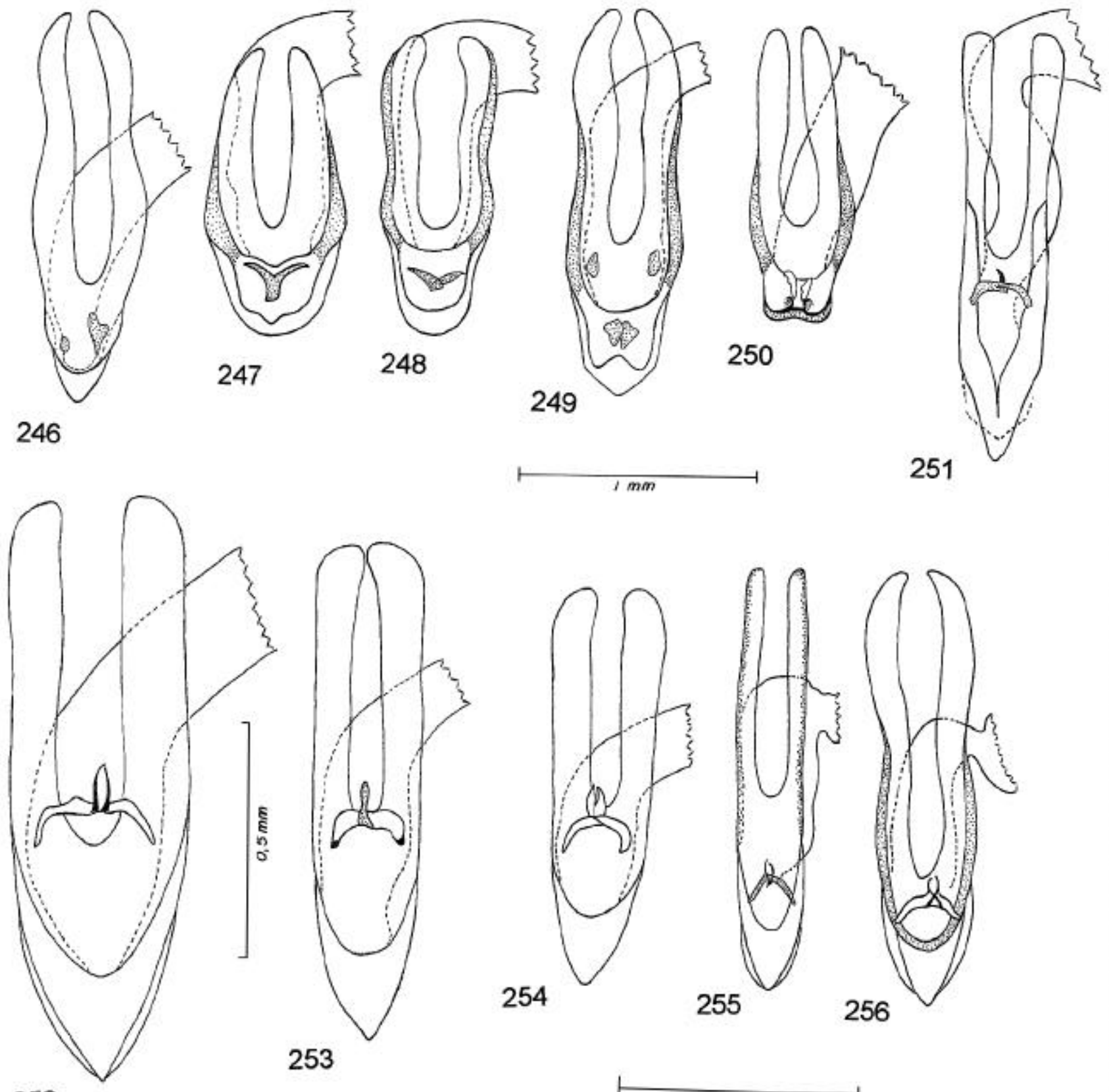

252
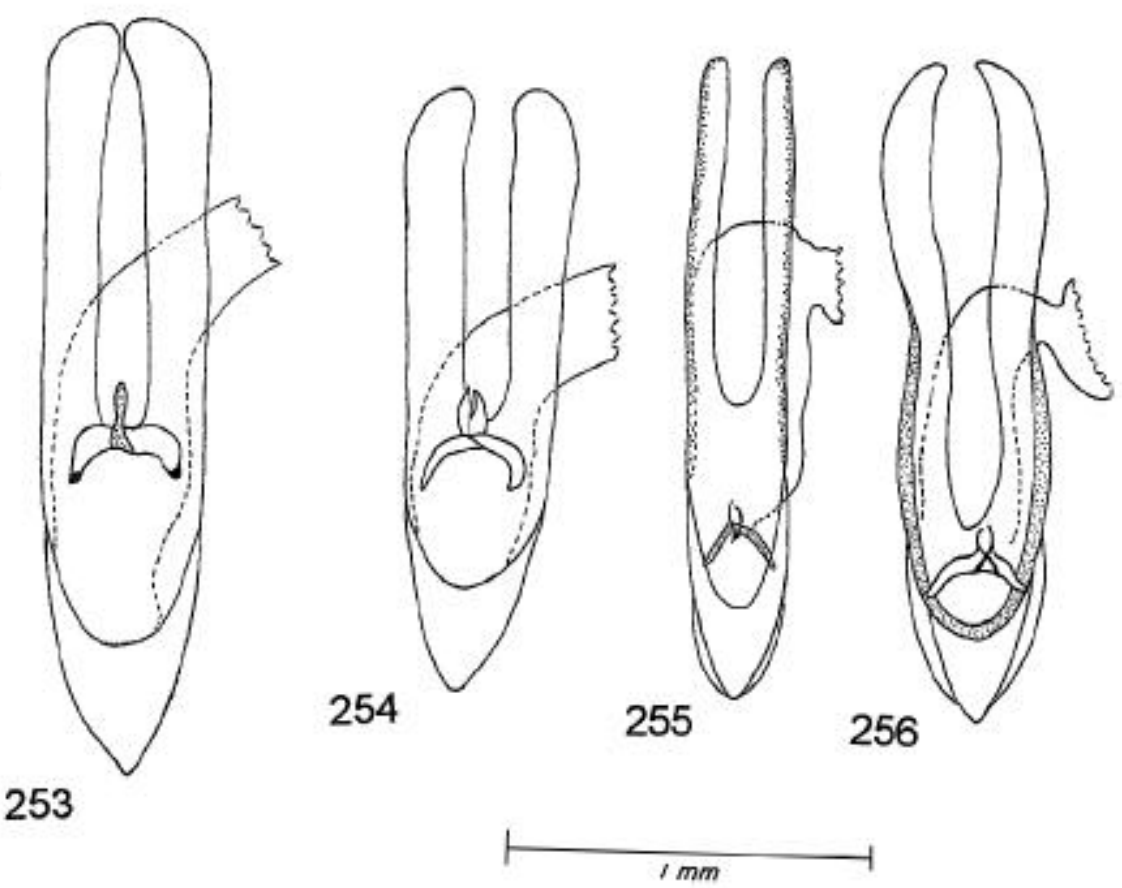

Figs. 246-256.Terminália masculina, lobo médio: 246, Cleomenes; 247, Ischionodonta platensis; 248, I. rufomarginata; 249, Rhopalophora collaris; 250, R. neivae; 251, Disaulax; 252, Cosmisoma scopulicorne; 253, Closteropus; 254, Gurubira; 255, Lissozodes; 256, Argyrodines. Figs. 246-251 e 253-256, respectivamente, na mesma escala. 

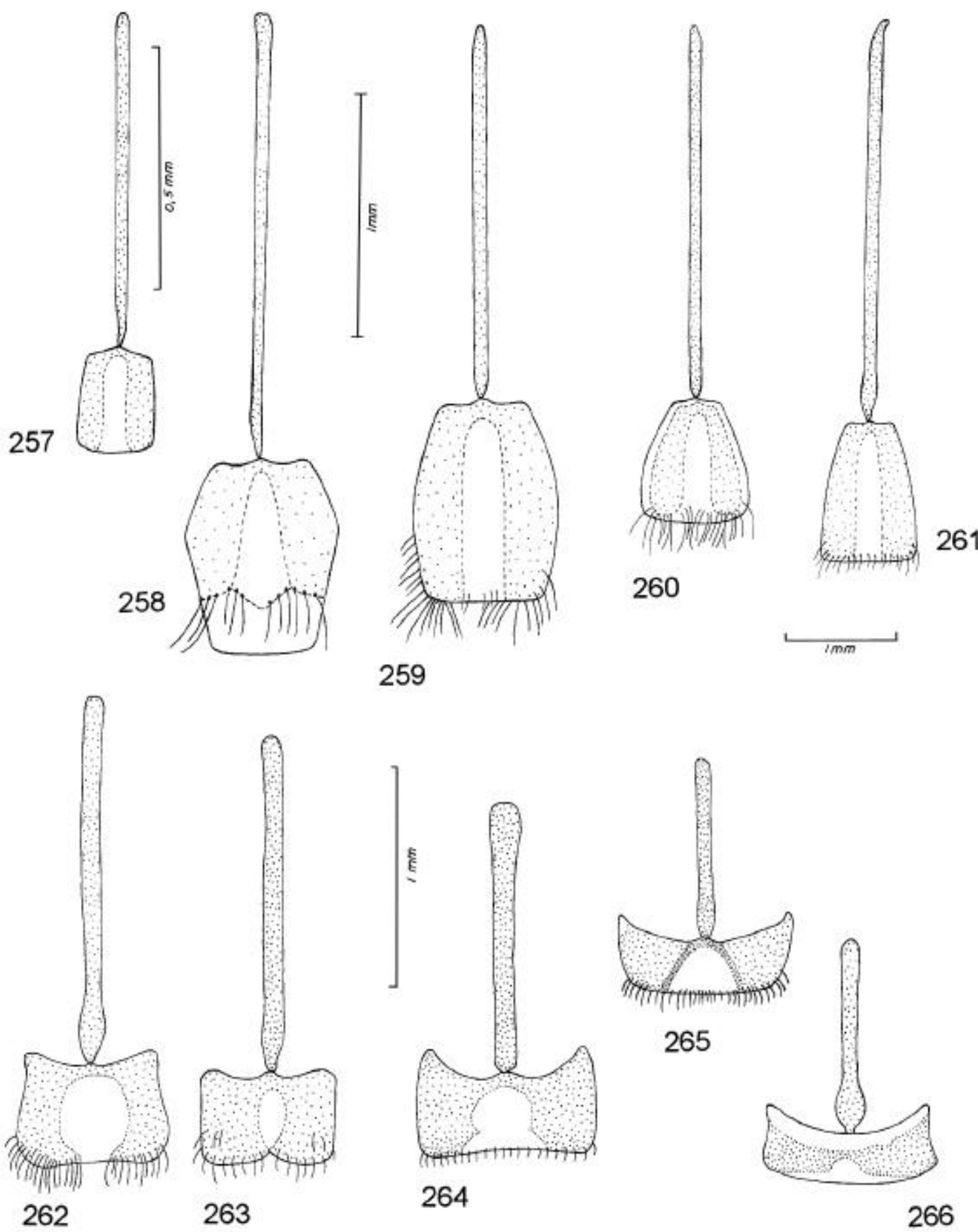

Figs. 257-266. Terminália feminina, esternito VIII e apódema ventral: 257, Cleomenes; 258, Cosmisoma scopulicorne; 259, Argyrodines; 260, Disaulax; 261, Closteropus; 262, Thalusia atrata; 263, Lathusia ferruginea; 264, Dirocoremia simplicipes; 265, D. bruchi; 266, D. ingae. 

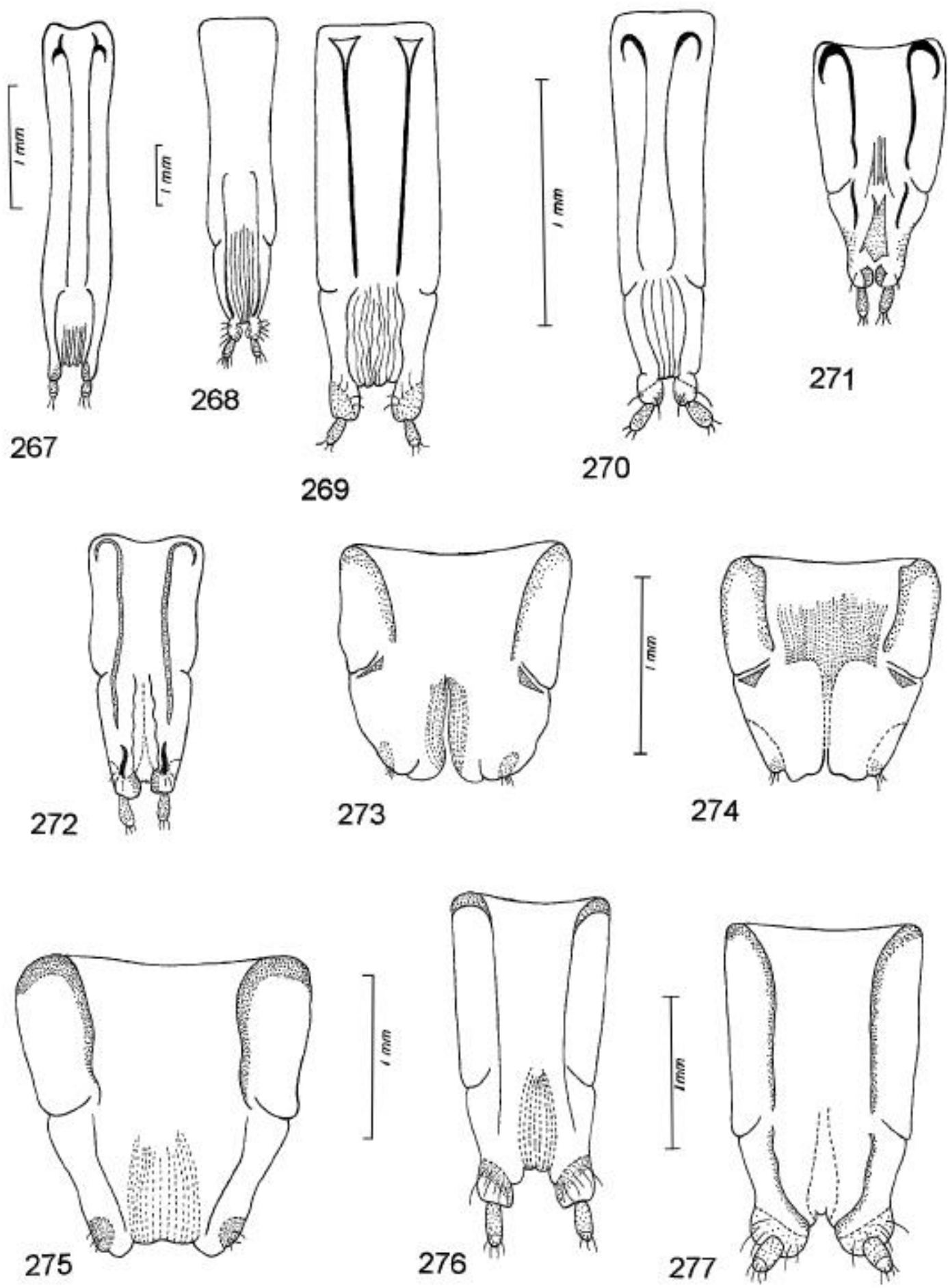

Figs. 267-277.Terminália feminina, ovipositor: 267, Cleomenes; 268, Gurubira; 269, Ischionodonta platensis; 270, Cosmisoma scopulicorne; 271, Rhopalophora neivae; 272, R. collaris; 273, Dirocoremia bruchi; 274, D. ingae; 275, D. simplicipes; 276, Coremia plumipes; 277, Thalusia erythromera. 

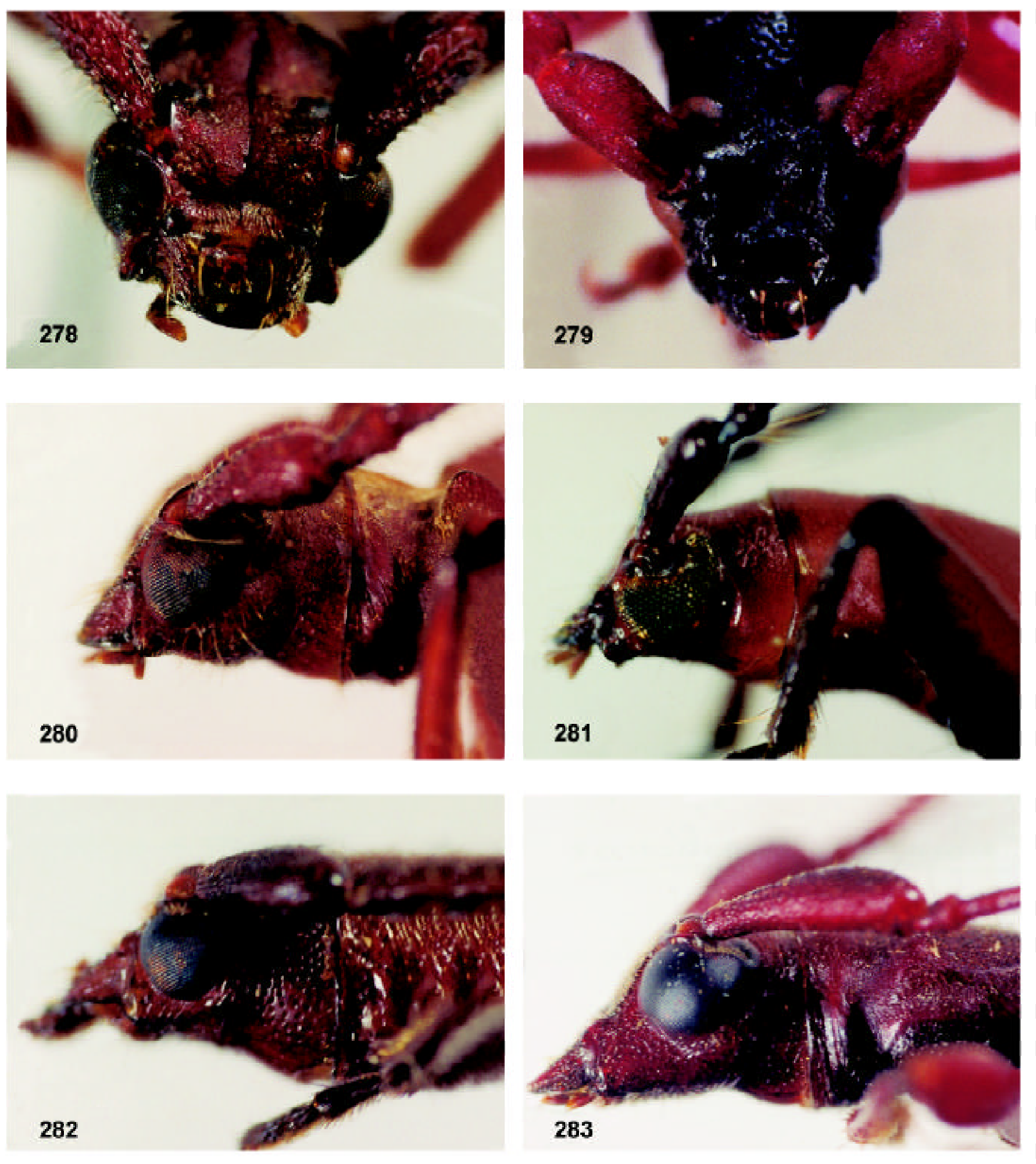

Figs. 278-279. Cabeça, frontal: 278, Ozodes; 279, Dirocoremia ingae. Figs. 280-283. Cabeça lateral: 280, Ozodes; 281, Elaphopsis; 282, Cycnoderus tenuatus; 283, Cosmisoma scopulicorne. 

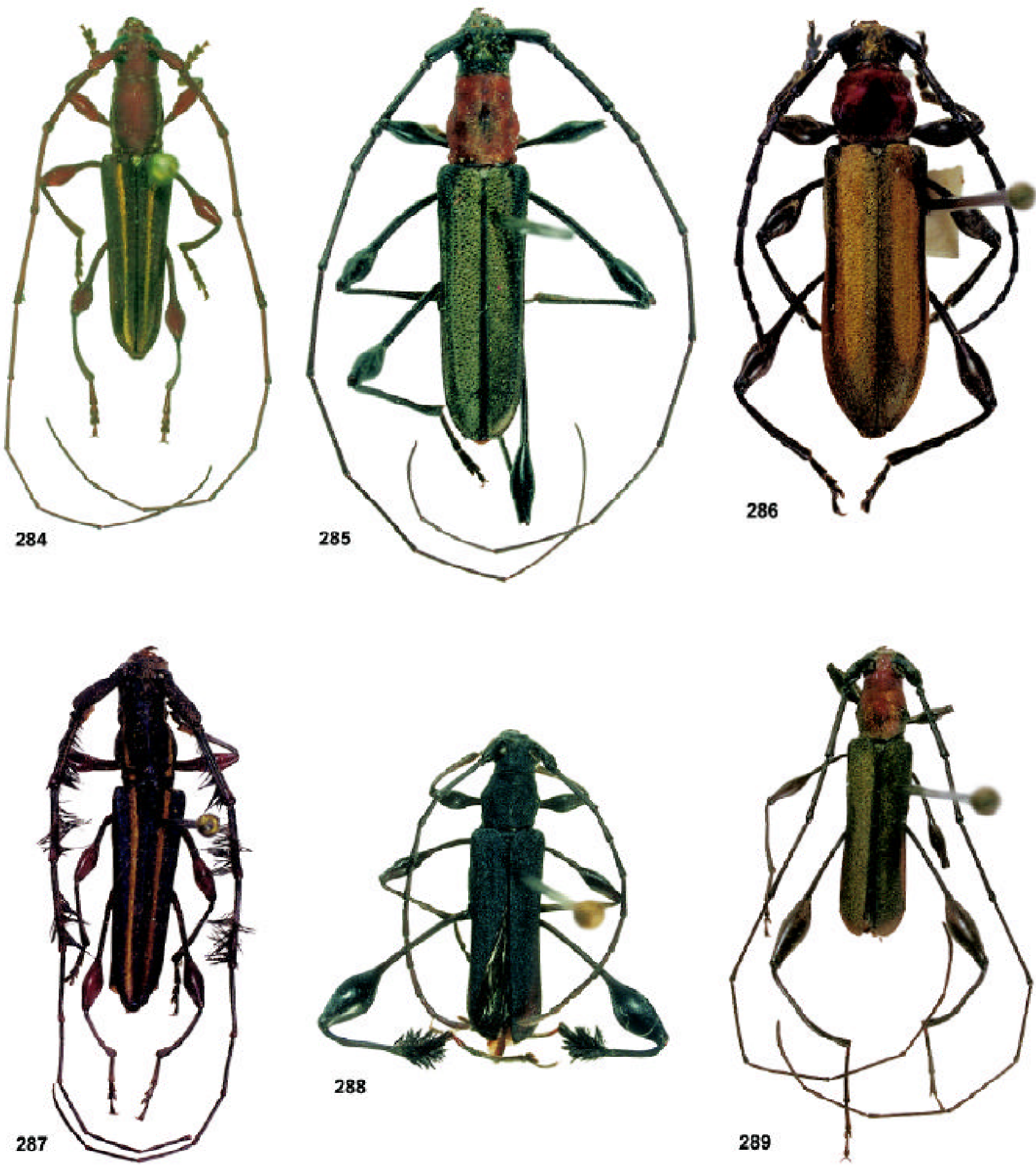

Figs. 284-289. 284, Cosmisoma batesi Zajciw, 1962; 285, Rhopalophora collaris (Germar, 1824); 286, Rhopalina discicollis (Chevrolat, 1859); 287, Disaulax hirsuticornis (Kirby, 1818); 288, Thalusia atrata (Melzer, 1818); 289, Dirocoremia simplicipes (Gounelle, 1911). 


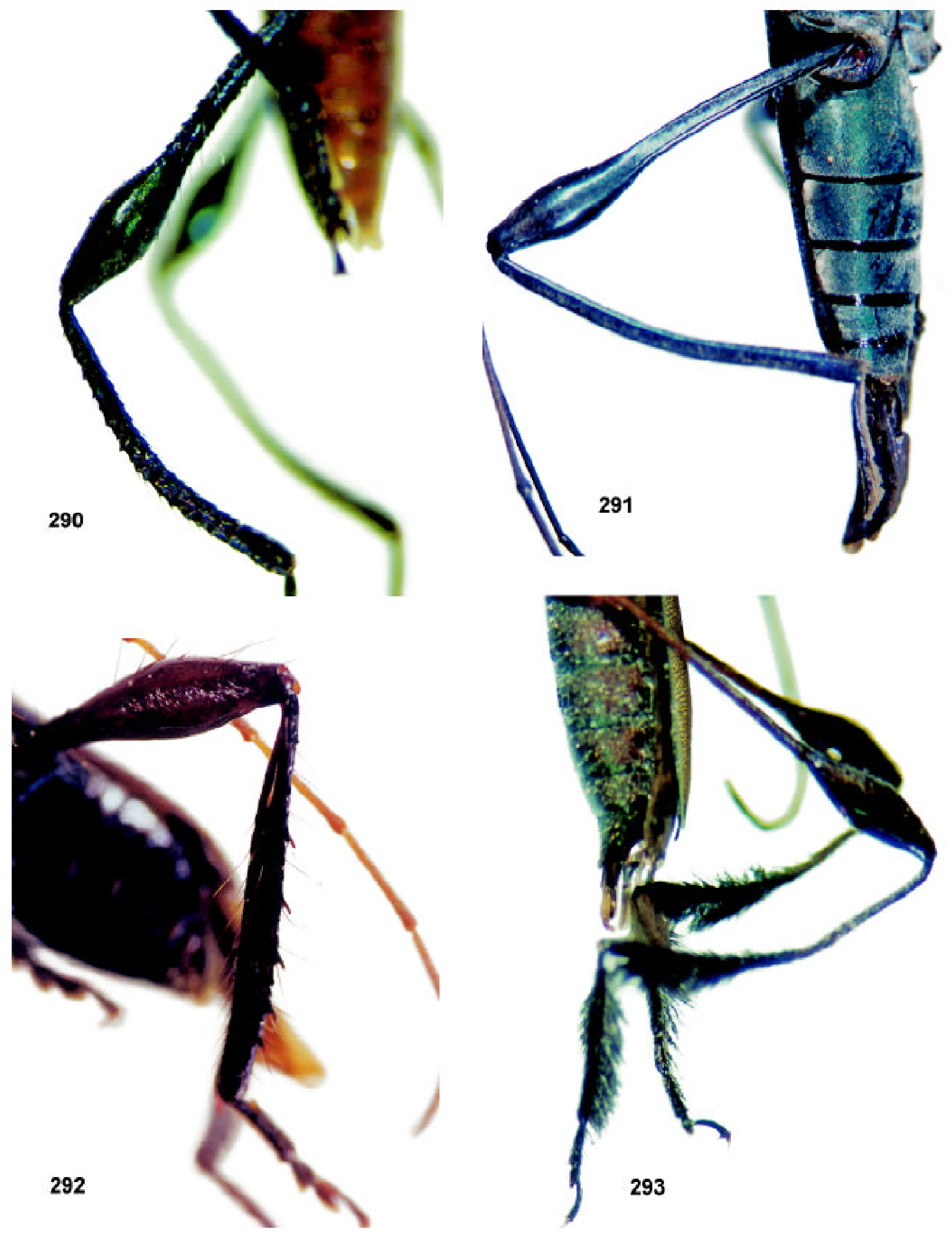

Figs. 290-293. Metatíbias. 290, Ischionodonta platensis; 291, Gurubira axillaris; 292, Argyrodines pulchella; 293, Cycnoderus barbatus. 

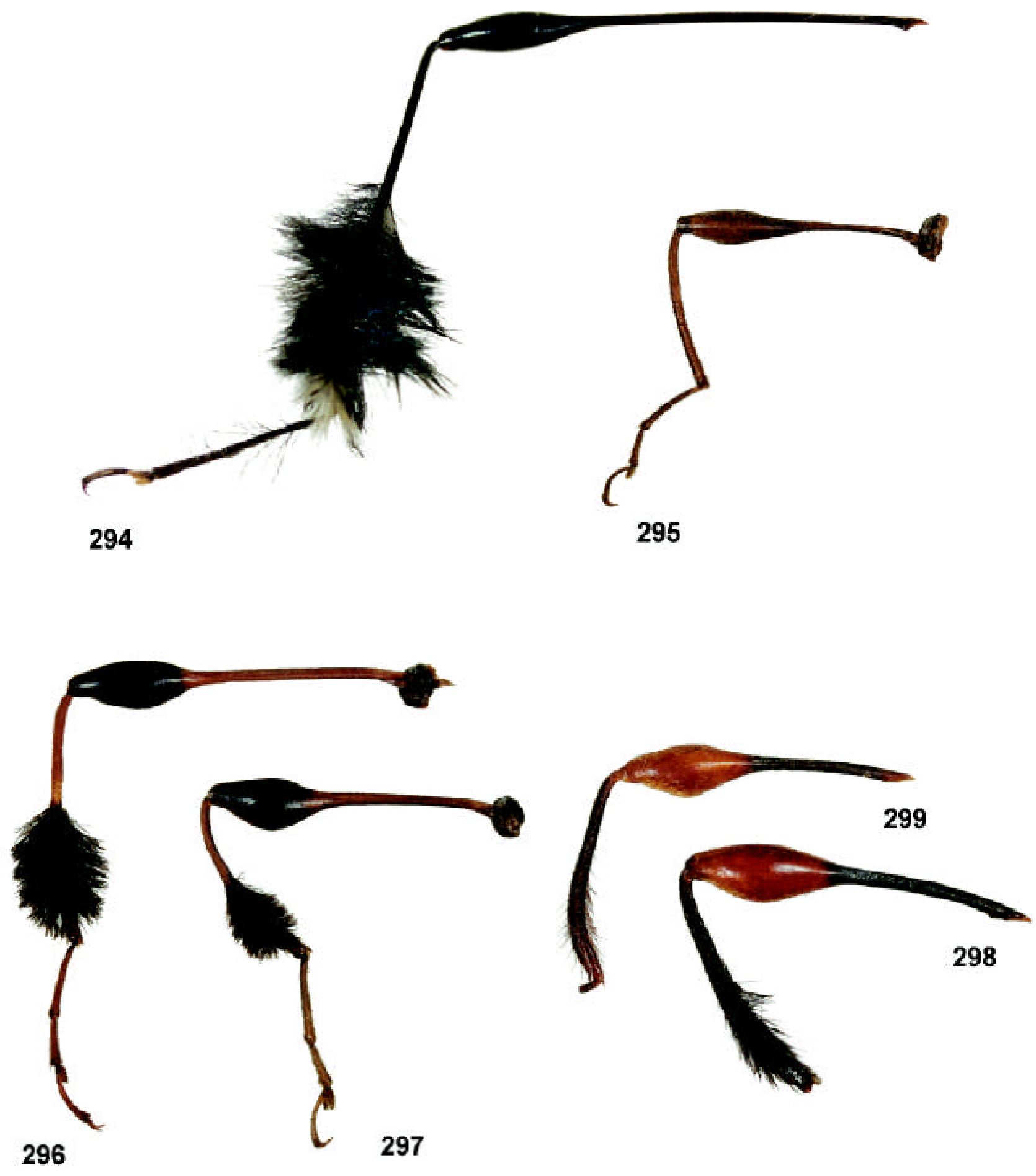

Figs. 294-299. Pernas posteriores. 294, Coremia plumipes; 295, Merocoremia monnei; 296, Dirocoremia ingae; 297, Thalusia erythromera; 298, Lathusia ferruginea, fêmea; 299, L. ferruginea, macho. 


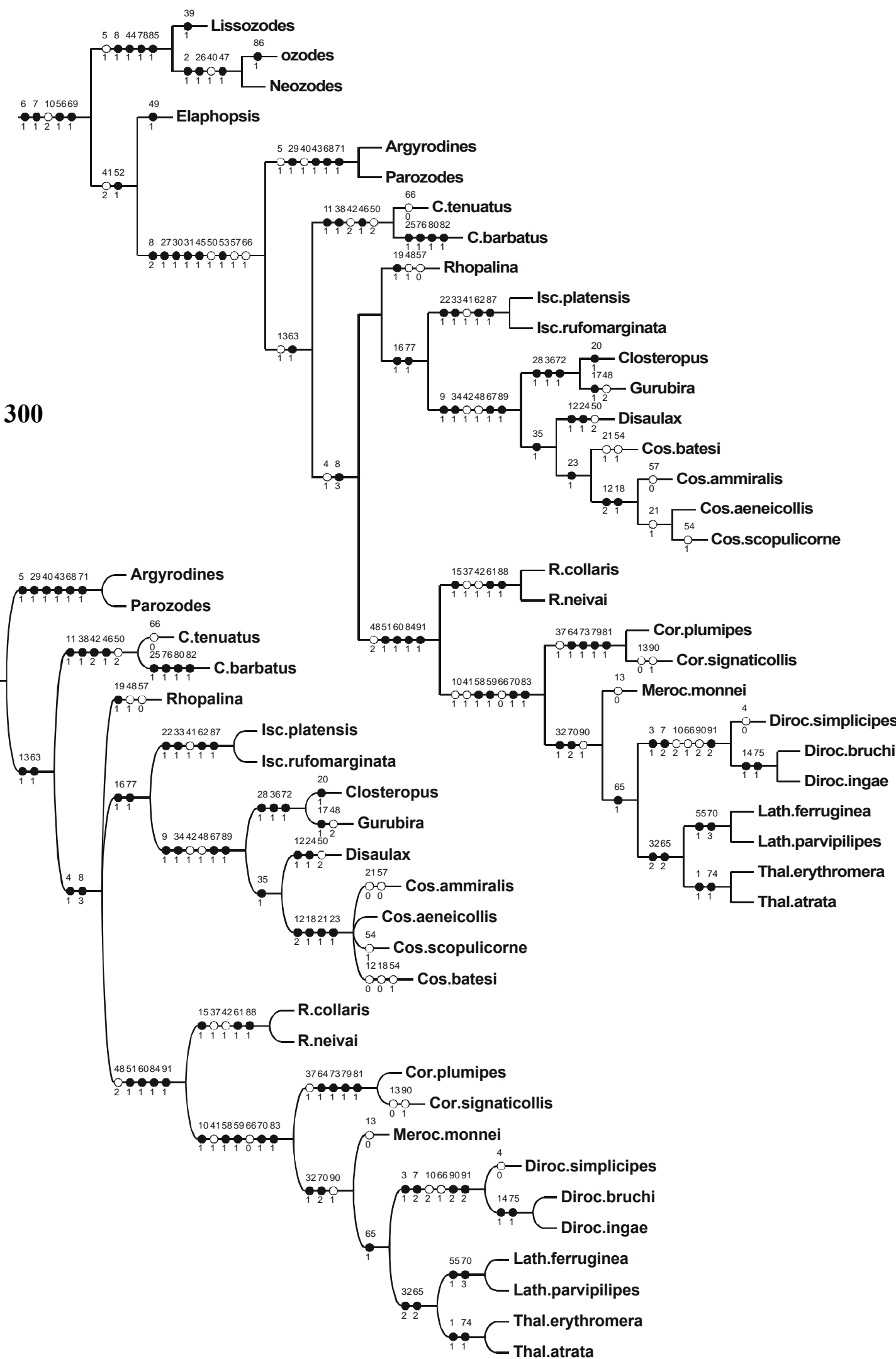

Figs. 300-301. 300, Relações filogenéticas dos gêneros americanos de Rhopalophorini, incluindo Ozodes e Lissozodes. Um dos 12 cladogramas de menor comprimento com sete caracteres multiestado não-ordenados e otimização DELTRAN; comprimento=126, IC=0.84, IR=0.94. 301, Cladograma de consenso estrito das relações filogenéticas dos gêneros americanos de Rhopalophorini; sete caracteres multiestado não-ordenados, otimização DELTRAN; comprimento=116; IC=0.91; IR=0.96. Círculos pretos=sinapomorfias, círculos brancos=homoplasias e/ou reversões. 


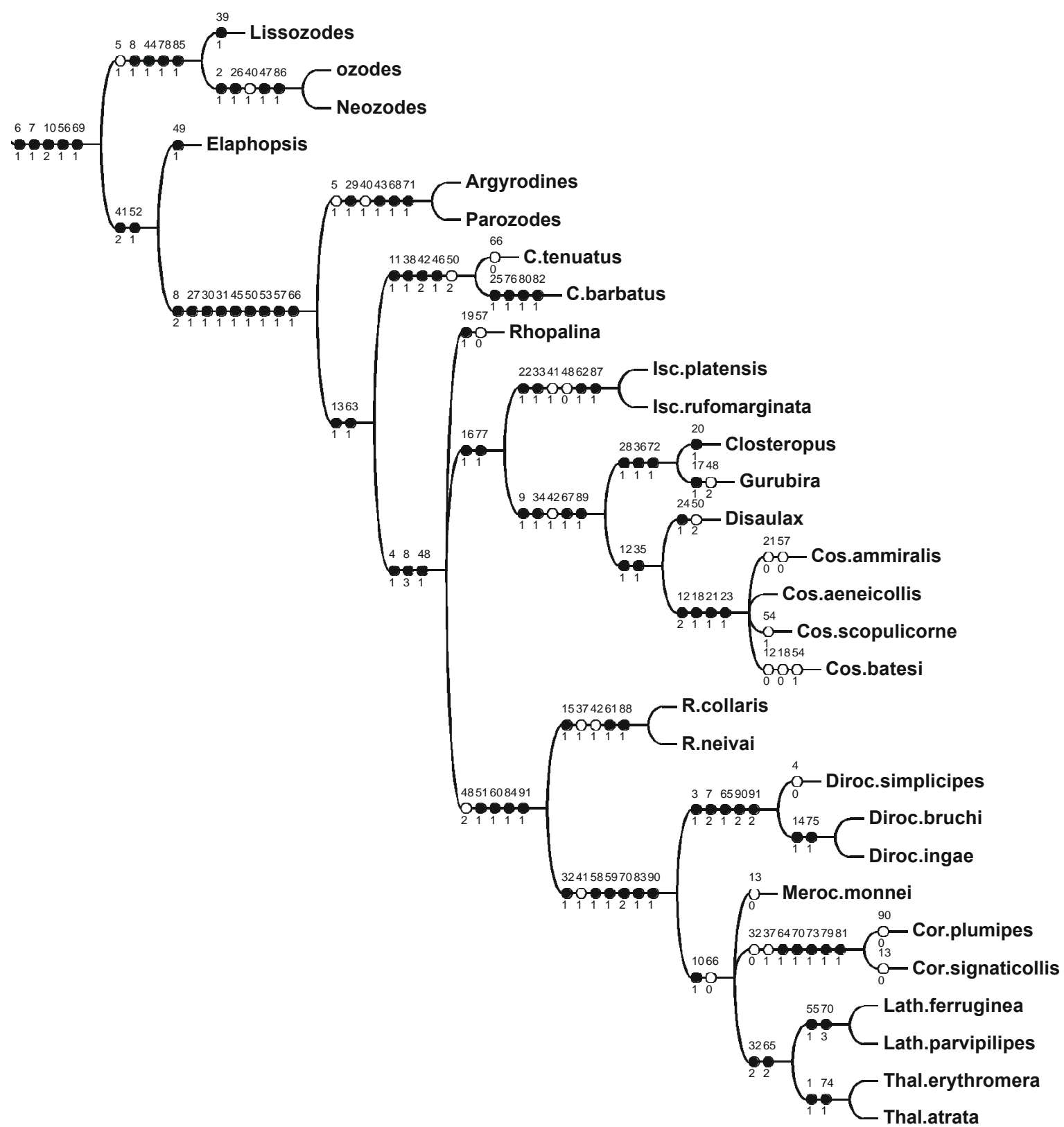

Fig. 302. Relações filogenéticas dos gêneros americanos de Rhopalophorini, incluindo Ozodes e Lissozodes. Cladograma de consenso estrito baseado em 36 árvores igualmente parcimoniosas; caracteres não-ordenados; otimização ACCTRAN; comprimento=124; IC=0.85; IR=0.94; ICR=0.79; círculos pretos=sinapomorfias, círculos brancos=homoplasias e/ou reversões.

\section{REFERÊNCIAS}

AмORIM, D. S. 1982. Classificação por seqüenciação:uma proposta para a denominação dos ramos retardados. Revista Brasileira de Zoologia 1(1): $1-9$

AмORiм, D. S. 1997. Elementos Básicos de Sistemática Filogenética $2^{a}$ ed. Ribeirão Preto, Holos-Sociedade Brasileira de Entomologia, $\mathrm{xviii}+276$.

Audinet-Serville, J. G. 1833. Nouvelle classification de la famille des longicornes (suite). Annales de la Societé Entomologique de France (1)2: 528-573.

Audinet-Serville, J. G.1834. Idem. Ibidem (1)1: 118-201.

AurivilLIUS, C. 1897. Neue oder wenig bekannte Coleoptera Longicornia
5. Entomologisk Tidskrift 18: 241-248.

Aurivillius, C.1912. Coleopterorum Catalogus, pars 39, Cerambycidae: Cerambycinae. Berlin, W. Junk, 574 p.

Bates, H. W. 1867. New Genera of Longicorn Coleoptera from the river Amazon. The Entomologist's Monthly Magazine 4: 22-28.

Bates, H. W. 1870. Contributions to an insect fauna of the Amazon Valley (Coleoptera, Cerambycidae). Transactions of the Entomogical Society of London 1870: 243-335; 391-441.

Bates, H. W. 1879. New genera and species of Callichrominae (Coleoptera, Longicornia). Cistula Entomológica 2: 395-419.

BlanCHARD, C. E. 1845. Histoire des insects, traitant de leurs moeurs et de leurs metamorphoses en général, et comprenant une nouvelle classification fondée sur leurs rapports naturels. 
Paris. Didot, 2:1-524.

Blatchley, W. S. 1910. On the Coleoptera known to occur in Indiana. Bulletin. Indiana Department of Geology and Natural Resources 1: 1-1386.

Bradley, J. C.1930. A Manual of the Genera of the Beetles of America North of Mexico. Ithaca, Daw. Illston \& CO., $360 \mathrm{p}$

Brooks, D. R.1989. Manual de Metodologia Cladística. Rio de Janeiro, Academia Brasileira de Ciências, 109 p.

Chenu, J. C. 1861. Encyclopédie Naturelle d'Histoire. Coléoptères. Paris, 3: vi+360 p.

Chevrolat, L. A 1859. Essai monographique sur le genre Rhopalophora. Arcana Natura 1: 57-64.

Crowson, R. A. 1938. The metendosternite in Coleoptera: a comparative study. Transactions of the Entomogical Society of London 87(17): 397- 416.

Crowson, R. A. 1944. Further studies on the metendosternite in Coleoptera. Transactions of the Entomogical Society of London 94(2): 273-310.

Crowson, R.A. 1955. The natural classification of the families of Coleptera. London, Nathaniel Lloid, 187 p.

Crowson, R. A. 1981. The biology of Coleoptera. London, Academic Press, vi $+745 p$.

Dias, M. M. 1981. Análise Cladística e Classificação de Anoplodermatinae (Coleoptera, Cerambycidae). Tese de Doutorado, Universidade de São Paulo, São Paulo, v+144 p.

Di IORIO, O. R. 2001. Systematics and biology of the species of the genus Ischionodonta Chevrolat, 1859 (Coleoptera: Cerambycidae: Cerambycinae: Rhopalophorini) from Argentina. Giornale Italiano di Entomologia 9: 263-291.

Ehara, S. 1954. Comparative anatomy of male genitalia in some Cerambycidae beetles. Journal of the Faculty of Science, Hokkaido University 12(1-2): 61-115.

Eldredge, N. \& J. Cracraft. 1980. Phylogenetic patterns and the evolutionary process. New York, Columbia University Press, vii+349 p.

Fragoso, S. A. 1978. Male and female terminalia as a basis for tribal classification of the subfamily Cerambycinae of America North of Mexico (Cerambycidae, Coleoptera). PhD Thesis, Florida University, $92 \mathrm{p}$.

Fragoso, S. A. 1985. The terminalia as a basis for the tribal classification of Cerambycidae (Coleoptera). Part I. Terminology and genital morphology of Cerambyx cerdo L. Revista Brasileira de Entomologia 29(1): 125-134.

Goloboff, P. A. 1993. NONA Version 2.0 (for Windows). Publicado pelo autor. INSUE Fundación y Instituto Miguel Lillo, Tucumán.

Gounelle, E. 1911.Liste des cérambycides de la region deJathay, Etat de Goyaz, Brésil. Annales de la Societé Entomologique de France 80: $103-252$.

Gressit, J. L. 1951. Longicorn beetles of China. Longicornia 2: 1-667.

Gressit, J. L. \& J. A. Rondon. 1970.Cerambycidae of Laos. Pacific Insect Monograph 84: 1-314.

Giesbert E. F. \& J. A. Chemsak. 1993. A review of the Rhopalophorini (Coeopttera: Cerambycidae) of the North and Central America. Insecta Mundi 7(1/2):27-64.

Guérin-Menéville, F. E. 1844. Iconographie du Régne animal de G. Cuvier, Insectes. Paris, Baillière, 7: iv $+576 p$.

Hennig, W. 1966. Phylogenetic systematics. Urbana, Univ.Illinois, $263 \mathrm{p}$.

IugA, V. G. \& A. Rosca. 1962. La morphologie de l'apex abdominal ches les Cerambycidae (Col.), comparé à celui des Hyménoptères. Travaux du Muséum d'Histoire Naturelle Grigore Antipa 3: $101-156$.

Lacordaire, J. T. 1869. Histoire naturelle des Insects. Genera des Coléopteres. Paris, Libraire Encyclopédique du Roret, 8: 1-552; 9(1): 1-409.

LAPORTE, F. L. N. 1840. Histoire Naturelle des Insectes Coléopteres. Paris, Duménil, 2: 1-563.

LeConte, J. L. 1850. An attempt to classify the longicorn Coleoptera of the part of America north of México. Journal of the Academy of Natural Sciences of Philadelphia (2)1: 311-340; 2: 5-38
LeConte, J. L. 1873. Classification of the Coleoptera of North America. Part II. Smithsonian Miscellaneous Collections 11(264): 169238; (265): 279-348

LeConte, J. L. \& G. H. Horn. 1883. Classification of the Coleoptera of North America. Smithsonian Miscellaneous Collections 26(507): xxxvi $+567 \mathrm{p}$

LENG, C. W. 1884. Synopses of the Coleoptera (Cerambycidae). Bulletin of the Brooklyn Entomological Society 7(8): 112-116.

Lindroth, C. H. \& E. palmen. 1970. Coleoptera, p. 80-88. In: S. L. Tuxen (ed.) Taxonomist's Glossary of Genitalia in Insects. Copenhagen, Munksgarrd, $359 \mathrm{p}$.

Lingafelter, S. W. 1998. The genera of Elaphidiini Thomson,1864 (Coleoptera: Cerambycidae). Proceedings of the Entomological Society of Washington 20: 1-118.

LinsLey, E. G. 1942. Contributions toward a knowledgr of the insect fauna of lower California. No. 2 (Coleoptera: Cerambycidae). Proceedings of the California Academy of Sciences 24: 21-96.

Linsley E. G. 1961. The Cerambycidae of North America. Part I. Introduction. University of California. Publications in Entomology 18: 1-97.

Linsley, E. G. 1962.The Cerambycidae of North America. Part III. Taxonomy and classification of the subfamily Cerambycinae, tribes Opsimini through Megaderini. University of California. Publications in Entomology 20: 1-188.

Linsley, E. G. 1964. The Cerambycidae of North America. Part IV Taxonomy and classification of the subfamily Cerambycinae, tribes Elaphidionini through Rhinothragini. University of California. Publications in Entomology 21: 1-165.

Maddison, W. P.; M. J. Donaghue \& D. R. Maddison. 1984. Outgroups analysis and parsymony. Systematic Zoology 33: 83-103.

Marinoni, R. C. 1979. Contribuição à sistemática de Lamiinae (Cerambycidae, Coleoptera). Tese de Doutorado. Curitiba, Universidade Federal do Paraná, 147 p.

Marinoni, R. C. \& L. M. Almeida. 1983. Sobre a venação alar em Coccinellidae e Cerambycidae (Coleoptera). Revista Brasileira de Entomologia 27(3/4): 267-275.

Marques, M. I. 1994 a. Revisão do gênero Coremia A.- Serville, 1834 (Coleoptera, Cerambycidae,Compsocerini).Tese de Mestrado, Curitiba, Universidade Federal do Paraná, ix +150 p.

Marques, M. I. 1994 b. Dirocoremia subgen. n. de Coremia A.- Serville, 1834 (Coleoptera, Cerambycidae, Compsocerini). Revista Brasileira de Zoologia 11(2): 311-324.

Marques, M. I. 1994 c. Merocoremia monnei, gen. n., sp. n. de Compsocerini (Coleoptera, Cerambycidae, Cerambycinae) Revista Brasileira de Zoologia 11(2): 345-353.

MARques, M. I. \& NAPP, D. S. 1996.Revisão e transferência para Rhopalophorini (Coleoptera, Cerambycidae) dos gêneros Coremia A.- Serville, 1834 e Merocoremia Marques, 1994. Revista Brasileira de Entomologia 40(3/4): 379-423.

Martins U. R. 1967. Monografia da tribo Ibidionini (Coleoptera, Cerambycidae). Parte II. Arquivos de Zoologia 16(2): 321-630.

Martins, U. R. 1975. Longicórneos da coleção Hudepohl III (Coleoptera, Cerambycidae). Papéis Avulsos de Zoologia 29(2): 7-20.

Mermudes, J. R. M. 1999. Morfologia comparada dos gêneros neotropicais de Cleomenini Lacordaire, 1869 (Coleoptera, Cerambycidae, Cerambycinae). Tese de Mestrado. Curitiba, Universidade Federal do Paraná, xii+89 p.

Mermudes, J. R. M. \& D. S. NAPP. 2001. Revision of Eupempelus Bates and its transference to Heteropsini Lacordaire (Coleoptera, Cerambycidae, Cerambycinae). Revista Brasileira de Zoologia 18(1): 245-253.

Mermudes, J. R. M. \& D. S. NAPP. 2002. Redescrição e transferência do gênero Fregolia Gounelle, 1911 para Callidiopini (Coleoptera, Cerambycidae). Revista Brasileira Entomologia 46(4): 553-559.

Monné, M. A 1994. Catalogue of the Cerambycidae (Coleoptera) of the Western Hemisphere. Part X. São Paulo, Sociedade Brasileira de Entomologia, $81 \mathrm{p}$.

Monné, M. A. 1989. Novos táxons e sinonímia em Rhopalophorini (Coleoptera, Cerambycidae, Cerambycinae). Revista Brasileira de Biologia 49(3): 737-741. 
Monné, M. A. 2001. Catalogue of the Neotropical Cerambycidae (Coleoptera) with known host-plant. Part II: Subfamily Cerambycinae, tribes Graciliini to Trachyderini. Publicações Avulsas do Museu Nacional 90: 1-119.

Monné, M. A. \& E. F. Giesbert. 1994. Checklist of the Cerambycidae and Disteniidae (Coleoptera) of the Western Hemisphere. Burbank, Wolfsgarden Books, IV+ 410 p.

Monné, M. A. \& P. R. Magno. 1988. Gênero Cosmisoma A.-Serville, 1834: Notas, novos taxa e chave para as espécies sul-americanas (Coleoptera, Cerambycidae, Rhopalophorini). Boletim do Museu Nacional (n.s.) Zool., 319: 1-27.

NAPP, D. S.1994. Phylogenetic relationships among the subfamilies of Cerambycidae (Coleoptera, Chrysomeloidea). Revista Brasileira de Entomologia 38(2):265-419.

Napp, D. S. \& M. I. Marques. 1998. New species of Ischionodonta Chevrolat, 1850 from Brazil and redescription of I. brasiliensis Chevrolat, 1859 (Coleoptera, Cerambycidae, Rhopalophorini). Coleopterists Bulletin 52(2): 127-133.

NAPP, D. S. \& M. I. MARQues, 1999a. Gurubira gen. n. of Rhopalophorini (Coleoptera, Cerambycidae). Revista Brasileira de Entomologia $43(1 / 2): 35-45$.

NAPP, D. S. \& M. I. MARQues. 1999b. Revision of the genus Ischionodonta Chevrolat, 1859 (Coleoptera, Cerambycidae). Revista Brasileira de Entomologia 43(1/2): 109-130.

Nelson, G. J. 1972. Phylogenetic relationships and classification. Systematic Zoology 21(2): 227-231.

Nelson, G. J. \& N. I. Platnick. 1981. Systematics and Biogeography: Cladistics and Vicariance. New York, Columbia University Press, $567 \mathrm{p}$.

Nixon, K. C. 1999. Winclada (Beta), version 0.9.99m24. Publicado pelo autor, Ithaca.

Nixon, K. C. \& J. M. Carptenter. 1993. On outgroups. Cladistics 9: 413426.

PAGE, R. D. M. 2001. NDE (NEXUS data editor for Windows). Version 0.5.0. NDE-home page (http//:taxonomy.zoology.gla.ac.uk/rod/NDE/ nde.html)
Platnick, N. I.; C. E. Griswold \& J. A. Coddington.1991. On missing entries in cladistic analysis. Cladistics 7: 337-343p.

SaAlas, U. 1936. Über das Flügelgeäder und die phylogenetische entwicklung der Cerambyciden. Annales Zoologici Societatis Zoologicae-Botanicae Fennicae Vanamo 4(1): 1-198.

Santos, B. B. Dos. 1999. Análise cladística da tribo Heteropsini Blanchard, 1845 (Coleoptera, Cerambycidae, Cerambycinae). Tese de Doutorado, Curitiba, Universidade Federal do Paraná, vii+118 p.

Swofford, D. L. 2000. PAUP, Versão 4.0.0. Sunderland, Sinauer Associates. Thomson, J. 1860. Essai d'une classification de la famille des Cerambycidae et materiaux pour servir a une monographie de celle famille. Paris, $404 \mathrm{p}$.

Thomson, J. 1864. Systema Cerambycidarum ou exposé de tour les genres compris dans la famille des Cerambycidae et familles limitrophes. Mémoires de la Société Royale des Sciences de Liège 19: 1540 .

Tippmann, F.F. 1960. Studien Über neotropische Longicornier III. Koleopterologische Rundschau 37-38: 82-217.

Wathrous, L. E. \& Q. D. WheELER. 1981. The out-group comparision method of charater analysis. Systematic Zoology 30:1-11.

White, A. 1855. Catalogue of the Coleopterous insects of the Brithish Museum. Longicornia 2. London, 8: 175-412.

WiLEy, E. O. 1979. An annotated Linnean hierarchy, with comments on natural taxa and competing systems. Systematic Zoology 28(3): 308-337.

Wiley, E. O. 1981. Phylogenetics: The Theory and Pratice of Phylogenetics Systematics. New York, Wiley, 439 p.

Wiley, E. O.; D. Siegel-Causey; D. R. Brooks \& V. A. FunK. 1991.The Compleat Cladist. A primer of phylogenetic procedures. Lawrence, University of Kansas, ix +157 p.

Zajciw, D. 1958. Novos Longicórneos neotrópicos (Col.,Cerambycidae). Revista Brasileira de Entomologia. 8: 233-262.

ZAJCIw, D. 1962. Revisão das espécies brasileiras do gênero Cosmisoma A.- Serville, 1834 (Coleoptera, Cerambycidae,Cerambycinae). Arquivos de Zoologia 11(10):285-314. 